AUTARQUIA ASSOCIADA À UNIVERSIDADE DE SÃO PAULO

\title{
ESTUDO DOS POLUENTES ORGÂNICOS PERSISTENTES (POPS) NO SEDIMENTO DA REPRESA BILLINGS - SP VIA CROMATOGRAFIA A GÁS ACOPLADA À ESPECTROMETRIA DE MASSAS
}

KATIA APARECIDA MESQUITA

Dissertação apresentada como parte dos requisitos para obtenção do Grau de Mestre em Ciências na Área de Tecnologia Nuclear - Materiais

Orientador:

Prof. Dr. José Oscar Vega Bustillos 
INSTITUTO DE PESQUISAS ENERGÉTICAS E NUCLEARES

Autarquia associada à Universidade de São Paulo

ESTUDO DOS POLUENTES ORGÂNICOS PERSISTENTES (POPS) NO SEDIMENTO DA REPRESA BILLINGS - SP VIA CROMATOGRAFIA A GÁS ACOPLADA À ESPECTROMETRIA DE MASSAS

KATIA APARECIDA MESQUITA

Dissertação apresentada como parte dos requisitos para obtenção do Grau de Mestre em Ciências na Área de Tecnologia Nuclear - Materiais

Orientador:

Prof. Dr. José Oscar Vega Bustillos 
À Deus primeiramente, ao meu companheiro e incentivador, Wagner Marchetti de Lima, e aos meus pais, Maria e Antonio, pelo apoio. 


\section{AGRADECIMENTOS}

À Deus primeiramente, pois sem Ele nada seria possível

Ao meu marido Wagner Marchetti de Lima pela paciência e incentivo.

Aos meus pais, Maria e Antonio, por tudo o que já fizeram e ainda fazem por mim.

À Dr. José Oscar Vega Bustillos pela orientação, confiança e incentivo.

À Labcris Análise de Meio Ambiente e Serviços por permitir que eu cursasse o mestrado em horário de trabalho.

Ao Ricardo Donaire de Carvalho Guerra pela grande ajuda.

Ao meu amigo de muitos anos Fábio Domingos da Silva, pela amizade sincera e ajuda em todos os momentos que precisei, inclusive este trabalho. Muito obrigada por tudo.

Ao Dr. Gilson Alves Quináglia pela grande ajuda com o projeto e a coleta das amostras. Muito obrigada!

À Companhia Ambiental do Estado de São Paulo, CETESB, pela realização das coletas das amostras. Muito obrigada!

À Silvana de Oliveira Canuto, pela amizade de anos e ajuda neste trabalho.

Ao Instituto de Pesquisas Energéticas e Nucleares, IPEN, pela oportunidade de realizar o meu sonho de cursar mestrado.

E a todos que direta ou indiretamente participaram da execução deste trabalho. 


\section{Estudo dos Poluentes Orgânicos Persistentes (POPs) no sedimento da}

Represa Billings-SP viaCromatografia a Gás e Espectrometria de Massas

\section{KATIA APARECIDA MESQUITA}

RESUMO

O estudo objetivou desenvolver uma novo método de extração para analisar os poluentes orgânicos persistentes (POPs), no sedimento da Represa Billings em São Paulo, via cromatografia a gás com espectrometria de massas (GC/MS). O Tratado de Estocolmo realizado na Suécia em 1972, patrocinado pela ONU, possuindo 113 países participantes, inclundo o Brasil objetivou a eliminação de menos doze POPs, colaborando com a questão ambiental. Os POPs são compostos que persistem no meio ambiente e são altamente estáveis, podendo ultrapassar a barreira placentária. Neste trabalho foram abordados o Aldrin, Endrin, Dieldrin, DDT. DDE, DDD e Heptacloro. Para garantir a confiabilidade dos resultados analíticos, foram realizados ensaios de validação do método, baseados nas diretrizes do INMETRO. O método de extração dos analitos foi o Quechers, obtendo resultados de recuperação entre 40 e $120 \%$ para todos os POPs analisados neste trabalho, valores aceitáveis para matrizes complexas como o sedimento. Os limites de detecção e quantificação fora, 0,3 e $0,5 \mu \mathrm{g} / \mathrm{kg}$ respectivamente. As amostras analisadas não apresentaram contaminação significativa por POPs perante a Legislação Brasileira vigente. 


\begin{abstract}
The objective of this study was to develop a new extraction method to analyze persistent organic pollutants (POPs) in the Billings Reservoir sediment in São Paulo, using gas chromatography with mass spectrometry (GC / MS). The 1972 Stockholm Treaty, sponsored by the UN, with 113 participating countries, including Brazil, aimed at eliminating at least twelve POPs, collaborating with the environmental issue. POPs are compounds that persist in the environment and are highly stable and can overcome the placental barrier. In this work were approached: Aldrin, Endrin, Dieldrin, DDT. DDE, DDD and Heptachlor. In order to guarantee the reliability of the analytical results, validation tests of the method were carried out, based on INMETRO guidelines. The method of extraction of the analytes was Quechers, obtaining results of recovery between 40 and $120 \%$ for all POPs analyzed in this work, acceptable values for complex matrices such as sediment. The limits of detection and quantification were, respectively, 0.3 and $0.5 \mu \mathrm{g} / \mathrm{kg}$. The analyzed samples did not present significant contamination by POPs before the current Brazilian Legislation.
\end{abstract}




\section{SUMÁRIO}

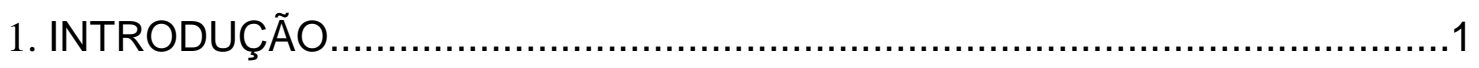

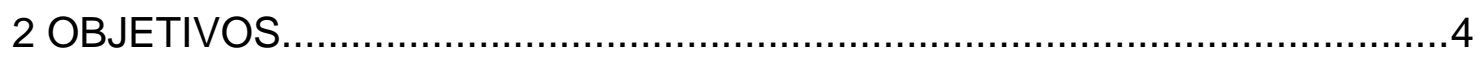

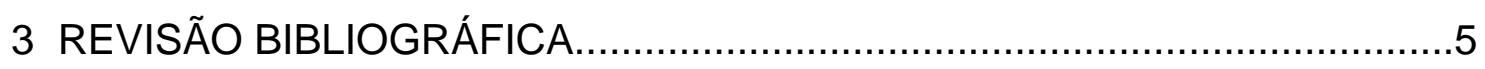

3.1 Poluentes Orgânicos Persistentes.....................................................

3.1.1 Comportamento no meio ambiente...........................................

3.1.2 Exposição humana e efeitos à saúde.............................................

3.1.3 Convenção de Estocolmo.......................................................14

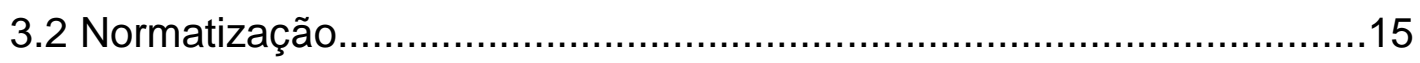

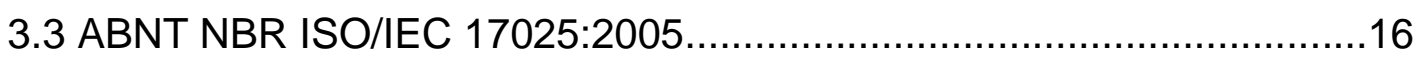

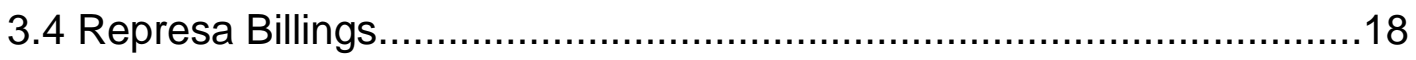

3.5 Importância dos Sedimentos .............................................................20

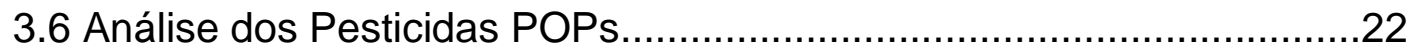

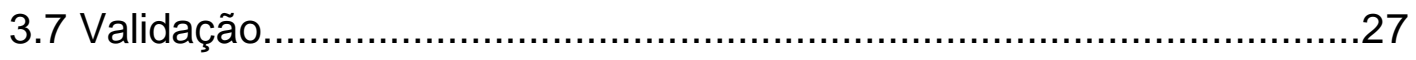

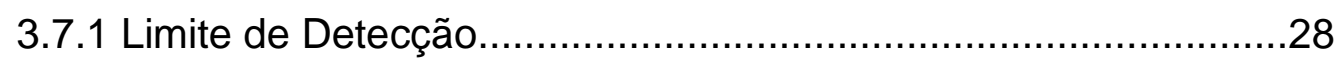

3.7.2 Limite de Quantificação..........................................................29

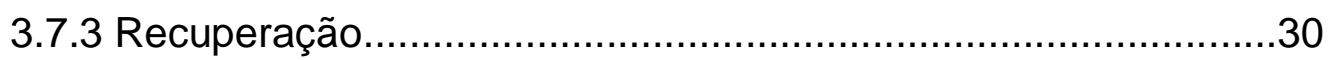

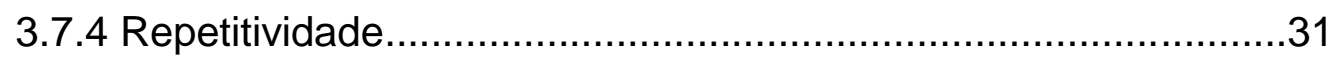

3.7.5 Incerteza de Medição..............................................................

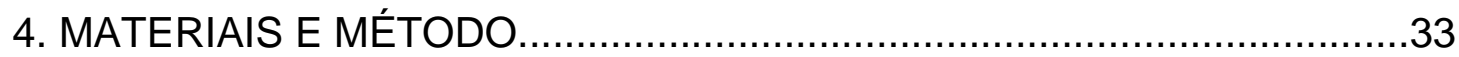

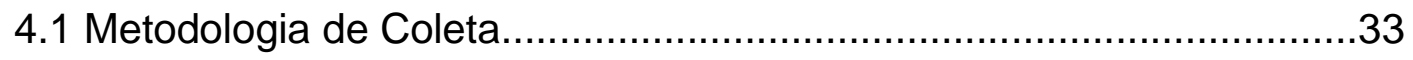

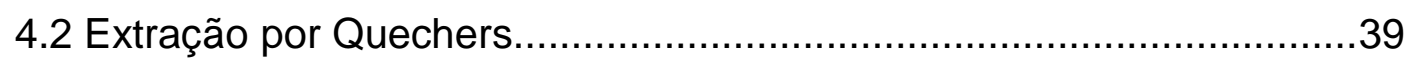

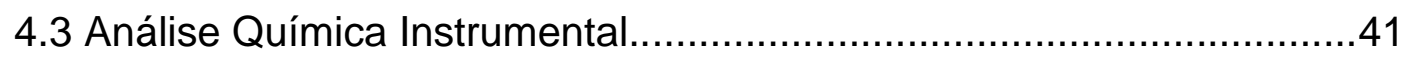

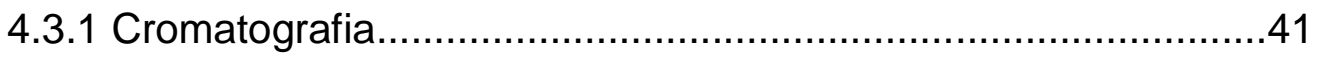

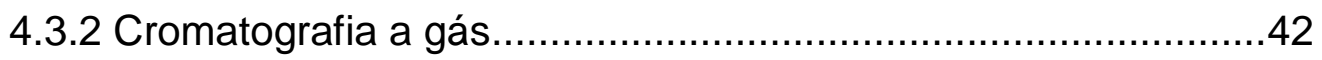

4.4 Detector por Captura de Elétrons......................................................44

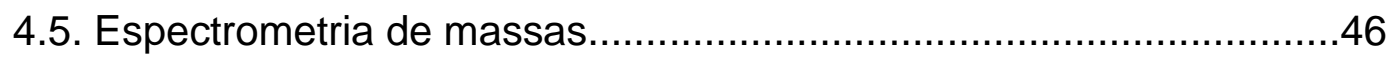

4.5.1 Formação do espectro de massas............................................51

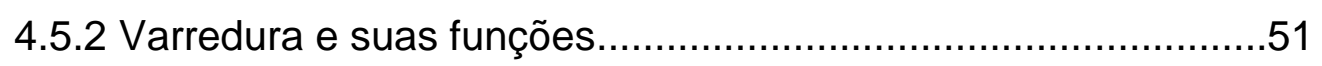

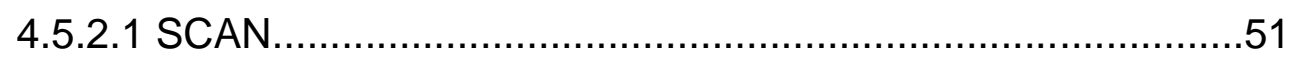


4.5.2.2 Método de varredura SIM..............................................52

4.5.2.3 Método de varredura MIC................................................52

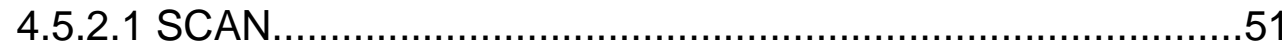

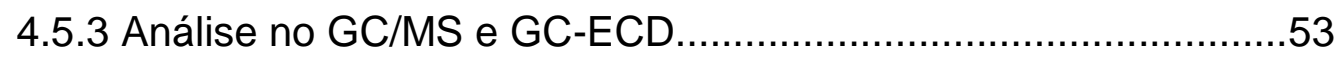

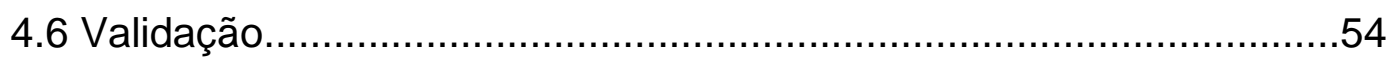

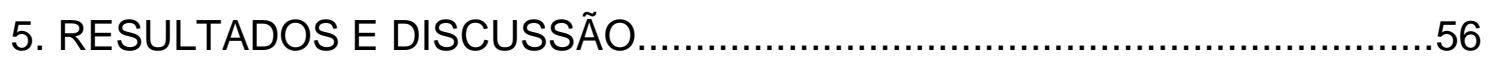

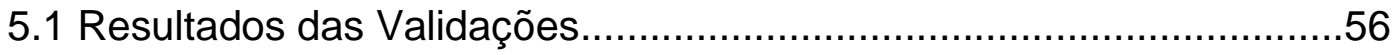

5.2 Resultados dos Limites de Detecção................................................64

5.3 Resultados dos Limites de Quantificação..........................................64

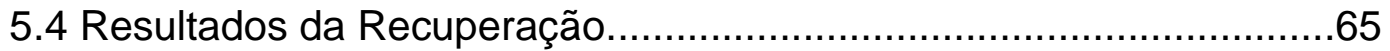

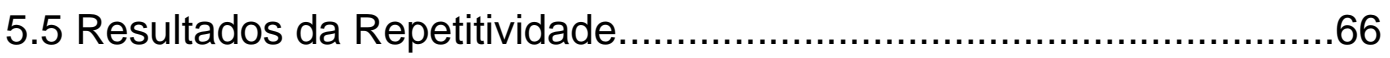

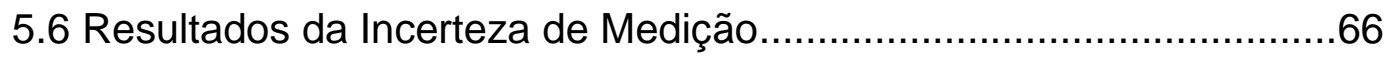

5.7 Resultados do padrão controle.......................................................

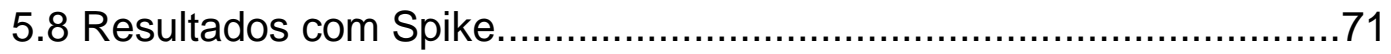

5.9 Resultados das amostra da Represa Billings......................................74

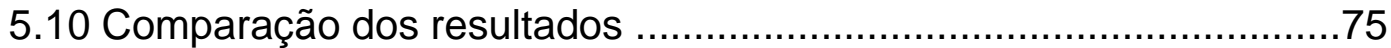

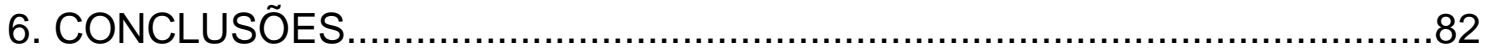

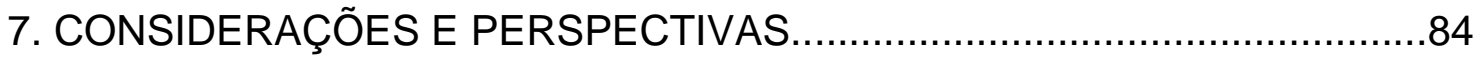

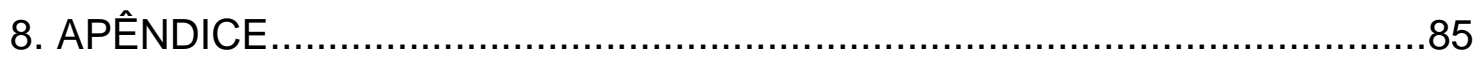

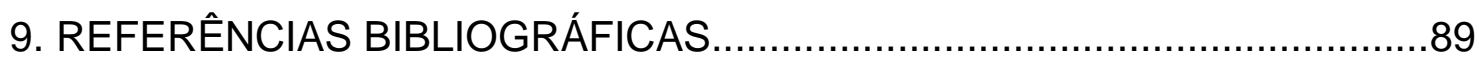




\section{LISTA DE FIGURAS}

FIGURA 1 Criança sendo pulverizada com DDT na Segunda Guerra Mundial na Alemanha. 10

FIGURA 2 Represa Billings em São Paulo .20

FIGURA 3 Direção do Sedimento, da água e dos fluxos da água intersticial..21

FIGURA 4 Fluxograma representativo do método Quechers original.. .24

FIGURA 5 Pontos coletados na Represa Billings.

FIGURA 6 Materiais utilizados na coleta de sedimentos: draga, frascaria, pás e bandeja. 35

FIGURA 7 Draga de Van Veen descendo para realizar a coleta dos sedimentos. .35

FIGURA 8 Draga sendo puxada da coleta de sedimentos da Represa Billings .36

FIGURA 9 Sedimento coletado na Represa Billings. .37

FIGURA 10 Sedimento coletado sendo transferido para bandeja para posteriormente ser armazenado em frasco âmbar. 38

FIGURA 11 Sedimento coletado na Represa billings pronta para ser acondcionado em frasco âmbar de $1 \mathrm{~kg}$. .38

FIGURA 12 Esquema de extração Quechers 39

FIGURA 13 Centrífuga e amostras utilizadas na análise via Quechers. 40

FIGURA 14 Amostras em processo de extração via Quechers. 40

FIGURA 15 Amostras extraídas prontas para serem injetadas no cromatógrafo 41

FIGURA 16 Cromatógrafos a gás da marca Perkin Elmer Clarus 500 com detector FID e ECD e injetor automático .43

FIGURA 17 Coluna Capilar dentro do forno do cromatógrafo a gás. 44

FIGURA 18 Esquema de um detector de Captura de elétrons. 45

FIGURA 19 Detectores FID E ECD visto de fora do cromatógrafo a gás da Perkin Elmer. 46

FIGURA 20 Primeiro espectrômetro de massas 47

FIGURA 21 Cromatoógrafo a gás com espectrômetro de massas Perkin Elmer Clarus 600 . 
FIGURA 22 Fonte de íons e quadrupolo GC/MS da Perkin Elmer. .49

FIGURA 23 Quadrupolo GC/MS da Perkin Elmer.

FIGURA 24 Curva de calibração do Aldrin

FIGURA 25 Curva de calibração do DDD.............................................58

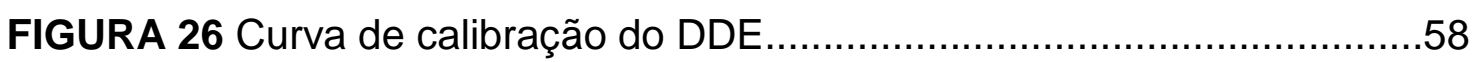

FIGURA 27 Curva de calibração do DDT ...............................................58

FIGURA 28 Curva de calibração do Dieldrin............................................58

FIGURA 29 Curva de calibração do Endrin.....................................................58

FIGURA 30 Curva de calibração do Heptacloro.........................................58

FIGURA 31 Avaliação gráfica com a contribuição gráfica das incertezas do Aldrin. 67

FIGURA 32 Avaliação gráfica com a contribuição gráfica das incertezas do

Dieldrin

FIGURA 33 Avaliação gráfica com a contribuição gráfica das incertezas do Enldrin .68

FIGURA 34 Avaliação gráfica com a contribuição gráfica das incertezas do DDE 68

FIGURA 35 Avaliação gráfica com a contribuição gráfica das incertezas do DDT 69

FIGURA 36 Avaliação gráfica com a contribuição gráfica das incertezas do DDD. 69

FIGURA 37 Avaliação gráfica com a contribuição gráfica das incertezas do Heptacloro. .70

FIGURA 38 Cromatograma do padrão controle..................................... 70

FIGURA 39 Cromatograma do Spike $2^{\circ}$ Linha............................................. 71

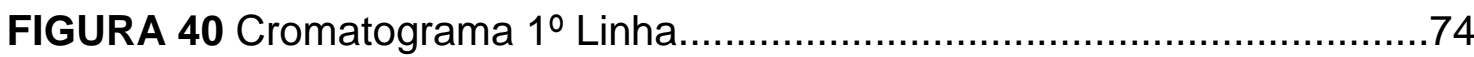

FIGURA 41 Gráfico comparativo da amostra de Endrin BILL2100.................75

FIGURA 42 Gráfico comparativo da amostra de Dieldrin BILL2100................76

FIGURA 43 Gráfico comparativo da amostra de Heptacloro BILL2100............76

FIGURA 44 Gráfico comparativo da amostra de DDD BILL2100_..................77

FIGURA 45 Gráfico comparativo da amostra de DDE BILL2100..................77

FIGURA 46 Gráfico comparativo da amostra de DDT BILL2100....................78

FIGURA 47 Gráfico comparativo da amostra de Endrin BILL2900.................78

FIGURA 48 Gráfico comparativo da amostra de Heptacloro BILL2900............79 
FIGURA 49 Gráfico comparativo da amostra de DDD BILL2900 ....................79

FIGURA 50 Gráfico comparativo da amostra de DDE BILL2900 ....................80

FIGURA 51 Gráfico comparativo da amostra de DDT BILL2900....................80 


\section{LISTA DE TABELAS}

TABELA 1 Fórmulas e aplicações dos POPs estudados................................13

TABELA 2 Rampa de termperatura do forno do cromatógrafo.........................53

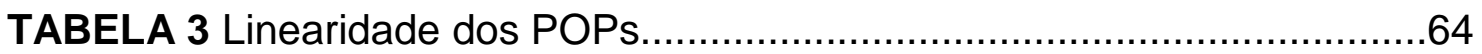

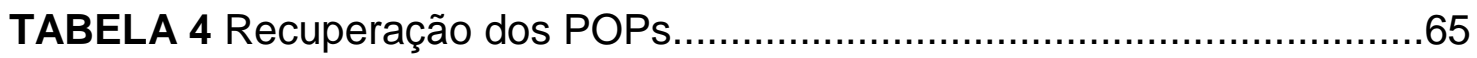

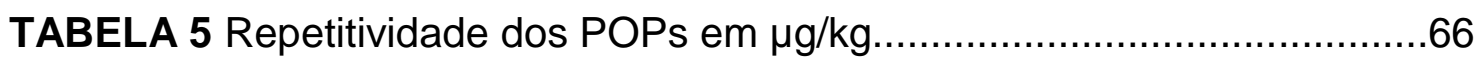

TABELA 6 Resultados do padrão conttrole dos POPs....................................71

TABELA 7 Resultado do Spike de 0,03 mg/kg de amostra 2 o Linha.................72

TABELA 8 Resultado do Spike de $0,010 \mathrm{mg} / \mathrm{kg}$ da amostra Bororé.................72

TABELA 9 Resultado do Spike de $0,010 \mathrm{mg} / \mathrm{kg}$ da amostra Corpo Central....73

TABELA 10 Resultado do Spike de $0,050 \mathrm{mg} / \mathrm{kg}$ da amostra Estoril...............73

TABELA 11 Resultados em $\mu \mathrm{g} / \mathrm{kg}$ das amostras........................................74 





\section{INTRODUÇÃO}

O aumento da população mundial e a crescente demanda de alimentos têm motivado o uso de grandes quantidades de pesticidas nas plantações para prevenir ou combater pragas, visando assegurar maior produtividade. Muitos produtos são utilizados para eliminar formas de vida vegetal ou animal indesejáveis na pecuária e nas culturas agrícolas. (Oliveira, 2011) Os Poluentes Orgânicos Persistentes (POPs) são compostos altamente estáveis que persistem no ambiente, resistindo à degradação química, fotolítica e biológica. (Estocolmo, 2001)

Os POPs podem bioacumular-se em oganismos vivos, sendo muito tóxico para os seres vivos. Atuam no sistema imunológico, endócrino e reprodutivo e são cancerígenos. São compostos lipofílicos e distribuem-se no interior das membranas celulares e depósitos de gordura, assim, organismos como as algas, que vivem em águas poluídas em compostos orgânicos persistentes, acumulam essas substâncias na medida em que elas possuem maior afinidade por lipídios biológicos do que pela água. Quando esses organismos são ingeridos por animais no próximo nível trófico como os crustáceos, os animais acumulam quantidades muito maiores. Os níveis tróficos da cadeia alimentar podem adquirir e armazenar concentrações extremamente altas de poluentes, cerca de 100.000 vezes a concentração encontrada na água. Uma característica muito importante é a lixiviação é o transporte dos POPs a longas distâncias pelo vento, água das chuvas e pelos animais. (Oliveira, 2011)

Os pesticidas começaram a ser usados em larga escala após a Segunda Guerra Mundial, tanto na proteção agrícola, quanto na prevenção de doenças como a malária. $\mathrm{O}$ uso destes pesticidas como o DDT, salvou milhões de pessoas nesta época, pois matava os insetos transmissores da doença. A partir dos anos 50 ficou mais evidente o efeito negativo destes compostos na agricultura e no meio ambiente.

A Declaração de Estocolmo, documento elaborado na Suécia em 1972, patrocinada pela ONU (Organização das Nações Unidas) e com participação de 113 países incluindo o Brasil, foi o primeiro instrumento global que obriga os governos a 
tomarem ações objetivando a eliminação destes poluentes no meio ambiente. (ESB, 2006)

Os sedimentos constituem um fator muito importante do sistema aquático, por suas participações no equilíbrio dos poluentes solúveis e por sua maior permanência no corpo d'água, sendo, em geral, integradores das cargas poluentes recebidas pelas águas. Os contaminantes dos sedimentos de fundo podem retornar ás águas por meio de alterações nas condições físico-químicas, $\mathrm{pH}$, alcalinidade, níveis de oxidação/redução, ou mesmo por meio de atividades biológicas e microbiológicas ${ }^{33}$.

O sedimento é considerado o compartimento mais importante para o estudo do impacto das Substâncias Tóxicas Persistentes (STP) no meio ambiente, pois é aqui que as STP apresentam os maiores tempos de residência. O sedimento fica acumulado no fundo e realiza constantes trocas de nutrientes e outras substâncias com a coluna d'água, podendo alterar a qualidade da água. (Almeida et.al, 2007). O monitoramento da contaminação da água e dos sedimentos da Represa Biilings é realizado pela Companhia Ambiental do Estado de São Paulo (CETESB), que possui histórico de contaminação de alguns POPs.

A análise de POPs necessita de duas etapas: a extração e a detecção. As técnicas de extração mais utilizadas são por Soxhlet e por ultrassom, mas ambas demandam muito solvente e tempo demasiado de análise. Em 2003, Michelangelo Anastassiades, introduziu a micro-extração chamada "Quechers" para obter uma eficaz extração do analito, diminuindo assim o volume de solvente utilizado pela técnica, conforme os novos protocolos da química verde. Inicialmente está técnica foi aplicada para alimentos, mas vem ganhando campo na extração de matrizes complexas como o solo e agora o sedimento.

A técnica da cromatografia gasosa é utilizada na determinação de compostos voláteis, podendo ser acoplada a diferentes detectores, como a espectrometria de massas (GC/MS) para detectar os POPs. Esta técnica é de alta confiabilidade e multielementar. O Detector de Captura de Elétrons (GC/ECD) possui alta sensibilidade para quantificação dos halogênios, como os compostos organoclorados. (Oliveira, 2011) 
A técnica de extração por Quechers na matriz sedimento é inédita, sendo necessário realizar o processo de validação, visando atender a norma do INMETRO (Instituto Nacional de Metrologia e Qualidade Instrumental), órgão responsável pela certificação e fiscalização de laboratório de análise, a fim de garantir a qualidade e confiabilidade dos dados gerados. A norma ABNT NBR ISO/IEC 17025:2005 exige que os laboratórios de ensaio cumpram os requisitos gerais para competência de laboratórios de ensaio e calibração. A norma é publicada internacionalmente pela International Organization of Standardization (ISO) em conjunto com a International Electrotechnical Commission (IEC). No Brasil a publicação é feita pela Associação Brasileira de Normas Técnicas (ABNT), e a norma recebe o nome ABNT NBR ISO/IEC 17025. (ABNT NBR ISO/IEC 17025, 2005)

A validação de um método analítico envolve algumas análises como a determinação do Limite de Detecção, Limite de Quantificação, Repetitividade, Recuperação e Incerteza de Medição. Todas essas análises foram realizadas neste trabalho.

Após a realização das análises, foi realizada a comparação de resultados, de acordo com a legislação para sedimentos do CONAMA 344 e 454, assim como os resultados obtidos pela CETESB em análises anteriores.

Este estudo objetivou determinar sete POPs no sedimento da Represa Billings, utilizando uma nova técnica de extração Quechers, seguido por técnicas instrumentais, como a cromatografia a gás e cromatografia a gás acoplada a espectrometria de massas, para a determinação dos POPs. 


\section{OBJETIVOS}

O objetivo geral do presente trabalho foi desenvolver um método de análise dos POPs em sedimentos da Represa Billings, utilizando a técnica de extração dos analítos via Quechers, juntamente com a identificação e quantificação destes analitos via cromatografia a gás acoplada à Espectrometria de Massas (GC/MS) e Cromatografia a Gás com detector de captura de elétrons (GC/ECD).

Como objetivos específicos têm-se:

1) Desenvolver método de extração e análise dos POPs em sedimento utilizando a técnica de extração via Quechers e análises via cromatografia a gás com detector de captura de elétrons $G C / E C D$, cromatografia à gás acoplada a Espectrometria de Massas GC/MS;

2) Otimizar as análises qualitativas e quantitativas dos POPs utilizando padrões certificados dos analitos POPs via GC/MS, GC/ECD;

3) Validar o método de extração e análises instrumentais para validação do IPEN;

4) Coletar as amostras de sedimentos na Represa Billings;

5) Analisar os sedimentos da Represa Billings - SP;

6) Estudo dos POPs na Represa Billings, comparando com dados anteriores da CETESB. 


\section{REVISÃO BIBLIOGRÁFICA}

\subsection{POLUENTES ORGÂNICOS PERSISTENTES - POPS}

Os Poluentes Orgânicos Persistentes (POPs) são tóxicos em seres vivos, pois podem bioacumular-se neles. Por terem grau de lipossolubilidade (solubilidade em gordura), podem ser acumulados na gordura dos animais, sendo tóxico para estes, inclusive o homem. (Sanches et.al, 2003)

O Dieldrin, por exemplo, pode ser acumulado na gordura corporal, leite materno, sêmen, fígado e pode ultrapassar a barreira placentária. (Campos et.al, 2010) Atuam negativamente nos seres vivos como disruptor dos sistemas reprodutivo, imunológico e endócrino, inclusive alguns POPs são considerados carcinogênicos. (Braul et. al, 2013)

Por serem altamente estáveis, os POPs podem ser transportados a longas distâncias pela lixiviação, disseminando seus efeitos nocivos para o reino animal. Um exemplo é a contaminação com DDT pelos ursos polares. (Malliaros et. al, 1997)

Como não são específicos, alguns POPs representam riscos para o homem e, com isso, tem aumentado a preocupação no que se diz respeito ao efeito destes compostos ao meio ambiente e à saúde, particularmente em países onde as atividades de vigilância, controle e gerenciamento são pouco desenvolvidas (Maroni et al, 2000)

Os pesticidas começaram a ser bastante utilizados após a Segunda Guerra Mundial, tanto na proteção de culturas agrícolas, como em prevenção de doenças como a malária. O uso destes pesticidas salvou milhões de pessoas ao serem utilizados para liquidar insetos transmissores de doenças. No entanto, o efeito negativo destes compostos na agricultura bem como no ambiente, começou a ser mais evidente a partir dos anos 50. (Koelmans et al, 2013)

Devido a sua importância, os POPs que foram estudados neste trabalho são: Aldrin $\left(\mathrm{C}_{12} \mathrm{H}_{8} \mathrm{Cl}_{6}\right)$, Dieldrin $\left(\mathrm{C}_{12} \mathrm{H}_{8} \mathrm{Cl}_{6} \mathrm{O}\right)$, Endrin $\left(\mathrm{C}_{12} \mathrm{H}_{8} \mathrm{Cl}_{6} \mathrm{O}\right)$, DDE $\left(\mathrm{C}_{14} \mathrm{H}_{8} \mathrm{C}_{14}\right)$, DDT $\left(\mathrm{C}_{14} \mathrm{H}_{9} \mathrm{C}_{5}\right)$ e DDD $\left(\mathrm{C}_{14} \mathrm{H}_{10} \mathrm{C}_{4}\right)$ e Heptacloro $\left(\mathrm{C}_{10} \mathrm{H}_{5} \mathrm{Cl}_{7}\right)$. 
O Aldrin (1,2,3,4,10,10-Hexaidro-1,4,4a,5,8,8a-hexaidro-1,4-endo,exo-5,8metanonaftaleno) é rapidamente metabolizado para Dieldrin tanto pelas plantas como pelos animais e, por esta razão, apresenta persistência moderada sendo $t_{1 / 2}$ (meia vida) no solo de 20 a 100 dias. (Almeida et al, 2007)

Aldrin e Dieldrin são compostos organoclorados sintéticos, sólidos à temperatura ambiente, praticamente insolúveis em água, que se apresentam como um pó branco quando puros e com coloração parda, sendo $90 \%$ de pureza para o Aldrin e $85 \%$ de pureza para o Dieldrin. Essas substâncias foram muito utilizadas como inseticida entre as décadas de 50 e 70, principalmente nas culturas de algodão e milho, mas seu uso foi banido devido às altas persistências no ambiente e capacidade de bioacumulação. (CETESB, 2014)

O pesticida Endrin (1,4,5,6,9,9-Hexacloro-1a,2,2a,3,6,6a,7,7a-octaidro-2,7:3,6imetanoft[2,3-b]oxireno), é altamente persistente no solo e em alguns casos já foram relatados $t_{1 / 2}$ de até 12 anos. (Almeida et al, 2007)

O Heptacloro (1,4,5,6,7,8,8-Heptacloro-3a,4,7,7a-octraidro-4,7-metanoindeno), é metabolizado em solos, plantas e animais para heptacloro epóxido, que é mais estável em sistemas biológicos, além de cancerígeno. No solo de regiões temperadas o $t_{1 / 2}$ é de 0,7 a 2 anos. (CETESB, 2014)

O Diclorodifeniltricloroetano (DDT) - (1,1,1-Tricloro-2,2-bis-(4-clorofenil)etano), salvou várias vidas no controle de pragas como a malária, porém sua persistência e lipofilicidade causou a morte de vários animais. O DDT é altamente persistente em solos com $t_{1 / 2}$ de cerca de 1,1 a 3,4 anos. Também exibe altos fatores de bioconcentração. No ambiente, o DDT tem alta reatividade e atua como interferente endócrino. Este é metabolizado para DDD e DDE, sendo o DDE produto de degradação da maioria das reações que ocorrem no meio ambiente. O inseticida organoclorado DDT foi extensivamente usado na agricultura, mas foi banido em diversos países devido à persistência no ambiente e biomagnificação na cadeia alimentar. Atualmente é utilizado no controle de mosquitos vetores de malária em alguns países da África, como Zâmbia. O Brasil proíbe a fabricação, importação, exportação, manutenção em estoque, comercialização e uso do DDT, devido a Lei 11.936 de 14 de maio de 2009. (Almeida et al, 2007) 


\subsubsection{Comportamento no meio ambiente}

O Aldrin e o Dieldrin ainda podem ser encontrados no ambiente devido à alta persistência, mesmo que não mais utilizados. O Aldrin é convertido em dieldrin sob ação da luz solar e de bactérias. Desse modo, o Dieldrin é predominante no ambiente, mesmo quando a substância utilizada foi o Aldrin. Ambos os compostos podem ser encontrados na atmosfera a partir de arraste pelo vento por aplicação na lavoura, evaporação de águas contaminadas e adsorção a partículas em suspensão. Uma vez na atmosfera, o Dieldrin pode ser convertido em fotoaldrin ou fotodieldrin, ambos produtos da degradação do Aldrin e Dieldrin por radiação solar. No solo, o Aldrin pode evaporar lentamente ou sofrer oxidação, originando o Dieldrin. A persistência do composto no solo depende do clima da região. Em países de clima temperado, $75 \%$ do Aldrin é oxidado a Dieldrin em um ano. Já em países de clima tropical, os compostos desaparecem do solo rapidamente, pois $90 \%$ do Aldrin e Dieldrin sofrem evaporação em 1 mês. (Almeida et al, 2007)

$\mathrm{Na}$ água, a degradação dos compostos é lenta e eles tendem a se acumular no sedimento. Não é comum a presença de Aldrin e Dieldrin em águas subterrâneas devido à resistência que eles possuem a lixiviação no solo. Tanto o Aldrin quanto seu principal produto de degradação são altamente lipossolúveis, o que, juntamente com a alta persistência, faz com que possuam uma grande capacidade de bioacumulação e biomagnificação. (Almeida et al, 2007)

O Endrin não se dissolve muito bem na água. No meio aquoso, liga-se fortemente às partículas do sedimento, nele se concentrando. É encontrado em águas subterrâneas e superficiais, mas apenas em níveis reduzidos. Pode ser encontrado na atmosfera após a nebulização de culturas agrícolas. Neste meio apresenta meia-vida de poucos dias. A persistência da substância no ambiente depende das condições locais e estimativas indicam que o Endrin pode permanecer no solo por mais de 10 anos. Os mecanismos de decomposição do Endrin no meio ambiente incluem fotodecomposição e degradação bacteriana. Essa última depende 
da presença de espécies microbianas apropriadas e condições propícias do solo, sob anaerobiose. (Almeida et al, 2007)

O DDT e seus metabólitos aderem firmemente ao solo, permanecendo nas camadas superficiais. $\mathrm{Na}$ água ficam adsorvidos ao material particulado e fixos aos sedimentos. A degradação do DDT no ar ambiente ocorre por foto-oxidação atmosférica ou por fotólise na superfície da água. A meia-vida estimada na atmosfera é de 1,5 a 3 dias. (Almeida et al, 2007)

DDE e DDD são produtos de degradação do DDT por interações químicas no ambiente (volatilização e reação com luz solar) ou biotransformação por microrganismos do solo. Ao perder uma molécula de $\mathrm{HCl}$, por degradação biológica ou ambiental, o p,p'-DDT forma o metabólito 2,2-bis- $p$-clorofenil-1,1-dicloroetileno, conhecido como DDE. Este composto é ainda mais resistente às degradações que o DDT. Outro metabólito formado é o DDD, 2,2-bis-p-clorofenil-1,1-dicloroetano. A biodegradação das formas DDE e DDD é lenta e ocorre por descloração redutiva. A persistência do DDT e seus metabólitos em combinação com sua alta afinidade por lipídios contribuem para a bioacumulação e biomagnificação desses compostos no ambiente. (Almeida et al, 2007)

O heptacloro é moderadamente persistente no solo, onde é convertido para a forma epóxido e a outros produtos de degradação. O heptacloro epóxido degrada mais lentamente e, portanto, é mais persistente que o heptacloro. Tanto o heptacloro como sua forma epóxido adsorvem fortemente aos sedimentos e ambos são bioconcentrados em organismos aquáticos e terrestres. Rápida metabolização do heptacloro à sua forma epóxido ocorre em organismos de níveis tróficos superiores, tornando a biomagnificação do heptacloro insignificante nesses organismos, porém a biomagnificação do epóxido é significativa na cadeia alimentar terrestre devido a sua alta persistência e lipofilicidade. O heptacloro e sua forma epóxido podem ser transportados a longas distâncias e são removidos da atmosfera por deposição úmida e seca' (Almeida et al, 2007) 


\subsubsection{Exposição humana e efeitos à saúde}

O Aldrin e o Dieldrin são tóxicos para o homem. As exposições ocupacionais ocorreram em operações de controle de insetos, aplicações agrícolas, combate a mosquitos e fabricação de agrotóxicos. Atualmente as exposições ambientais podem ocorrer por contato com o ar, água, alimentos e solo contaminados. A via de exposição mais comum é por alimentos, sejam de origem vegetal ou animal. Não foram relatados efeitos irreversíveis em intoxicações agudas e subagudas. Os sintomas da intoxicação são cefaleia, tontura, náusea, vômito, tremor muscular, mioclonia e convulsões (Dores et. al, 2001) As intoxicações crônicas geralmente ocorrem por exposição simultânea ao Aldrin, Dieldrin e Endrin e foram associadas ao aumento de câncer hepático e biliar, embora o estudo tenha apresentado como limitação a ausência de informações sobre os níveis de exposição (Colabuono, 2011)

A Agência Internacional de Pesquisa em Câncer (IARC) classifica o Aldrin e o Dieldrin no Grupo 3 - não classificável quanto à carcinogenicidade. Essa categoria comumente é usada para agentes para os quais a evidência de câncer é inadequada em humanos e inadequada ou limitada em animais de experimentação. (Silva, 2012)

A população geral pode ser exposta ao Endrin por ingestão de alimentos e água contaminados, inalação de ar e contato com solo de áreas de disposição de resíduos perigosos. Estudos com animais mostram que o Endrin pode afetar 0 sistema nervoso, causando tremores e convulsões. Existem relatos de diminuição do ganho de peso e danos histopatológicos no fígado e rins de animais expostos por via oral por curto prazo. (Silva, 2012)

Estudos com roedores alimentados com Endrin durante a prenhez mostraram anormalidades esqueléticas nas crias. Em seres humanos a exposição aguda a altas doses pode levar rapidamente a sinais e sintomas de intoxicação, como excitabilidade e convulsões, e a morte pode ocorrer entre 20 minutos e 12 horas após a exposição. Não foram observados efeitos em trabalhadores sob exposição crônica ao endrin por via respiratória e dérmica. A Agência Internacional de Pesquisa em Câncer (IARC) classifica o endrin no Grupo 3 - não classificável quanto à carcinogenicidade para o ser humano. (Amato et. al, 2002) 
A população geral não está exposta ao DDT, DDE ou DDD, mas a uma mistura dos 3 compostos, uma vez que DDE e DDD são produtos metabólicos e de degradação do DDT. A principal via de exposição é por ingestão de alimentos contaminados, particularmente alimentos gordurosos de origem animal e leite materno. Apesar de o DDT e seus produtos de biotransformação estarem presentes na atmosfera, eles estão presentes em baixas concentrações e as exposições dérmica e inalatória são mínimas (Amato et. al, 2002)

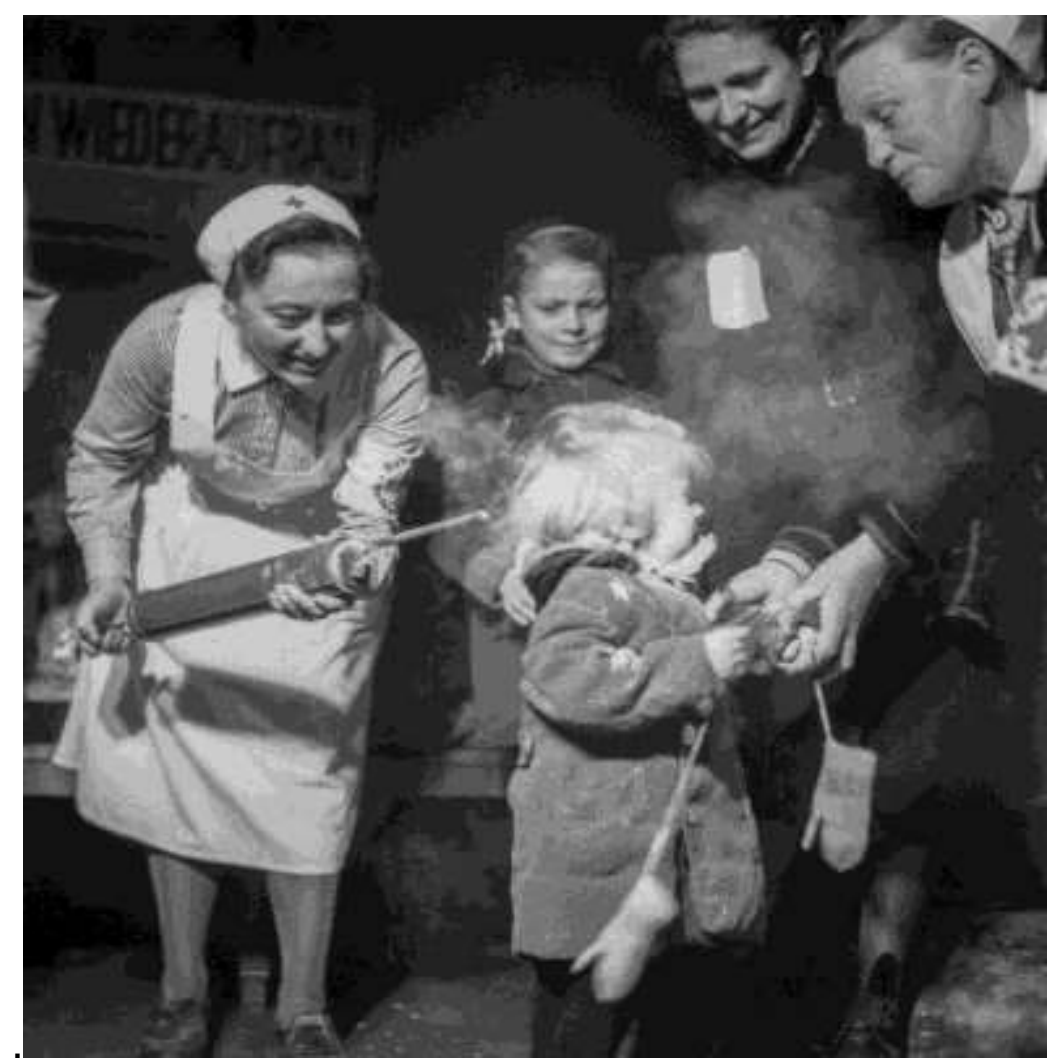

FIGURA 1 Criança sendo pulverizada com DDT na Segunda Guerra Mundial, na Alemanha. (Challoner, 2010.)

A exposição por ingestão de água potável também é considerada mínima, uma vez que o DDT é pouco solúvel em água. O DDT e o DDE podem atravessar a placenta e ser excretados no leite materno. O DDE é o principal metabólito do DDT no sistema biológico. Os efeitos agudos na exposição leve a moderada incluem náusea, diarreia, aumento da atividade enzimática do fígado, irritação (dos olhos, 
nariz e garganta), mal-estar e excitabilidade. Em doses altas podem ocorrer tremores e convulsões. Entretanto, devido à estabilidade química, o DDT acumula na cadeia alimentar e tecidos de organismos expostos, incluindo pessoas que vivem em casas tratadas com DDT contra malária. (CETESB, 2017) A FIG.1 ilustra uma criança sendo pulverizada com DDT na época da Segunda Guerra Mundial.

Estudos epidemiológicos com crianças expostas ambientalmente ao DDT e DDE não encontraram anormalidades neurológicas ou de desenvolvimento. Contudo, a exposição ocupacional crônica ao DDT pode estar associada com diminuição permanente das funções neurocomportamentais, como atenção verbal, velocidade visual, motora e aumento de sintomas neuropsicológicos e psiquiátricos. A Agência Internacional de Pesquisa em Câncer (IARC) classifica o DDT no Grupo 2B possível cancerígeno humano com base na indução de tumores hepáticos em animais. (CETESB, 2017)

A exposição ao heptacloro geralmente ocorre por ingestão de alimentos contaminados, como peixes, mariscos, derivados do leite, carnes e aves. As crianças que consomem grandes quantidades de leite podem ser mais expostas se o leite estiver contaminado com o composto, e podem ser expostas também por leite materno. Outras fontes de exposição são ingestão de água, inalação de ar ou contato com solo contaminado em locais com resíduos perigosos contendo heptacloro e heptacloro epóxido. Pessoas que vivem em casas que passaram por processos de descupinização com heptacloro podem ser expostas por via inalatória. Não há informação de casos de intoxicação acidental ou suicida com o composto. Estudos epidemiológicos não demonstraram clara relação entre efeitos adversos e a exposição ao heptacloro.

A toxicidade aguda do heptacloro em animais está associada com alterações no sistema nervoso central, como hiperexcitabilidade, tremores, convulsões e paralisia. A toxicidade aguda do heptacloro epóxido é maior do que do heptacloro.

Estudos com animais demonstraram que a exposição crônica ao heptacloro causa aumento do fígado e lesões, diminuição da fertilidade, mortalidade neonatal e alterações no sistema imunológico da prole. Roedores expostos na fase pré-natal apresentaram efeitos neurológicos sutis. A Agência Internacional de Pesquisa em 
Câncer (IARC) classifica o heptacloro no Grupo 2B - possível cancerígeno humano (CETESB, 2017)

Na TAB.1 são apresentados os POPs estudados neste trabalho, discriminando o nome da substância, a fórmula estrutural e molecular e suas aplicações. Os compostos DDE e DDD não aparecem na tabela por serem degradação do DDT. 
TABELA 1 Fórmulas e aplicações dos POPs estudados. (Oliveira, 2011)

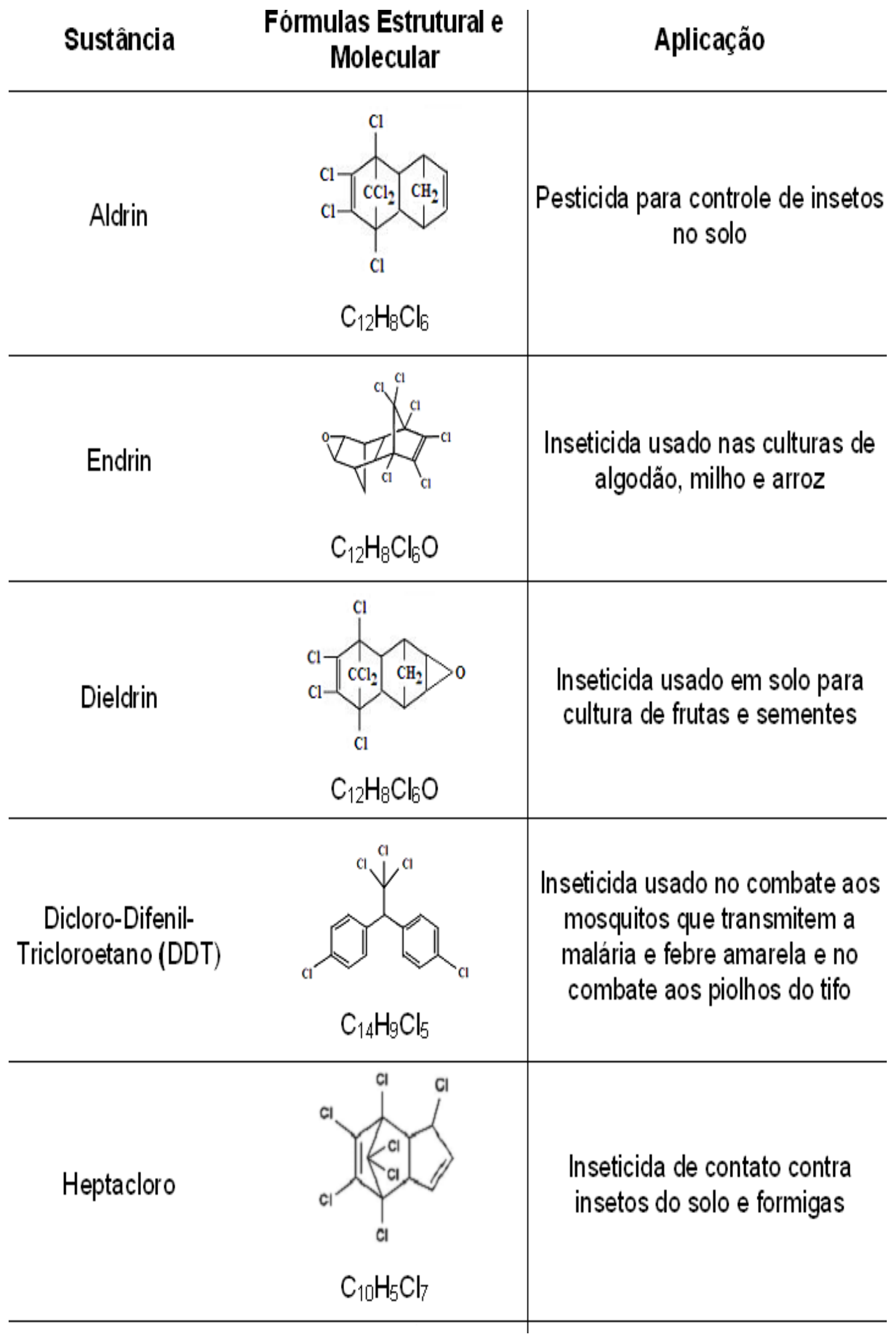




\subsubsection{Convenção de Estocolmo}

A Convenção de Estocolmo determinou que os Países-Parte adotassem medidas de controle relacionadas a todas as etapas do ciclo de vida - produção, importação, exportação, uso e destinação final - das substâncias POPs. (MMA, 2017)

A Declaração de Estocolmo, documento que insere no vocabulário mundial conceitos como ecologia e educação ambiental. Elaborado na Conferência ocorrida na Suécia em 1972 e prestigiada por 113 países, inclusive o Brasil. Patrocinada pela Organização das Nações Unidas (ONU) vem a ser o primeiro instrumento global que obriga os governos a tomarem ações objetivando a eliminação desses poluentes no meio ambiente. O documento prevê a eliminação de doze POPs: Hexaclorobenzeno, Heptacloro, Clordano, Dioxinas, Furanos, DDT, Aldrin, Dieldrin, Endrin, Mirex, Toxafeno e PCBs. A lista inicial dos doze POPs da Convenção de Estocolmo é dividida em oito pesticidas, duas substâncias químicas industriais e quatro não intencionais. (Estocolmo, 2001)

De 2 a 13 de novembro de 1998, foi realizada em Buenos Aires na Argentina, a quarta Conferência das Partes na Convenção-Quadro das Nações Unidas sobre Mudança do Clima (COP-4). A reunião centrou esforços na implementação e ratificação do Protocolo de Kyoto, adotado na COP-3. (Secima, 2017)

Durante a COP 4, foram incluídos nove POPs, foram eles: ácido perfluorooctano e seus sais perfluorooctano sulfonil fluoreto, alfa hexaclorociclohexano, beta hexaclorociclohexano, clordecone, hexabromobifenil, éter hexabromodifenil e éter heptabromobifenil, lindano, pentaclorobenzeno, éter tetrabromodifenil e éter pentabromodifenil. $\mathrm{Na}$ COP 5 , foi inserido o endossulfam. (CETESB, 2014)

A Convenção visa à eliminação e/ou restrição dos POPs, seus estoques e resíduos, a redução da liberação de suas emissões não intencionais no meio ambiente, além da identificação e gestão de áreas contaminadas por essas substâncias. Numa posição preventiva, o tratado determinou que os governos promovam as melhores tecnologias e práticas no seu campo tecnológico e previnam o desenvolvimento de novos POPs. Indo mais além, define como seu objetivo final a 
eliminação total dos POPs. A Convenção apresenta opções inovadoras e objetivas de ações para a gestão adequada dessas substâncias. (MMA, 2017)

Os países participantes deverão elaborar Planos Nacionais de Implementação da Convenção de Estocolmo (NIP), identificando prioridades, prazos e estratégias de cumprimento das obrigações constantes da Convenção. Constitui-se, portanto, num instrumento vinculante, que compreende substâncias altamente tóxicas e prejudiciais ao homem e ao meio ambiente, de grande interesse e acompanhamento por parte do setor industrial e da sociedade civil. (MMA, 2017)

A Convenção POPs entrou em vigor em 17/05/2004, após 50 países a ratificarem. Atualmente, 164 Partes integram a Convenção de Estocolmo. O Brasil aprovou o texto da Convenção por meio do Decreto Legislativo № 204, de 7 de maio de 2004, e promulgou o texto da Convenção em 2005, via o Decreto № 5.472, de 20 de junho de 2005. (MMA, 2017)

A Secretaria de Mudanças Climáticas e Qualidade Ambiental do Ministério do Meio Ambiente desempenham a função de Ponto Focal Técnico da Convenção, juntamente com a Divisão de Política Ambiental e Desenvolvimento Sustentável do Ministério das Relações Exteriores, que atua como Ponto Focal Oficial. (MMA, 2017)

\section{2 - Normatização}

No Brasil, há duas agências credenciadoras para verificar a competência de laboratórios de ensaio: a ANVISA (Agência Nacional de Vigilância Sanitária) e o INMETRO (Instituto Nacional de Metrologia, Normalização e Qualidade Industrial). Estes órgãos disponibilizam guias para o procedimento de validação de métodos analíticos, respectivamente, a Resolução ANVISA RE ํㅜ 899, de 29/05/2003 e o documento INMETRO DOQ-CGCRE-008, de março/2003. Para análises ambientais, são utilizados os parâmetros do INMETRO. Tais parâmetros para validação de métodos têm sido definidos em diferentes grupos de trabalho de organizações nacionais ou internacionais. (ANVISA, 2003; INMETRO, 2011) 
A IUPAC "International Union of Pure and Applied Chemystry" redigiu um documento técnico que define um guia para validação de métodos analíticos que tem sido utilizado pela ISO (International Organization for Standardization). (Thompson et.al, 2002)

Estes orgãos, IUPAC, ISO, ANVISA, INMETRO, exigem o item "validação de métodos analíticos" como um requisito fundamental no credenciamento para a qualidade assegurada e demonstração de competência técnica. (ICH, 1995)

O que se pode observar é que não há um procedimento normatizado que estabeleça como executar a validação de métodos instrumentais de separação. Como estes organismos são responsáveis por acompanhar e credenciar a competência de laboratórios de ensaios, é importante ressaltar que as diferentes terminologias e até algumas características de desempenho do método têm, em sua maior parte, o mesmo significado, porém descrito de uma maneira distinta, para aplicações diferentes. Em laboratórios de análises ambientais, a ABNT NBR ISO/IEC 17025:2005é a norma utilizada como referência e o INMETRO é o orgão responsável pelo cumprimento desta norma. (INMETRO, 2011)

\subsection{ABNT NBR ISO/IEC 17025:2005}

A ABNT NBR ISO/IEC 17025:2005 é uma norma para a padronização de testes laboratoriais, apenas para laboratórios de ensaio e calibração. (ISO, 1999)

A primeira edição desta Norma foi elaborada como resultado de ampla experiência na implementação do ABNT ISO/IEC Guia 25 (Norma Internacional anterior a ISO/IEC 17025, que apresentava requisitos técnicos e específicos para laboratórios de ensaio, mas não contemplava os laboratórios de calibração) e da EN 45001 (Norma Internacional para saúde e segurança ocupacional). Todos os requisitos que os laboratórios de ensaio e calibração têm que atender se desejarem demonstrar que têm implementado um sistema de gestão, que são tecnicamente competentes e que são capazes de produzir resultados tecnicamente válidos, necessitam da ABNT NBR ISO/IEC 17025:2005. 
O crescimento do uso de sistemas de gestão, em geral, tem aumentado a necessidade de assegurar que laboratórios que fazem parte de organizações maiores ou que oferecem outros serviços possam operar de acordo com um sistema de gestão que esteja em conformidade com a ABNT NBR ISO 9001, bem como com esta Norma. Portanto, foram tomados cuidados para incorporar todos os requisitos da ABNT NBR ISO 9001 que são pertinentes ao escopo dos serviços de ensaio e calibração cobertos pelo sistema de gestão do laboratório. Os laboratórios de calibração e ensaio que atendam a esta Norma, portanto, permanecerão também de acordo com a ABNT NBR ISO 9001. (ISO, 1999)

A conformidade do sistema de gestão da qualidade sob o qual o laboratório opera com os requisitos da ABNT NBR ISO 9001 por si só não demonstra a competência do laboratório para produzir dados e resultados tecnicamente válidos. A conformidade demonstrada com esta Norma também não implica conformidade do sistema de gestão da qualidade sob o qual o laboratório opera com todos os requisitos da ABNT NBR ISO 9001. Convém que a aceitação de resultados de ensaio e calibração entre países seja facilitada se os laboratórios atenderem a esta Norma e se eles obtiverem a acreditação de organismos que tenham acordos de reconhecimento mútuo com organismos equivalentes de outros países, os quais utilizem esta Norma. (ISO, 1999)

O uso desta Norma facilitará a cooperação entre laboratórios e outros organismos, auxiliando na troca de informação e experiência e na harmonização de normas e procedimentos. (ISO, 1999) O INMETRO (Instituto Nacional de Metrologia, Qualidade e Tecnologia), é o responsável pela verificação dos cumprimentos da ABNT NBR ISO/IEC 17025:2005 nos laboratórios de análise. Por isso, todos os certificados de padrões utilizados para realização de qualquer análise, devem possuir esta norma. É de extrema importância a utilização de padrões certificados conforme exigência do INMETRO. (ISO, 1999)

Na norma internacional ISO/IEC 17025, o item 5.4.5, apresenta a "validação de métodos" como um dos requisitos técnicos importantes na qualidade assegurada dos laboratórios de ensaio, bem como a documentação do trabalho de validação. (ISO, 1999) 


\subsection{REPRESA BILLINGS}

A Represa Billings foi construída em 1925 e tem uma capacidade de armazenamento de água de 995 milhões de $\mathrm{m}^{3}$, tendo 10 vezes a capacidade da Represa Cantareira. A construção da represa teve início em 1925 e término em 1927, quando se iniciou o enchimento do reservatório. A represa Billings foi criada para gerar energia elétrica para a cidade de São Paulo, por meio da usina Henry Borden, localizada em Cubatão. O projeto da represa é de autoria do engenheiro estadunidense Asa White Kenney Billings (devido a ele a represa recebeu este nome), funcionário da empresa Light (The São Paulo Tramway, Light and Power Company, Limited). O engenheiro Billings propôs o barramento do rio Grande (ou Jurubatuba), nas proximidades do bairro Pedreira, em Santo Amaro, para formação

de um reservatório e, posteriormente, o desvio das águas desse para o rio das Pedras. (GESP, 2017)

Na década de 1940 teve início o desvio de parte das águas do rio Tietê para a represa, aumentando-se assim sua vazão, o que possibilitou a ampliação da capacidade de geração de energia elétrica. O desvio das águas foi possível revertendo-se o curso natural do rio Pinheiros por meio da construção de duas usinas elevatórias, Pedreira e Traição, situadas no leito do próprio rio. Em seguida a água assim desviada foi lançada em um túnel escavado na serra do Mar para movimentar as turbinas de uma usina hidrelétrica que foi construída ao pé da serra, em Cubatão (Henry Borden II). Por fim, após passar pela usina, a água foi despejada no rio Cubatão e seguiria em direção ao mar. (Maciel, 2017)

O crescimento populacional da região metropolitana de São Paulo obrigou o Poder Público a buscar alternativas para atender à crescente demanda por água. A dificuldade para viabilizar novos locais onde a água pudesse ser armazenada, captada, transportada, tratada e oferecida à população obrigou ao uso múltiplo das águas, como é o caso da represa Billings. Posteriormente, com a reversão das águas do rio Pinheiros, constatou-se sua utilidade no controle de enchentes e afastamento de efluentes industriais e domésticos da cidade de São Paulo, despejados no rio Tietê. A cidade crescia rapidamente e a falta de investimentos em 
sistemas de coleta e tratamento de esgotos ocasionou aumento da poluição do rio Tietê e de seus afluentes. Com o passar do tempo o bombeamento das águas poluídas dos rios Tietê e Pinheiros passou a comprometer a qualidade da água da represa, também utilizada para abastecer a população. A gravidade da situação provocou embate entre o Poder Público e setores da sociedade civil organizada. Entidades ambientalistas exigiam a paralisação do bombeamento. (PMSA, 2017)

Representantes de indústrias reivindicavam sua manutenção para suprir a demanda por energia elétrica. O impasse foi finalizado em 1993, com a decisão do governo estadual de limitar o bombeamento para controlar enchentes em São Paulo, nos períodos de chuvas intensas. (PMSA, 2017)

Alguns especialistas, como a Dra. Marussia Whately, coordenadora da Aliança pelas Águas, alerta para a necessidade de rever o uso da Represa Billings, alegando que daria mais segurança hídrica, além de ajudar a construir um modelo mais sustentável de abastecimento da região metropolitana de São Paulo. Segundo Whately, deve-se recuperar uma Represa que já existe e não gastar bilhões para construir novas represas em locais distantes. Podendo não trazer os resultados necessários, ela sugeriu que a água do Rio Pinheiros deixe de ser bombeada para a represa' (PMSA, 2017)

Em janeiro de 2017, o Governador do Estado de São Paulo, Geraldo Alckmin, assinou autorização da despoluição da Represa no Programa Pró-Billings, que são obras de melhoria ambiental que abrangem coleta, afastamento e tratamento de esgoto. O governador Geraldo Alckmin assinou a autorização para a publicação do edital de licitação que beneficiará 250 mil habitantes. O lote a ser licitado inclui a construção de 34 Estações Elevatórias de Esgotos (EEE), 60 quilômetros de tubulações para coleta e afastamento dos dejetos e 7.566 ligações domiciliares em bairros como Jardim Laura, Las Palmas, Pinheirinho, Los Angeles, Represa e Imigrantes, em São Bernardo do Campo. (PMSA, 2017)

O controle da qualidade da Represa Billings inclui a água e o sedimento. Por meio deste controle é possível identificar a maioria dos contaminantes, como os Poluentes Orgânicos Persistentes. (PMSA, 2017)

A FIG.2, ilustra a Bacia Hidrográfica da Represa Billings. 


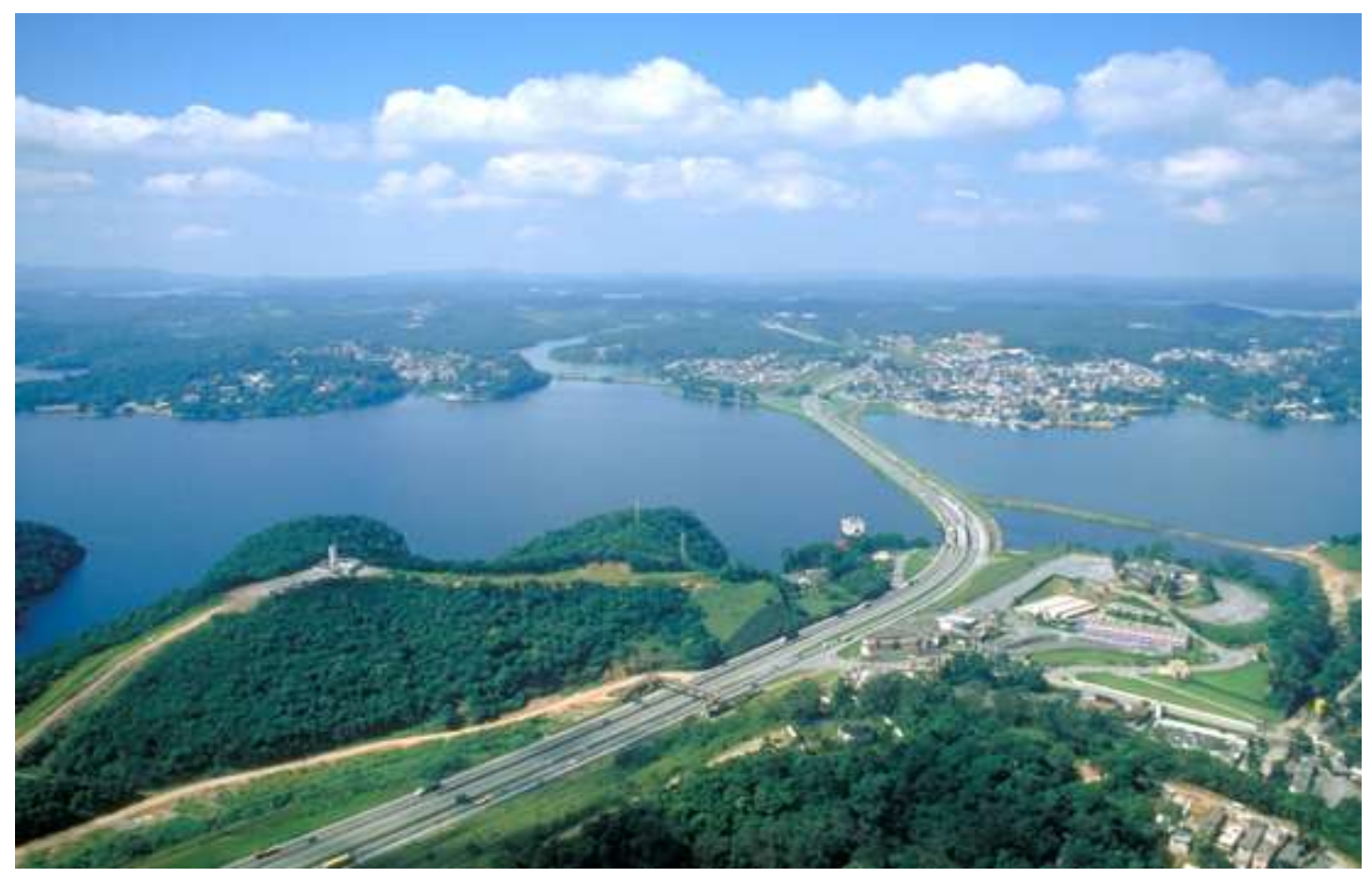

FIGURA 2 Represa Billings em São Paulo (Sabesp, 2017)

\section{5 - IMPORTÂNCIA DOS SEDIMENTOS}

Ao avaliar um ambiente aquático, como uma represa deve-se avaliar além da água, também o sedimento. Deve-se avaliar um ambiente aquático sob uma perspectiva evolutiva dessa qualidade e visando a exploração desse ambiente como um recurso natural renovável, é necessário que se avalie o estado de qualidade do sedimento' (Mozeto et. al, 1997)

O sedimento é considerado o compartimento mais importante para o estudo do impacto das Substâncias Tóxicas Persistentes (STP) no meio ambiente, pois é ali que as STP apresentam os maiores tempos de residência. Quando depositado no fundo, tem papel fundamental na evolução da qualidade dos ecossistemas aquáticos.

Ele fica acumulado no fundo e realiza constantes trocas de nutrientes e outras substâncias com a coluna d'água, não apenas armazenando a sujeira trazida por rios, ventos ou chuvas. Devido a esta interação, o sedimento pode alterar a qualidade da água. (EPA, 1992) 
Um dos meios pela qual os contaminantes no sedimento são transferidos para os organismos é a água intersticial (interface do sedimento com a água). A análise desta água intersticial vem se tornando um aspecto importante em programas ambientais, principalmente na identificação de substâncias tóxicas e na avaliação da qualidade dos sedimentos' (EPA, 1992)

Devido ao desenvolvimento de pesquisas sobre a contaminação em sedimentos, foram estabelecidos critérios de qualidade para sedimentos, que são úteis na avaliação da qualidade ambiental destes sedimentos e ainda na determinação de recuperação de áreas contaminadas. (EPA, 1992)

É importante no corpo hídrico conhecer a migração dos constituintes do sedimento para a água e vice-versa. Algumas das muitas reações biogênicas dependem da matéria orgânica e uma grande variedade de reações ocorre no sedimento pela interação da matéria orgânica, com o oxigênio, nitrato, sulfato e bicabornato, levando a remoção do oxigênio dissolvido; a redução de nitrato, sulfato e bicabornato e a produção de dióxido de carbono, amônio, fosfato e gás metano. O produto destas reações pode acarretar em mudanças químicas nos sedimentos, como a dissolução de minerais, de carbonato de cálcio e solubilização do ferro e manganês após a remoção do oxigênio. (Stumm, 1996)

A FIG.3 ilustra a direção dos fluxos esperados para os constituintes dissolvidos entre água intersticial do sedimento e água da coluna d'água.

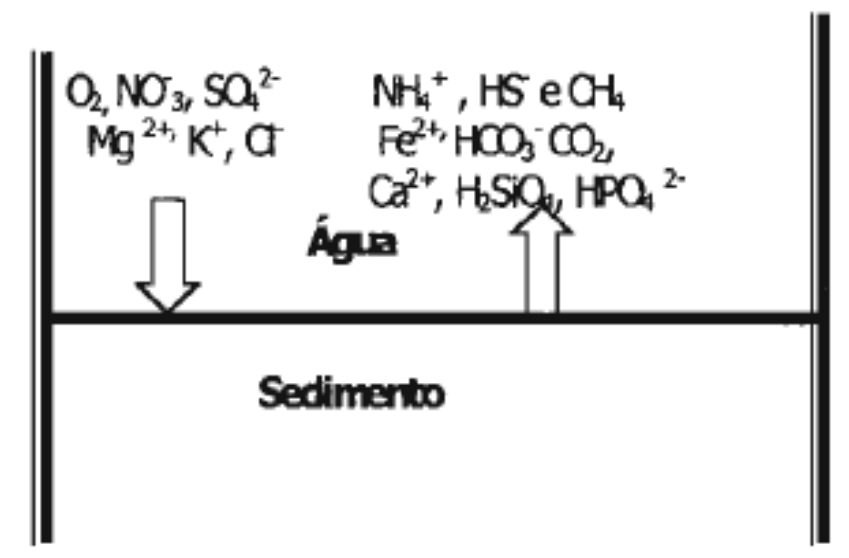

FIGURA 3 Direção do sedimento, da água e dos fluxos da água intersticial. (Stumm, 1996) 
A água intersticial e a sedimentação de partículas sólidas são os maiores fluxos entre a interface água-sedimento. As taxas de sedimentação variam bastante: de alguns centímetros por ano em lagos e reservatórios, a alguns milímetros por 1000 anos, nos oceanos. (Stumm, 1996)

Alguns fatores como porosidade do sedimento, profundidade, sedimentação e taxa de advecção da água intersticial, podem estabelecer uma relação entre concentração de água intersticial e concentração de sólidos. (Stumm, 1996)

$\mathrm{Na}$ interface sedimento-água, ocorrem reações redox, dependendo do tempo de deposição. A remineralização do nitrogênio e fósforo orgânico resulta no aumento da amônia fosfato. A diminuição da alcalinidade e resultado da decomposição da matéria orgânica tão direto (onde o nitrogênio orgânico é remineralizado para sal de amônio) quanto indireto. A calcita é dissolvida devido à liberação de dióxido de carbono associado à remineralização do carbono orgânico. Devido a estes fatores, conclui-se que alguns parâmetros físico-químicos da água intersticial, são de fato relacionados ao sedimento (Stumm, 1996)

\subsection{ANÁLISE DE PESTICIDAS POPS}

O processo de análise destes pesticidas pode ser dividido em duas etapas básicas: extração e detecção. A extração de pesticidas de amostras ambientais sólidas é frequentemente realizada utilizando-se solventes orgânicos com ou sem aquecimento. Estes modos de extração são realizados pelas técnicas sólido-líquido e pelo líquido-líquido. (Anastessiades et. al, 2007)

A extração de poluentes orgânicos de matrizes sólidas tem sido tradicionalmente realizada utilizando-se o método Soxhlet ou ultrassom. Além destes, há o Quechers que foi utilizado neste trabalho.

O método de extração por Quechers teve a sua introdução em 2003, por Michelangelo Anastassiades. A princípio, este método foi desenvolvido para extração de multirresíduo de pesticidas em alimentos, mas como a técnica se destaca por analisar as amostras em menos tempo e com baixa utilização de solventes de baixo custo. Este método foi adaptado desde a sua primeira versão, sendo testado para 
ser utilizado na extração de várias outras matrizes. Este método explora as possibilidades oferecidas pela instrumentação analítica moderna. (Anastessiades et. al, 2007)

Durante o seu desenvolvimento, grande ênfase foi dada para a obtenção de um procedimento dinâmico, que pudesse ser aplicado em qualquer laboratório, devido à simplificação das etapas como representado no fluxograma da FIG.4: Foram adicionadas $10 \mathrm{~g}$ de amostra ao tubo de teflon com capacidade de $50 \mathrm{~mL}$, posteriormente foram adicionados $10 \mathrm{~mL}$ de acetonitrila, agitou-se vigorosamente por 1 minuto, adicionou-se $4 \mathrm{~g}$ de sulfato de magnésio e $1 \mathrm{~g}$ de cloreto de sódio, agitouse vigorosamente por 1 minuto, adicionou-se o padrão interno (trifenilfosfato), agitouse por 30 segundos e centrifugou-se, transferiu-se para outro tubo $1 \mathrm{~mL}$ de extrato e adicionou-se $150 \mathrm{mg}$ de sulfato de magnésio e $25 \mathrm{mg}$ de PSA, agitou-se por 30 segundos e centrifugou-se. Realizadas estas etapas, a amostra ficou pronta para análise cromatográfica. (Anastessiades et. al, 2007) 


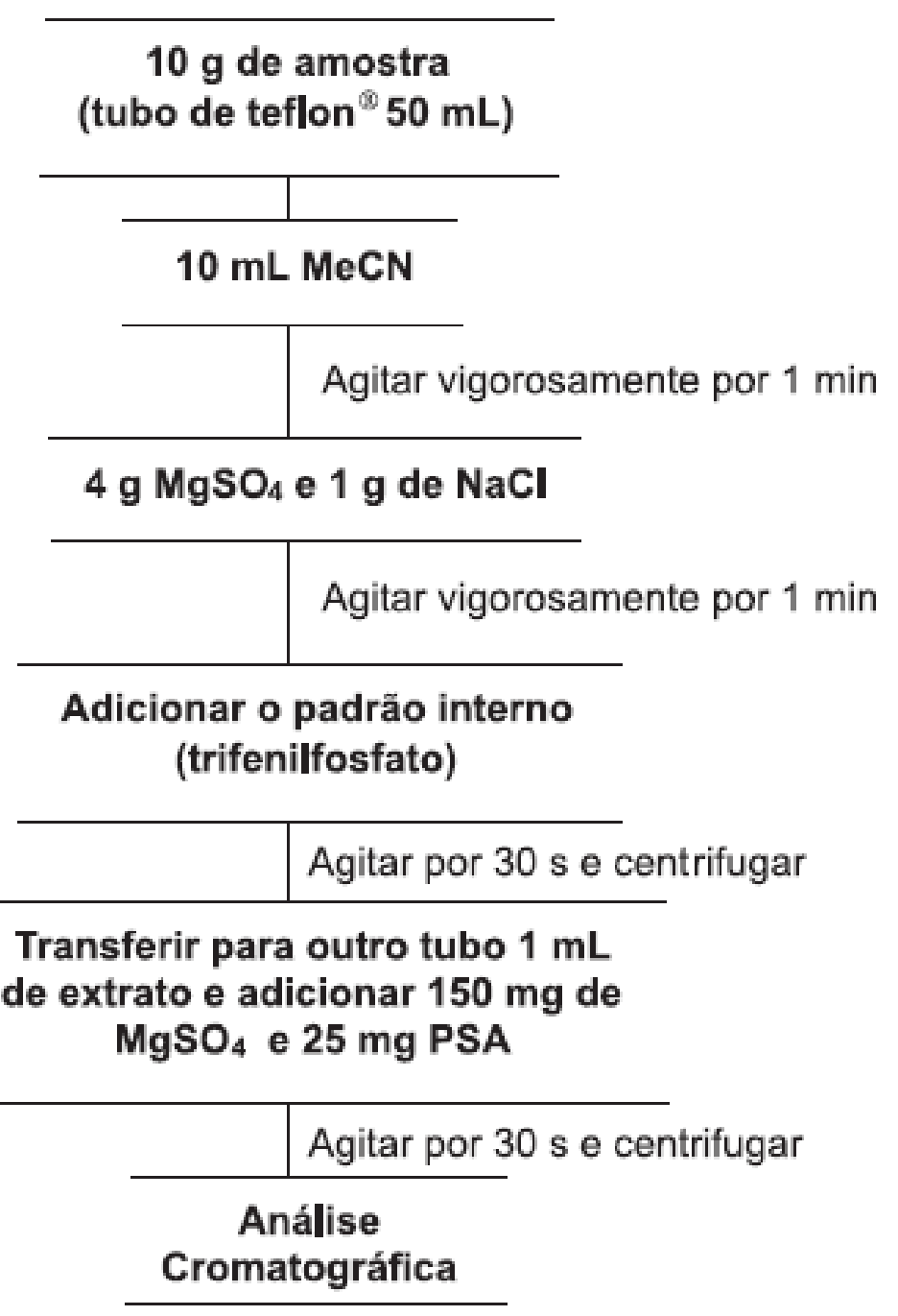

FIGURA 4 Fluxograma representativo do método Quechers original. (Anastessiades, 1996)

Quechers é um método de extração muito importante, pois além de rápido, fácil, barato, robusto e seguro, é também econômico e participa da química verde, pois o uso de solventes é mínimo, o que ajuda, e muito o meio ambiente. Em comparação com outros métodos como o Soxhlet, é muito rápido, uma vez que o Soxhlet pode levar mais de $24 \mathrm{~h}$ de extração da amostra e utilizar 1 a 2 litros de solvente. Com Quechers a extração é realizada em poucos minutos e com 
pouquíssimo solvente (cerca de 30 minutos de extração e $20 \mathrm{~mL}$ de solvente) (Anastessiades, 1996)

A quantidade de amostra para garantir de maneira simples uma maior eficiência do procedimento de preparo de amostra, usualmente, é utilizada uma pequena quantidade de amostra, desde que esta garanta representatividade estatística ao resultado final. De maneira geral, amostras sólidas, como a maioria dos alimentos, requerem etapas mais complexas e demoradas durante seu preparo. Uma das possibilidades de obter-se amostras sólidas homogêneas por meio do corte das amostras em pedaços menores seguido de processamento em homogeneizadores. (Anastessiades, 1996)

Baseado em dados da literatura, a quantidade de amostra escolhida no desenvolvimento do método Quechers foi de 5 a $10 \mathrm{~g}$, sendo esta considerada ideal quando comparada a quantidades de 15 a $100 \mathrm{~g}$ normalmente utilizadas em outros métodos multirresíduo (Prestes et.al, 2009)

Os solventes mais utilizados para extração multirresíduos de pesticidas são: acetato de etila, acetona e acetonitrila, sendo que cada um destes apresenta vantagens e desvantagens. Acetato de etila tem demonstrado ser um solvente com características universais, uma vez que possui capacidade para extrair pesticidas de diferentes classes em diversos tipos de amostras, porém os percentuais de recuperação de pesticidas com caráter básico ( $\mathrm{pKa}>4$ ) são baixos devido a problemas de degradação, sendo necessária a adição de hidróxido de sódio para um aumento destes percentuais. (Oliveira, 2011)

Acetona e acetonitrila são miscíveis com água e promovem a extração em uma fase única quando em contato com a matriz. Quando uma extração é realizada com acetona há necessidade de adição de solventes apolares para que ocorra a separação entre as fases orgânica e aquosa, o mesmo não é necessário quando se utiliza acetonitrila, uma vez que a adição de sais ao extrato faz com que ocorra tal separação. (Oliveira, 2011)

As desvantagens da utilização de acetonitrila como solvente de extração, quando comparada com acetona e acetato de etila incluem: grande volume de expansão durante vaporização no cromatógrafo a gás; interferências nos detectores 
termoiônico específico de chama e de condutividade eletrolítica, além de apresentar considerável toxicidade. A utilização de acetonitrila, entretanto, possibilita a extração de uma menor quantidade de coextrativos lipofílicos provenientes da amostra, como por exemplo, ceras, gorduras e pigmentos, e proporciona a extração de uma ampla faixa de pesticidas com diferentes polaridades. Acetonitrila quando acidificada permite recuperações satisfatórias de pesticidas que geralmente apresentam problemas de estabilidade. (Oliveira, 2011)

Sendo assim, acetonitrila foi escolhida como solvente de extração para o método Quechers, empregando-se $10 \mathrm{~mL}$ do solvente para $10 \mathrm{~g}$ de amostra, resultando uma relação $1 \mathrm{~g}$ de amostra por $1 \mathrm{~mL}$ de solvente, sem envolver etapa de evaporação. Este valor é considerado baixo se comparado a outros métodos de extração que normalmente apresentam uma relação entre amostra e solvente de 2 a $5 \mathrm{~g}$ por $1 \mathrm{~mL}$ no extrato final. Porém, com a instrumentação analítica disponível atualmente, esta relação é considerada adequada uma vez que valores de Limite de Detecção entre 10 e $100 \mu \mathrm{g} / \mathrm{kg}$ são obtidos para a maioria dos pesticidas comumente analisados. (Oliveira, 2011)

A adição de sais para promover o efeito "salting-ouf" (processo pelo qual substâncias solúveis em água são excluídas da fase aquosa pela adição de sais), tem sido utilizada em vários métodos multirresíduos. Dependendo da natureza do solvente utilizado na etapa de partição obtêm-se melhores percentuais de recuperação para analitos polares, uma vez que a adição de sais diminui a solubilidade destes compostos na fase aquosa, bem como a quantidade de água na fase orgânica e vice-versa. (Oliveira, 2011)

Os métodos multirresíduos que utilizam acetonitrila, desenvolvidos até então, não empregam adição de nenhum tipo de solvente apolar no processo de partição. $\mathrm{Na}$ extração com acetonitrila, a adição de sais é muito conveniente uma vez que é rápida, fácil, apresenta baixo custo, tem a grande vantagem de não diluir o extrato da amostra e proporciona a separação das fases orgânica e aquosa. A utilização de sais secantes para melhorar a recuperação de pesticidas polares utilizara sulfato de sódio $\left(\mathrm{Na}_{2} \mathrm{SO}_{4}\right)$. No desenvolvimento do método Quechers foi empregada uma mistura de $1 \mathrm{~g}$ de cloreto de sódio $(\mathrm{NaCl})$ e $4 \mathrm{~g}$ de sulfato de magnésio $\left(\mathrm{MgSO}_{4}\right)$. A 
escolha do $\mathrm{MgSO}_{4}$ foi devido a maior capacidade de remover água quando comparado a outros sais. Além de reduzir o volume de fase aquosa, sua hidratação é uma reação exotérmica, tendo como resultado o aquecimento entre 40 e $45 \stackrel{\circ}{\circ}$ da amostra durante as etapas de extração/partição, favorecendo a extração, especialmente dos compostos apolares. (Anastessiades, 1996)

Um novo método de clean-up denominado extração em fase sólida dispersiva (Dispersive Solid Phase Extraction, D-SPE) foi proposto colocado em contato com uma mistura contendo $25 \mathrm{mg}$ do sorvente amina primária-secundária (primary secondary amine, PSA) e $150 \mathrm{mg}$ de $\mathrm{MgSO}_{4}$. (Anastessiades, 1996)

Ao contrário dos métodos já existentes para clean-up com SPE que utilizam cartuchos ou colunas, a D-SPE permite que o clean-up e a redução de água residual sejam efetuados de uma forma rápida e simultânea. Esta etapa de remoção de água proporciona um extrato final de menor polaridade, facilitando assim a precipitação de coextrativos polares. (Anastessiades, 1996)

O sorvente retém as interferências da matriz, sendo que depois da agitação manual e centrifugação o extrato está pronto para ser injetado no sistema cromatográfico. A estrutura bidentada do PSA tem um elevado efeito quelante, devido à presença dos grupos amino primário e secundário. Como resultado, a retenção de ácidos graxos livres e de outros compostos polares presentes na matriz é muito forte. Um clean-up eficiente garante uma maior vida útil para os insersores, bem como para as colunas cromatográficas, reduzindo assim a contaminação do sistema cromatográfico. (Oliveira, 2011)

Desde o seu desenvolvimento, o método Quechers é utilizado na extração de resíduos de pesticidas. Além deste amplo campo de aplicação, este método tem sido usado na extração de outros tipos de analitos e outros tipos de matrizes (Prestes, 2009)

\subsection{Validação}

A validação de um método é um processo contínuo que começa no planejamento da estratégia analítica e continua ao longo de todo o seu 
desenvolvimento. Esta deve garantir por meio de estudos experimentais, que o método atenda às exigências das aplicações analíticas, assegurando a confiabilidade dos resultados. A técnica de separação, como a cromatografia gasosa (CG), têm se destacado na química analítica pela capacidade de realizarem análises qualitativas e quantitativas em amostras ambientais, farmacêuticas, biológicas entre outras. (ANVISA, 2003)

A necessidade de se mostrar a qualidade de medições químicas, por meio de sua comparabilidade, rastreabilidade e confiabilidade, é cada vez mais necessária e exigida. Dados analíticos não confiáveis podem conduzir a decisões desastrosas e a grandes prejuízos financeiros. Para garantir que um novo método analítico gere informações confiáveis e interpretáveis sobre a amostra, este deve sofrer uma avaliação denominada validação. (Leite, 2002)

\subsubsection{Limite de detecção (LD)}

O Limite de Detecção é a menor concentração de analito que produza uma resposta detectável. (INMETRO, 2011)

O LD pode ser calculado de quatro maneiras diferentes: método visual, método relação sinal-ruído, método baseado em parâmetros da curva analítica. O método visual é utilizado para determinar o limite de detecção utilizando a matriz com adição de concentrações conhecidas da substância de interesse, de tal modo que se possa distinguir entre ruído e sinal analítico pela visualização da menor concentração visível (detectável).

O método da relação sinal-ruído pode ser aplicado somente em procedimentos analíticos que mostram o ruído da linha de base. Para determinar a relação sinal-ruído é feita a comparação entre a medição dos sinais de amostras em baixas concentrações conhecidas do composto de interesse na matriz e um branco (matriz isenta do composto de interesse) destas amostras. Assim, é estabelecida uma concentração mínima na qual a substância pode ser facilmente detectada. A relação sinal-ruído pode ser de 3:1 ou 2:1, proporções geralmente aceitas como estimativas do limite de detecção. No método baseado em 
parâmetros da curva analítica, o limite de detecção (LD) pode ser expresso como demonstra a Equação 1:

$$
\mathrm{LD}=3,3 \cdot \frac{s}{S}
$$

Onde s é a estimativa do desvio padrão da resposta, que pode ser a estimativa do desvio padrão do branco, da equação da linha de regressão ou do coeficiente linear da equação e $S$ é a inclinação ou coeficiente angular da curva analítica. Para calcular estes dados, uma curva analítica deverá ser feita utilizando a matriz contendo o composto de interesse na faixa de concentração próxima ao limite de detecção. Softwares como Microsoft Excel ou Origin podem calcular os parâmetros da curva e a estimativa do desvio padrão relativo destes parâmetros. Para adquirir melhor compreensão dos cálculos envolvidos, pode-se consultar livros de estatística. (Box, et. al, 1987)

\subsubsection{Limite de quantificação (LQ)}

O Limite de Quantificação (LQ) é a menor concentração do analito que forma o limite mais baixo da faixa de trabalho. É o menor limite que consegue se quantificado. (Box, et. al, 1987)

O Limite de Quantificação para os compostos orgânicos é considerado o primeiro ou o segundo ponto da curva de calibração, neste trabalho, foi considerado o segundo ponto. O LQ foi expresso como concentração mais baixa do analito que pode ser determinada com um nível aceitável de incerteza. (Box, et. al, 1987) 


\subsubsection{Recuperação (Tendência)}

É o grau de concordância entre o resultado de uma medição e um valor verdadeiro do mensurando. A recuperação do analito pode ser estimada pela análise de amostras adicionadas com quantidades conhecidas do padrão (spike). As amostras podem ser adicionadas com o analito em pelo menos três diferentes concentrações, por exemplo, próximo ao limite de detecção, próximo à concentração máxima permissível e em uma concentração próxima à média da faixa de uso do método. (Thompson, 2002)

A limitação do procedimento de recuperação é a de que a substância adicionada não está, necessariamente, na mesma forma que se apresente na amostra. Isso pode implicar, por exemplo, na presença de substâncias adicionadas em uma forma que proporcione melhor detecção, ocasionando avaliações excessivamente otimistas da recuperação. Pelo fato de outros componentes da matriz poder interferir na separação, detecção ou na quantificação da substância, efeitos dos componentes da matriz devem ser investigados. É importante considerar como a eficiência do método varia em função da concentração da substância. Na maioria dos casos, a dispersão dos resultados aumenta com a diminuição da concentração e a recuperação pode diferir substancialmente a altas e baixas concentrações. Por esse motivo, a recuperação deve ser avaliada na faixa de concentração esperada para 0 composto de interesse. Isto pode ser feito adicionando a substância em pelo menos três diferentes concentrações. Para análises em nível de resíduos, o GARP (Grupo de Analistas de Resíduos Pesticidas) recomenda que se trabalhe nos níveis de adição de 1, 2 e 10 vezes o valor de limite de quantificação. (INMETRO, 2011) Para componentes em maiores concentrações, os níveis de adição podem ser 50, 75, 100, 125 e 150\% do nível esperado para a substância. (Snyder et. al, 1997)

Os intervalos aceitáveis de recuperação para análise de resíduos geralmente estão entre 50 e 120\%, com precisão de até $\pm 20 \%$. (Leite, 2002) Porém, 
dependendo da complexidade analítica e da amostra, este valor pode ser de 40 a $120 \%$, com precisão de até $\pm 15 \%$. (GARP, 1999)

\subsubsection{Repetitividade (Precisão, Precisão Intermediária e Reprodutibilidade)}

É o grau de dispersão entre medições independentes a partir de uma mesma amostra, amostras semelhantes ou padrões sob condições definidas. (Miller, 1988)

\subsubsection{Incerteza de medição}

A incerteza de medição é um parâmetro associado ao resultado de uma medição, que caracteriza a dispersão dos valores que podem ser razoavelmente atribuídos ao mensurando. (INMETRO, 2011)

. A estimativa de incerteza está associada ao resultado de uma medição com as seguintes etapas envolvidas:

a) Especificar o mensurando;

b) Os mensurados são as grandezas submetidas à medição;

c) Identificar os mensurados como as grandezas de saída $Y$ que dependem de uma série de grandezas de entrada $X$;

d) Identificar fontes de incerteza;

e) Listar as possíveis fontes de incerteza que contribuem para a incerteza dos parâmetros da relação estabelecida no mensurado;

f) Quantificar os componentes de incerteza;

g) Medir ou estimar a dimensão do componente de incerteza associado a cada fonte potencial de incerteza identificada, por meio de certificados de padrões de referência que calcula a incerteza referente ao padrão. (INMETRO, 2011)

Dentre as incertezas, há a incerteza padrão, em que:

a) Incerteza do resultado de uma medição expressa como um desvio padrão.

b) Incerteza padrão combinada. 
c) Incerteza padrão do resultado de uma medição, quando este resultado é obtido por meio dos valores de várias outras grandezas, sendo igual à raiz quadrada positiva de uma soma de termos, que constituem as variâncias ou co-variâncias destas outras grandezas, ponderadas de acordo com o quando o resultado da medição varia com mudanças nestas grandezas. (INMETRO, 2011)

Outra incerteza é a expandida:

a) Grandeza que define um intervalo em torno do resultado de uma medição com o qual se espera abranger uma grande fração da distribuição dos valores que possam ser razoavelmente atribuídos ao mensurado;

b) Fator de abrangência;

c) Fator numérico utilizado como um multiplicador da incerteza padrão combinada de modo a obter uma incerteza expandida. (INMETRO, 2011) 


\section{MATERIAIS E MÉTODOS}

\subsection{Método de Coleta}

As coletas das amostras foram realizadas pela CETESB (Companhia Ambiental do Estado de São Paulo) na Represa Billings.

Foram definidas áreas na represa, cujo histórico de contaminação de pesticidas é conhecido, sendo dentre eles alguns POPs reincidentes em duas delas, segundo histórico de análises da CETESB. Os pontos de coleta foram definidos e localizados por meio de suas coordenadas via GPS. Os oito pontos definidos estão ilustrados na FIG.5:
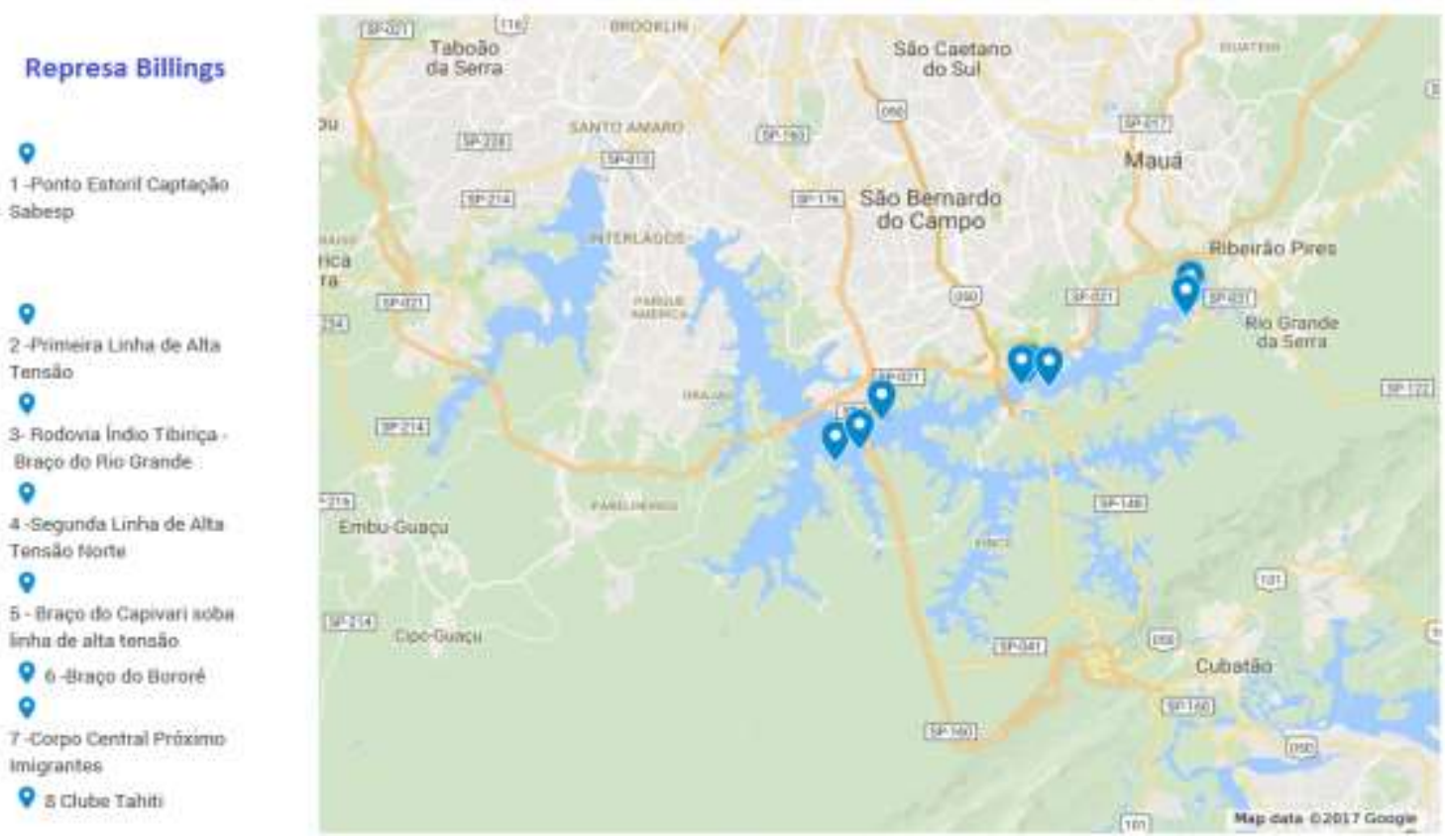

FIGURA 5 Pontos coletados na Represa Billings. (Google, 2017)

As amostras foram coletadas em frasco âmbar de $1 \mathrm{~kg}$. Duas coletas foram realizadas em meses diferentes. Uma coleta em novembro de 2014 e outra em janeiro de 2015. 
No procedimento de coleta, primeiramente foi medida a profundidade do corpo d'água. A coleta foi realizada na parte mais funda ou em profundidades estabelecidas anteriormente.

Para a coleta foram necessários draga de Van Veen, bandeja, pá, frasco âmbar, caixa térmica ou isopor, gelo ou gelox. As FIG.6 a 11 ilustram o processo de coleta de sedimento na Represa Billings.

Para realizar a coleta, armou-se a draga de Van Veen, pressionando os pinos para que ela se abra somente no fundo da Reprea Billings, conforme FIG.6. Posteriormente ela foi solta no corpo d'água. Ao atingir o fundo da represa, ela desarmou. Para que não haja perda da coleta do sedimento, ao atingir o fundo da Represa, o coletor da amostra, puxou a corda com força, para que ela fechasse rapidamente, para depois puxar até a superfície. Assim, retirou-a da Represa, evitando ao máximo a perda de sedimento, e acondicionou-se a amostra em frasco âmbar, limpos com detergente neutro e água, inertes e que forneçam proteção adequada contra a contaminação externa ou danos à amostra. As amostras foram acondicionadas em caixas térmicas ou isopor contendo gelo. Estas amostras estavam em uma temperatura de aproximadamente $4 \stackrel{\circ}{\circ} \mathrm{C}+/-0,5 \stackrel{\circ}{\circ}$. Os compostos organoclorados degradam com a luz e calor, e como os POPs são compostos organoclorados, é importante o frasco ser âmbar e o armazenamento ser em refrigerador. Todo material encontrado no sedimento sempre deve ser enviado para a análise juntamente com a amostra (ANA, 2011)

A FIG.6 ilustra a preparação para a coleta do sedimento, pois a coleta é uma etapa fundamental para a obtenção de uma análise eficaz. 


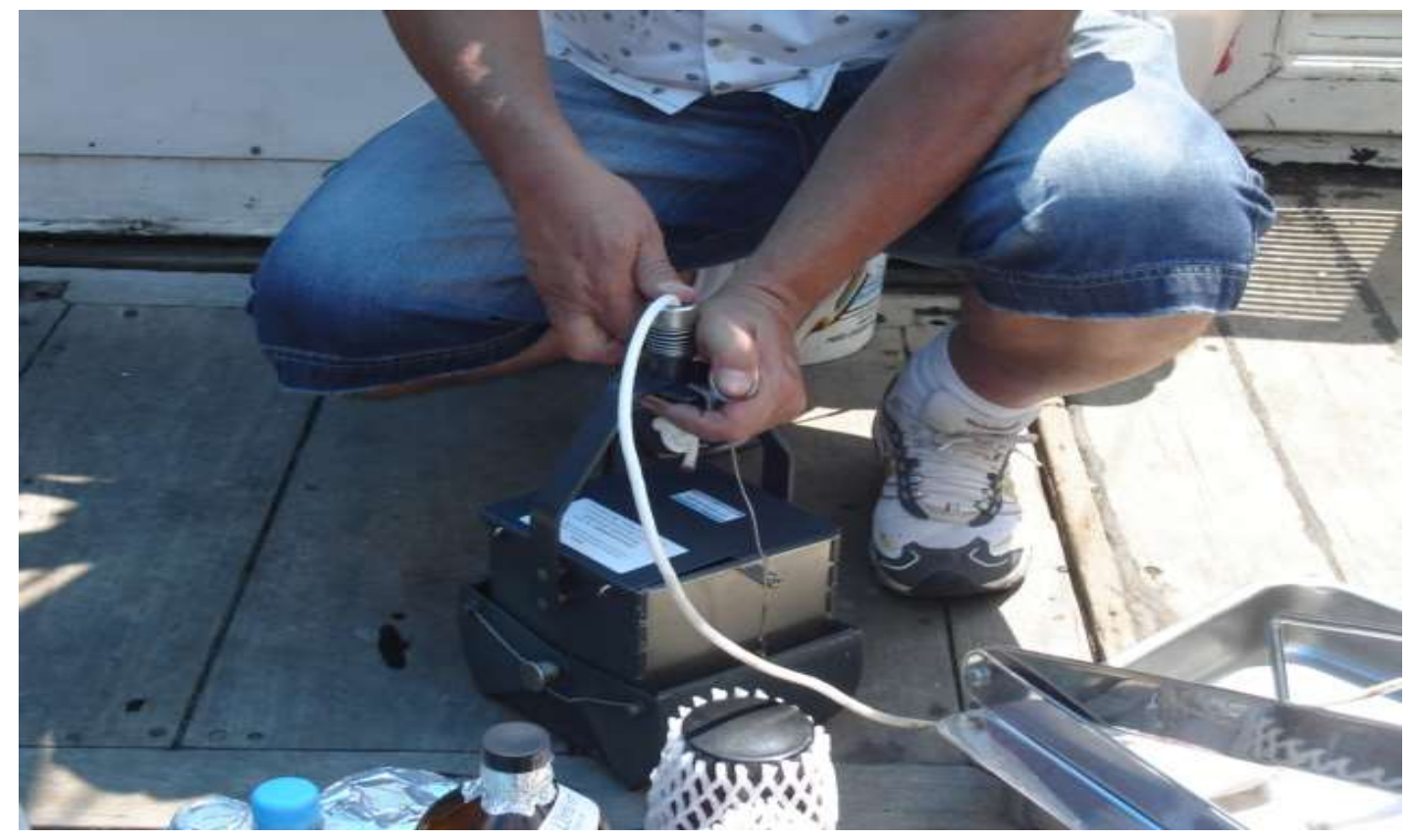

FIGURA 6 Materiais utilizados na coleta de sedimento: draga, frascarias, pá e bandeja. (o autor, 2014)

A FIG.7 ilustra o momento em que a draga de Van Veen voltava à superfície.

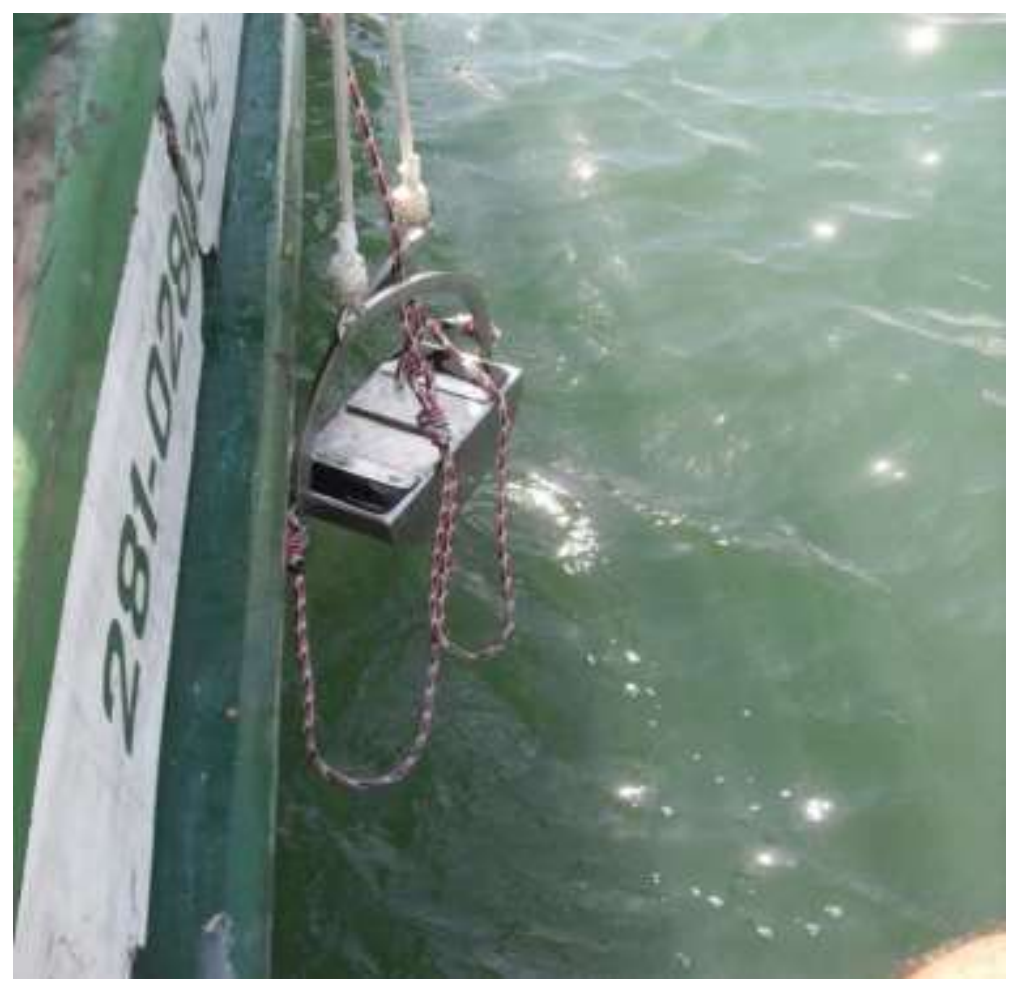

FIGURA 7 Draga de Van Veen descendo para realizar a coleta dos sedimentos. (o autor, 2014) 
A FIG.8 ilustra a chegando do fundo da Represa Billings com sedimento coletado.

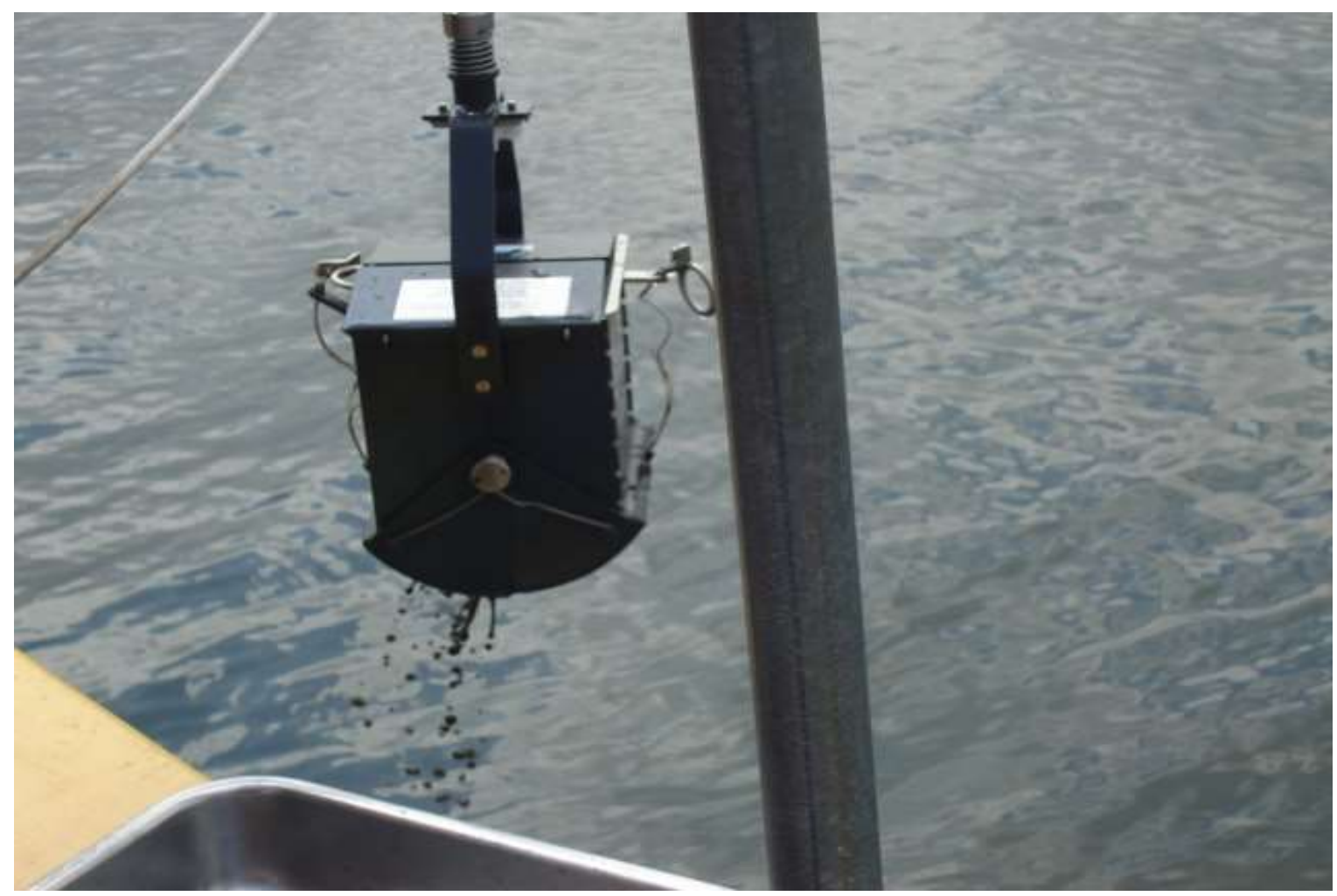

FIGURA 8 Draga sendo puxada da coleta de sedimento na Represa Billings. (o autor, 2014)

A FIG 9 ilustra a draga aberta por cima, apenas para visualização do sedimento coletado. 


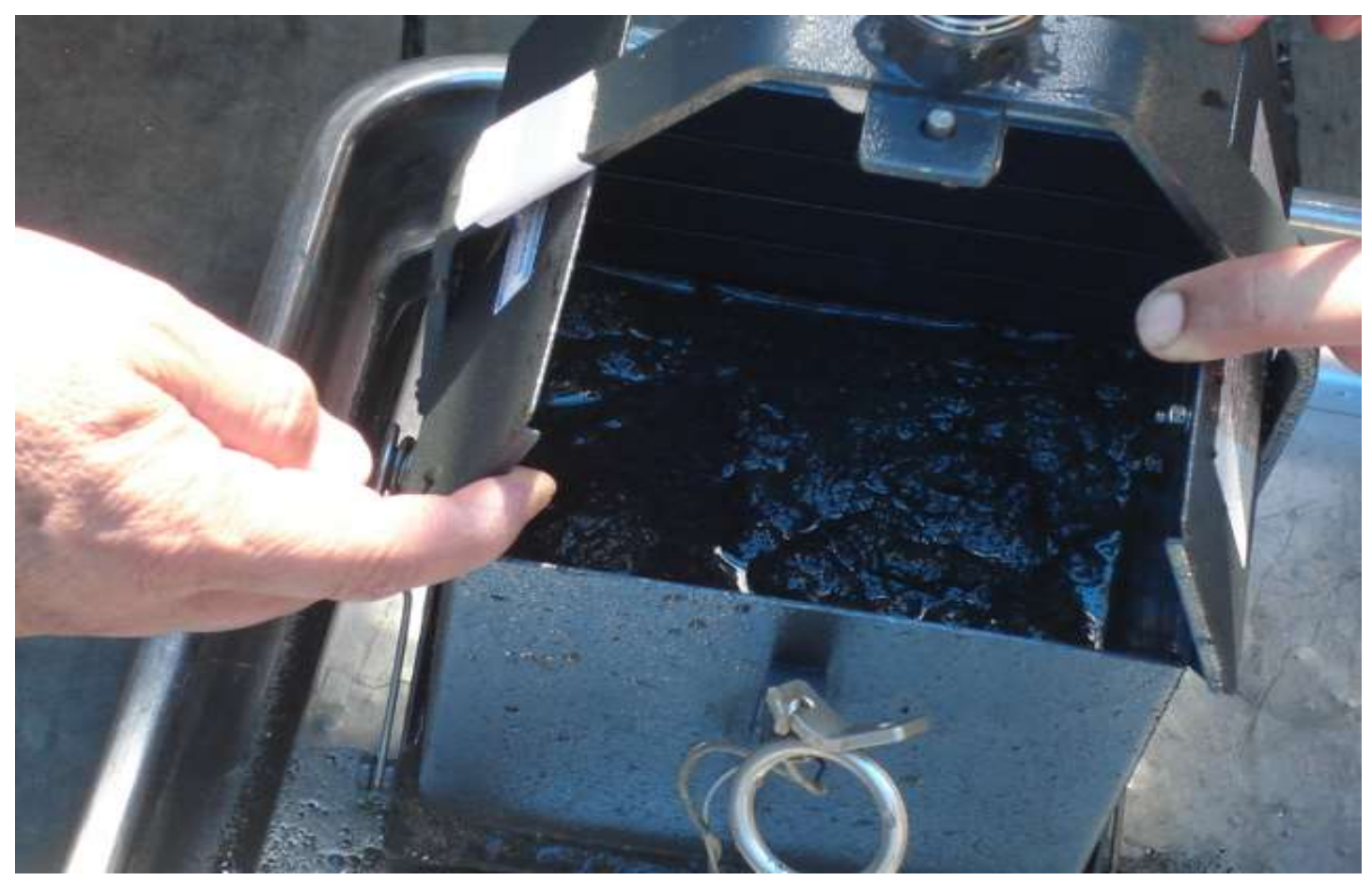

FIGURA 9 Sedimento coletado na Represa Billings. (o autor, 2014)

Na FIG.10, o sedimento é colocado na bandeja de inox limpa para evitar contaminação entre as amostras. Na FIG.11, uma pá é utilizada para mostrar o aspecto do sedimento. Após a foto, o sedimento foi acondicionado em frasco âmbar de $1 \mathrm{~kg}$ e armazenado em temperatura de $4^{\circ} \mathrm{C}+/-0,5 \stackrel{\circ}{ } \mathrm{C}$. 


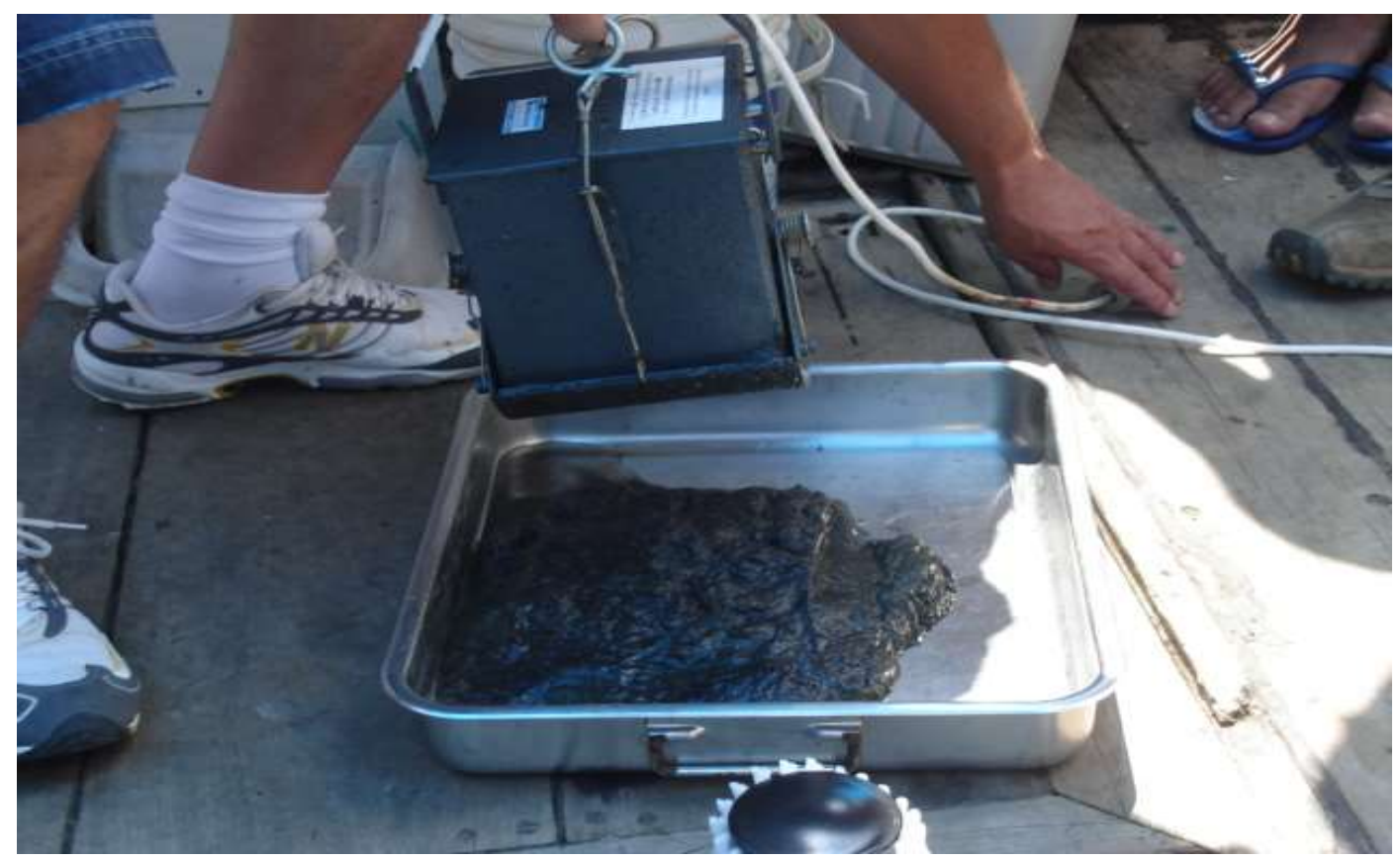

FIGURA 10 Sedimento coletado sendo transferido para a bandeja para posteriormente ser armazenado no frasco âmbar. (o autor, 2014)

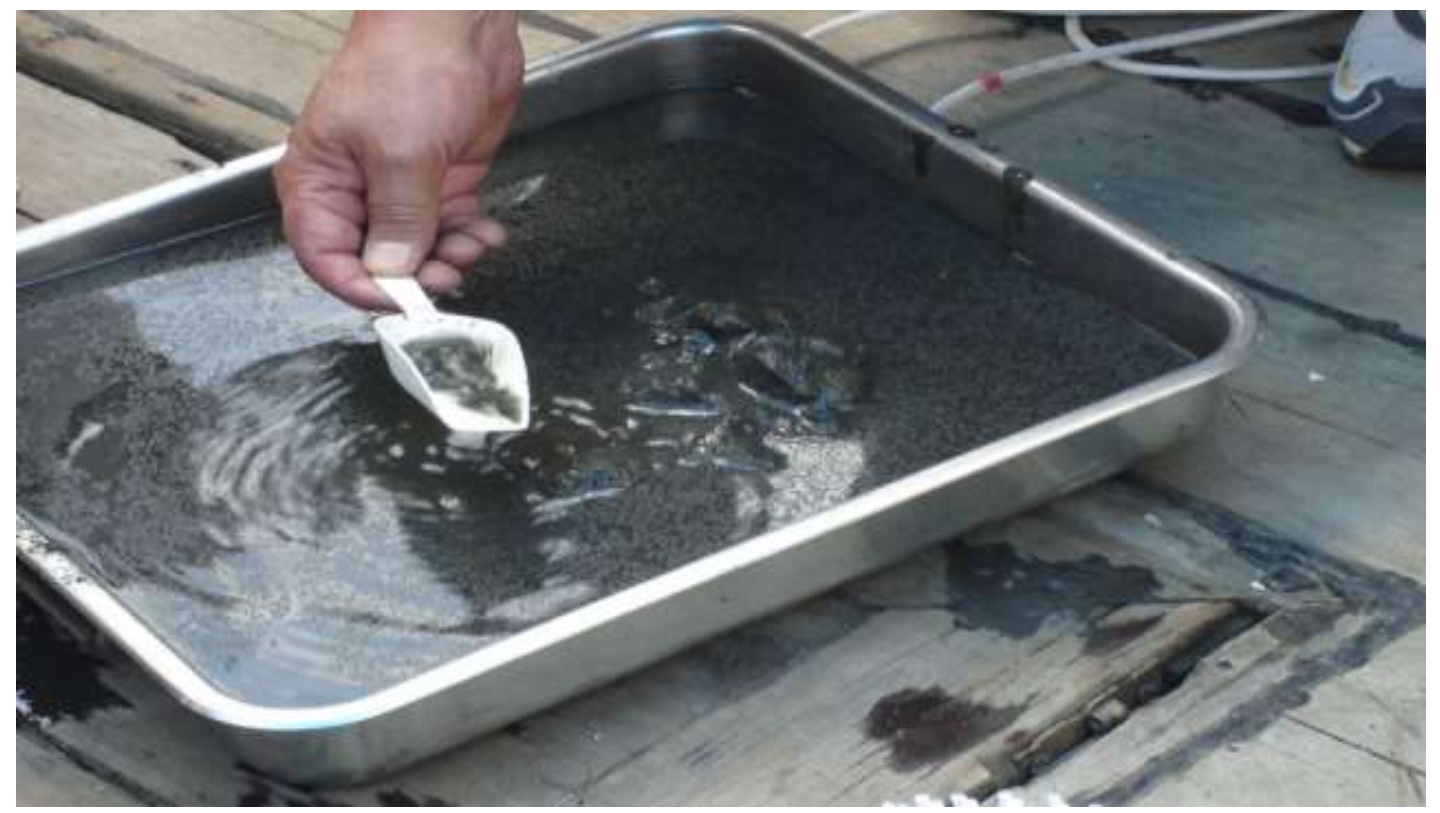

FIGURA 11: Sedimento coletado na Represa Billings pronto para ser acondicionado em frasco âmbar de $1 \mathrm{~kg}$. (o autor, 2014) 


\subsection{Extração por Quechers}

O branco, padrão controle, os quatro spikes (adição de padrão) e as oito amostras foram extraídos via Quechers, conforme os seguintes passos ilustrados na FIG. 12.

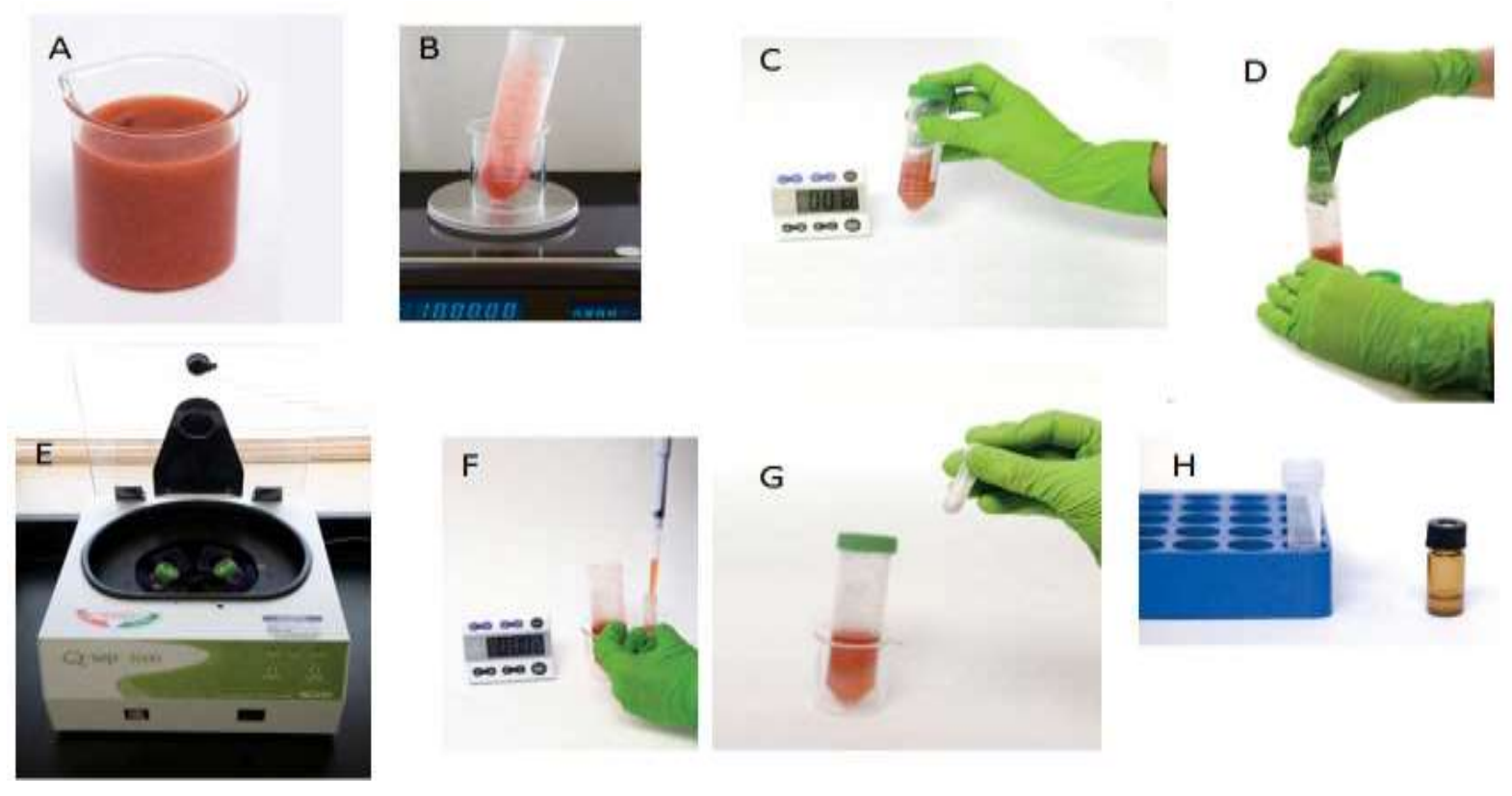

Figura 12: Esquema de extração Quechers. (Oliveira, 2011)

A- Foi pesada $10 \mathrm{~g}$ da amostra de sedimento;

B- Foi adicionado $20 \mathrm{~mL}$ de acetonitrila ;

C- Agitou-se por 2 minutos;

D- Adicionou-se $4 \mathrm{~g}$ de sulfato de magnésio, $1 \mathrm{~g}$ de cloreto de sódio, $1 \mathrm{~g}$ de citrato de sódio, $0,5 \mathrm{~g}$ de hidrogenocitrato de sódio sesquiidratado;

E- Agitou- se e centrifugou-se em 2 minutos cada;

F- A limpeza foi realizada adicionando ao sobrenadante, $150 \mathrm{mg}$ de bondesil PSA e $950 \mathrm{mg}$ de sulfato de magnésio;

G- Agitou-se e centrifugou-se 2 minutos cada;

H- Retirou-se o sobrenadante e colocou-se a amostra em vial de $2 \mathrm{~mL}$. Após toda a etapa descrita, a amostra estava pronta para análise via cromatografia. 
A FIG.13 ilustra a centrífuga que foi utilizada no processo de extração via Quechers e ao lado as 4 amostras que foram extraídas.

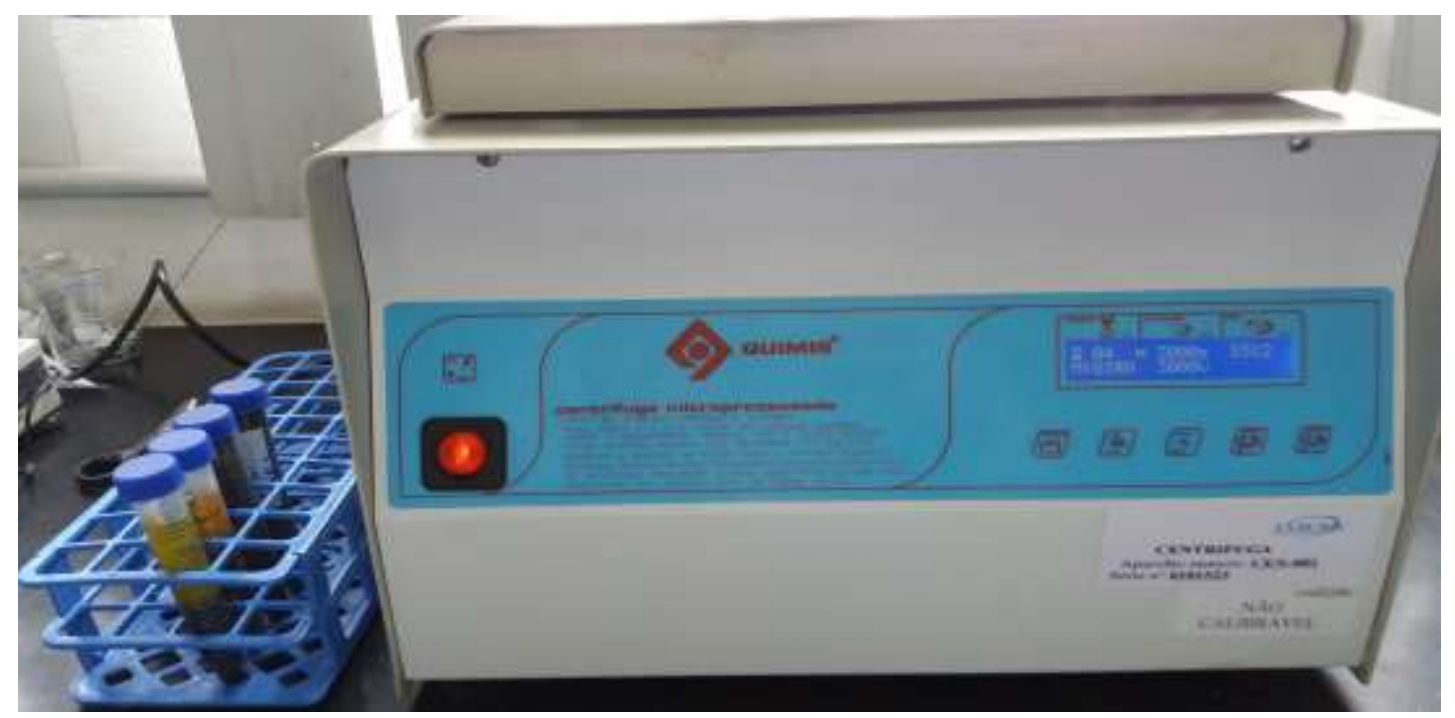

FIGURA 13: Centrífuga e amostras utilizadas na análise via QuEChERS.

(o autor, 2014)

A FIG.14 ilustra as 8 amostras que foram coletadas em seu processo final de extração via Quechers. Na FIG.15, as amostras foram acondicionadas em frascos de $2 \mathrm{~mL}$ prontas para injeção no cromatógrafo à gás.

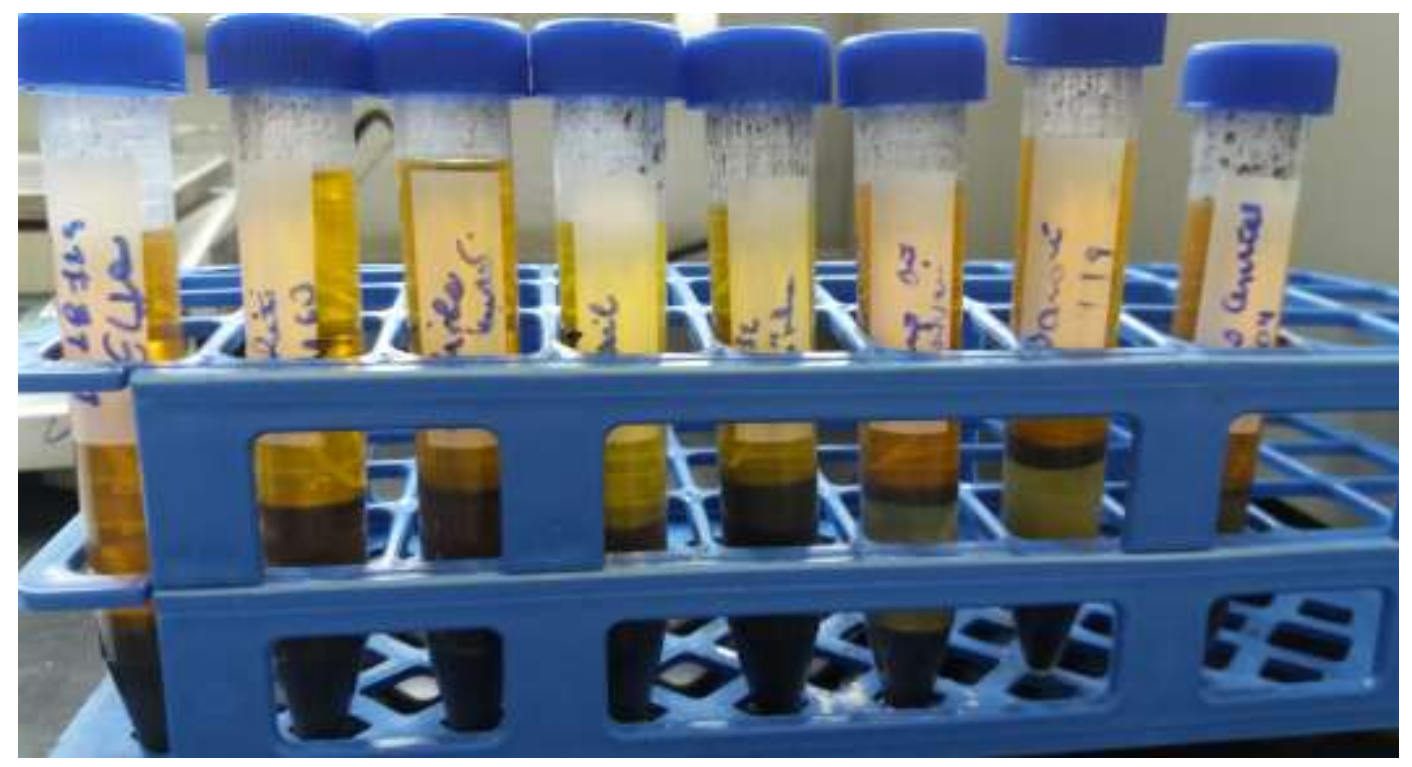

FIGURA 14: Amostras em processo de extração via QuEChERS. (o autor, 2015) 


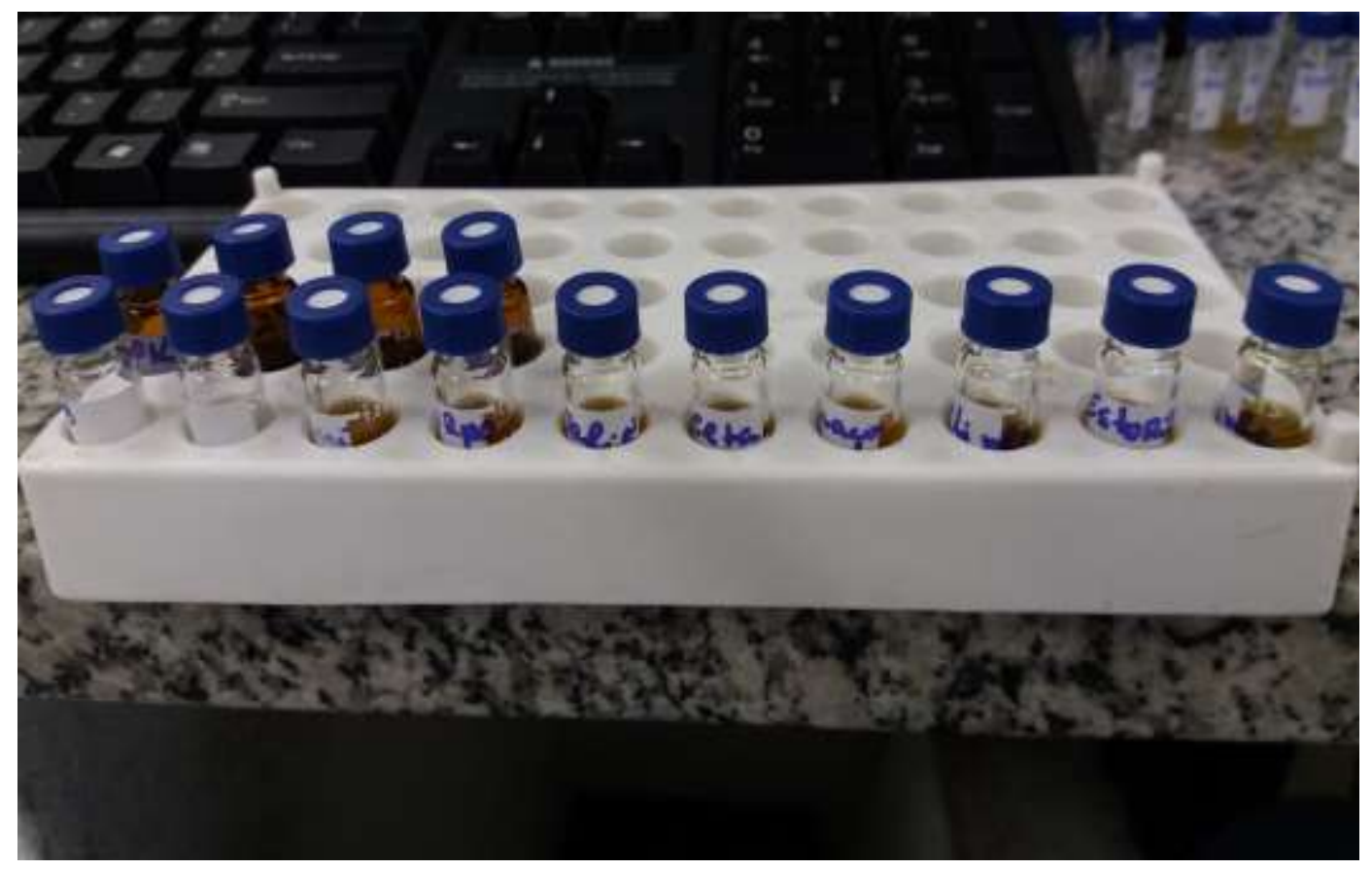

Figura 15: Amostras extraídas prontas para análise. (o autor, 2014)

\subsection{Análise Química Instrumental}

Para análise química qualitativa foi utilizado o cromatógrafo á gás acoplado a Espectrometria de Massas GC/MS e para análise quantitativa, o cromatógrafo à gás com detector de captura de elétrons GC/ECD. Ambos os cromatógrafos possuem o mesmo método de injeção para as amostras de POPs, assim como a mesma coluna cromatográfica e mesma temperatura do forno.

\subsubsection{CROMATOGRAFIA}

A técnica de cromatografia foi utilizada pela primeira vez em 1905, por Ramsey, para realizar a separação de vapores e mistura de gases. Entretanto, foi apenas em 1952, que Martin e James introduziram a técnica da cromatografia à gás, que é até hoje considerada uma das técnicas mais úteis para análises de COV - 
Compostos Orgânicos Voláteis ou derivados com características semelhantes. (Oliveira, 2011)

\subsubsection{Cromatografia a Gás}

Na cromatografia a gás, a amostra ao passar pela fase estacionária $(\mathrm{FE})$, ocorre a separação dos compostos de acordo com a afinidade com a coluna cromatográfica, e a temperatura aplicada ao sistema. Os compostos mais "leves" (possuem um número de massas menor) e com menos afinidade, saem primeiro, enquanto que os compostos mais "pesados" (possuem um número de massas maior) saem por último. Esta afinidade se dá devido à polaridade da coluna; existem colunas apolares, e polares. As FE polares reterão mais compostos polares, por meio de interações do tipo dipolos permanentes ou pontes de hidrogênio. Nas FE apolares as afinidades serão por compostos apolares por meio de interações de dipolo induzido. (Collings, et. al, 2006)

A FIG.16 ilustra um cromatógrafo à gás da marca Perkin Elmer, que foi utilizado neste trabalho. Este cromatógrafo possui dois detectores: Flame Ionization Detector (FID), muito utilizado para determinação de hidrocarbonetos e o Detector por Captura de Elétrons (ECD), utilizado para análise de compostos halogenados, como os organoclorados. Para a determinação dos POPs, foi utilizado somente o Detector ECD, pois os POPs estudados são compostos organoclorados. 


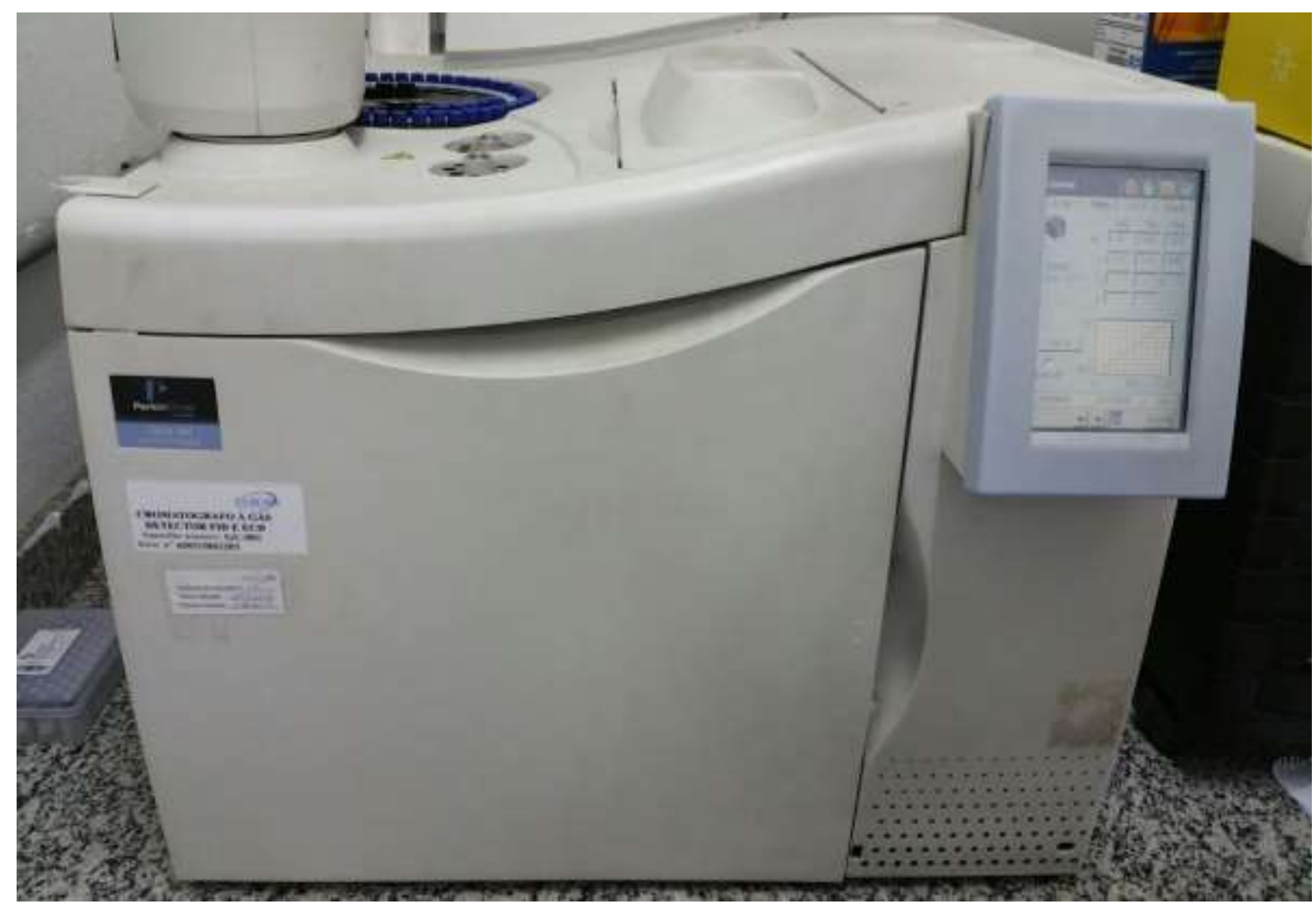

FIGURA 16 Cromatógrafo a gás da marca Perkin Elemer Clarus 500 com injetor FID e ECD e injetor automático. (o autor, 2014)

A coluna ideal para a análise depende do que se quer analisar. Outros fatores, como o fluxo do gás de arraste, a pressão, a temperatura de ebulição dos compostos, influenciam na eficiência do método cromatográfico. A FIG.17 ilustra a coluna capilar dentro do forno do cromatógrafo a gás da Perkin Elmer.

Após a separação na coluna cromatográfica, os analitos de interesse são enviados ao detector, onde é gerado um cromatograma, onde os analitos foram quantificados. 


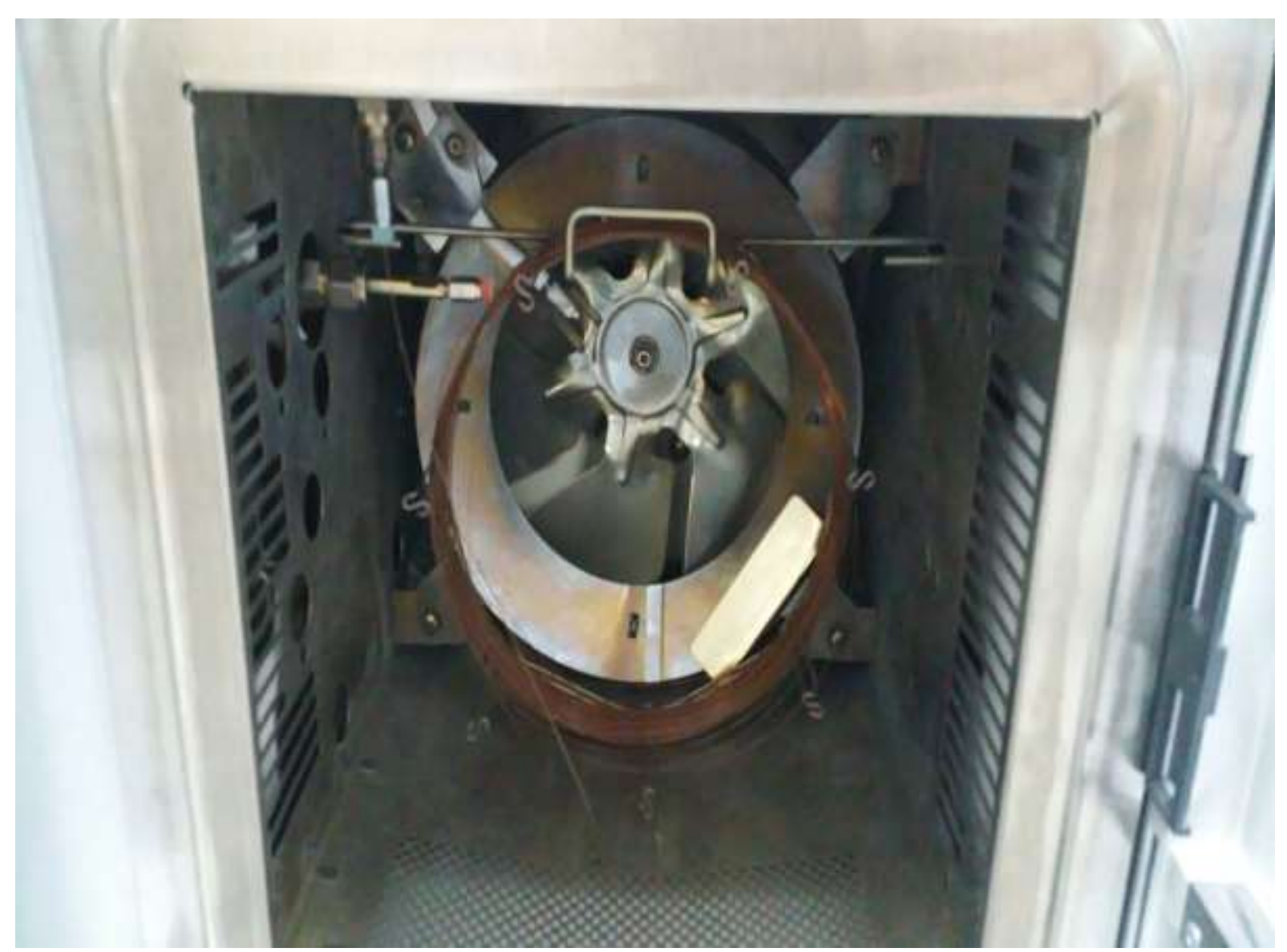

FIGURA 17 Coluna Capilar dentro do forno do cromatógrafo a gás. (o autor, 2014)

\subsection{DETECTOR POR CAPTURA DE ELÉTRONS (ECD)}

O Detector por Captura de Elétrons é seletivo, possuindo grande sensibilidade para moléculas eletronegativas como halogênios, aldeídos conjugados, nitrilas, nitratos e organometálicos, sendo insensível a hidrocarbonetos, alcoóis e cetonas. (Oliveira, 2011)

O ECD pode funcionar por meio de duas formas: por corrente pulsada ou corrente contínua. A diferença entre elas é que em corrente contínua, os elétrons adquirem mais energia cinética do que as moléculas do que a fase móvel (gás de arraste). Na corrente pulsada, o período de pulso fornecido é grande, se comparado a largura, favorecendo um equilíbrio térmico entre os elétrons e as moléculas de gás.

A detecção no ECD é realizada devido à eletronegatividade dos analitos eluídos, ou seja, da capacidade destes em formar íons negativos para capturar os 
elétrons. Para ocorrer a captura, esta depende muito da energia de colisão do elétron, de acordo com o processo de termalização. Este processo consiste na perda de energia gradual do gás de arraste provocada pela emissão de fótons ou elétron, emitidas pela fonte radioativa ${ }^{63} \mathrm{Ni}$ para colisão. Em um dado momento, elétrons com várias energias estão presentes no detector, ocupando um grande volume. Dentre estes, alguns tem a capacidade de ionizar átomos ou moléculas diretamente, sendo algumas realizadas por captura de elétrons. (Oliveira, 2011) A FIG.18 ilustra o esquema de detecção via GC-ECD. (A FIG.19, ilustra os detectores Flame Ionization Detector (FID) e o Detector por Captura de elétrons (ECD) visto de fora do cromatógrafo Perkin Elmer. O ECD está no compartimento redondo, atrás do FID). Neste trabalho foi utilizado somente o detector ECD.

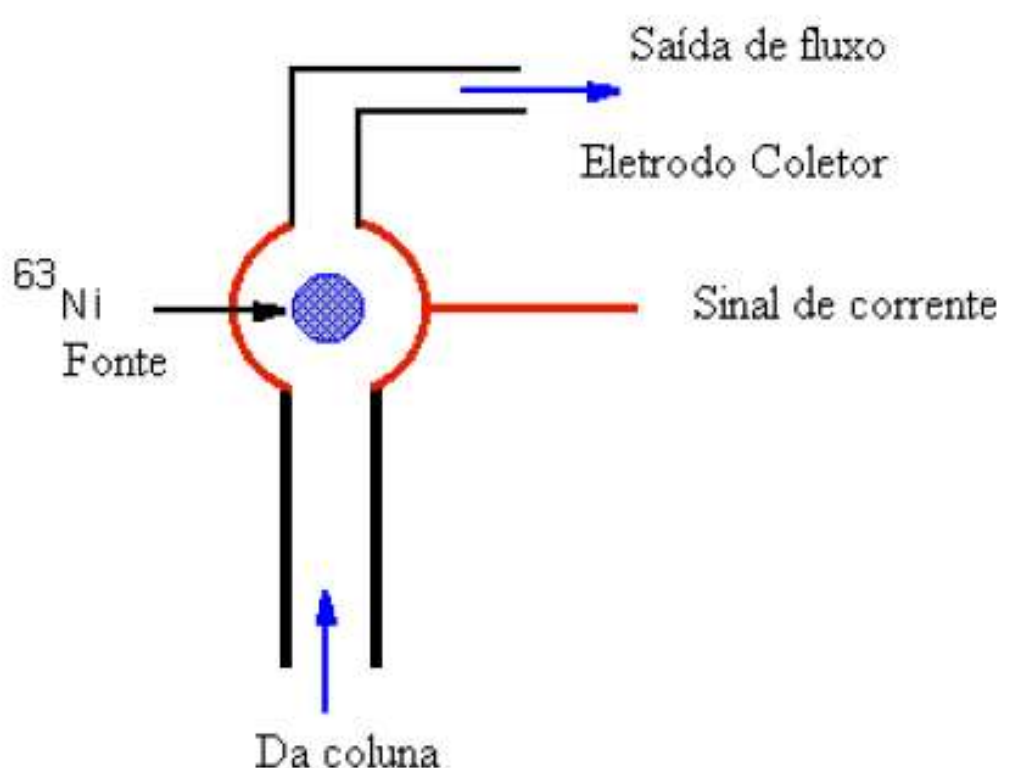

FIGURA 18 Esquema de um detector de captura de Elétrons. (Oliveira, 2011) 


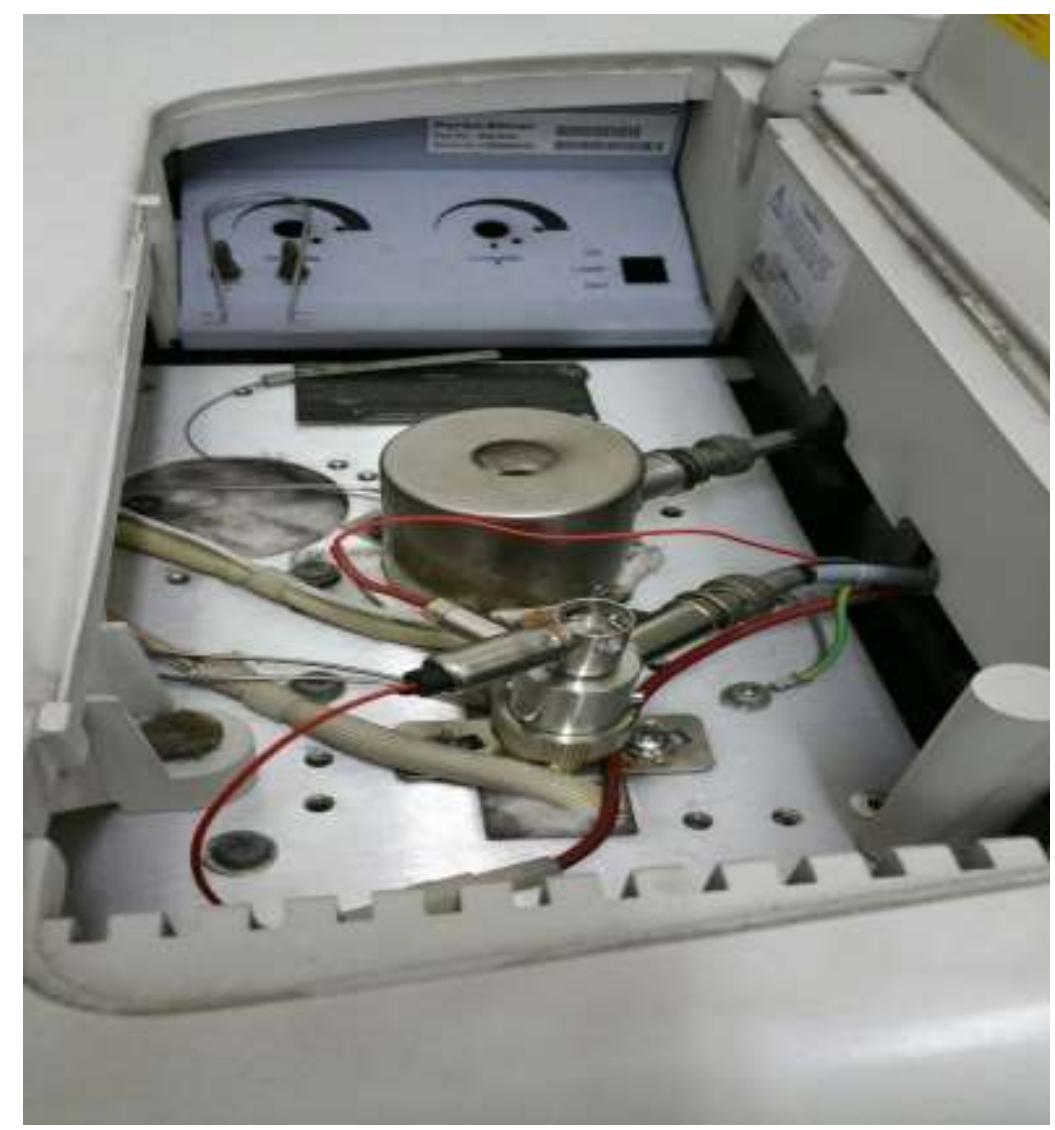

FIGURA 19 Detectores FID E ECD visto de fora do cromatógrafo a gás da Perkin Elmer. (o autor, 2017)

\subsection{A Espectrometria de Massas}

Em 1919, J. J. Thompson e F. W. Aston criaram o espectrógrafo de massas. Eles descobriram a causa das diferenças de massa de alguns isótopos não radiativos.

Ao introduzir gás neônio no instrumento, observaram quatro linhas que correspondiam a razões massa/carga de 10,11, 20, 22; o primeiro corresponde a íons duplamente carregados e o segundo par, a íons monoionizados dos isótopos 20 e 22 do Neônio. (Challoner, 2010)

A FIG 20 ilustra o primeiro espectrômetro de massas. 


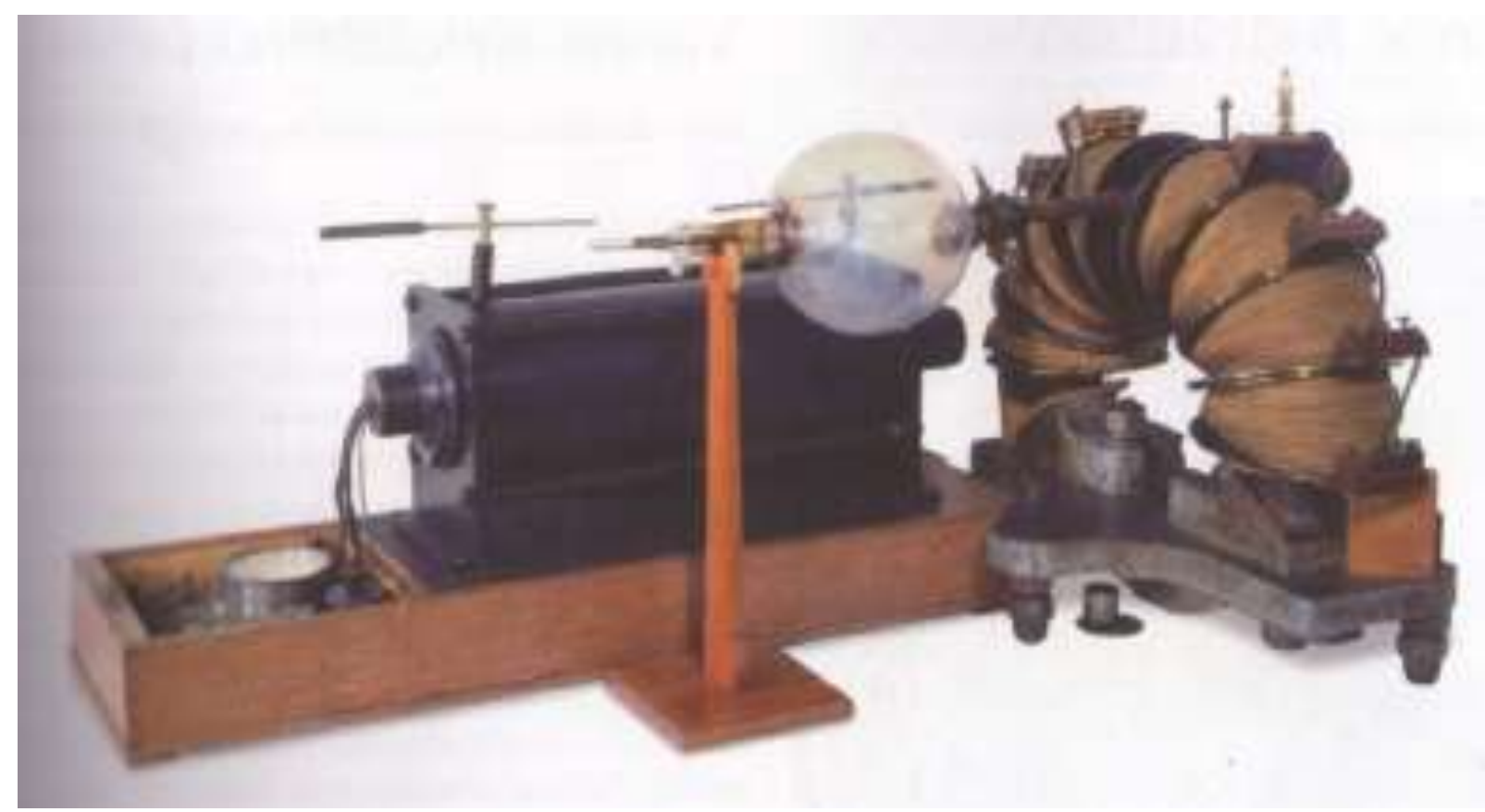

FIGURA 20 Primeiro espectrômetro de massas. (Oliveira, 2011)

Em 1918, A. J. Dempster dos EUA (Estados Unidos da América) desenvolveu seu espectrômetro de massas e conseguiu medir abundâncias isotópicas de vários elementos. A primeira análise orgânica foi realizada em 1940 por Hoover e Washburn. Ambos analisaram uma mistura de hidrocarbonetos.

Posteriormente, com o desenvolvimento de quadrupolos, de ressonância, de tempo de vôo, ciclotrônica, entre outros, teve início a ciência de espectrometria de massas.

$\mathrm{Na}$ FIG.21, o cromatógrafo a gás acoplado a espectrometria de massas utilizada neste trabalho. 


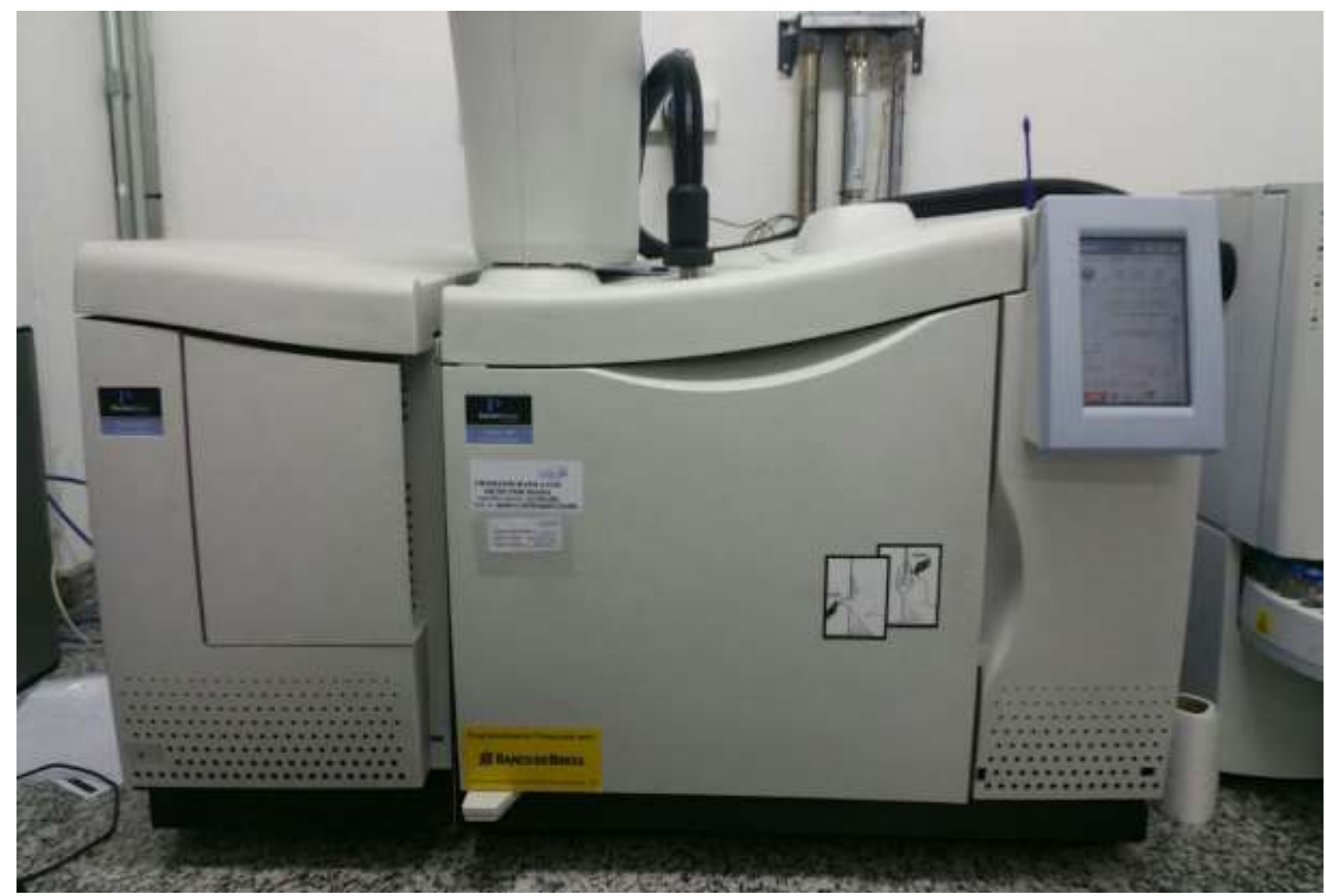

FIGURA 21 Cromatógrafo à gás com espectrômetro de massas Perkin Elmer Clarus 600. (o autor, 2017)

A composição do espectrômetro de massas, basicamente, possui uma fonte e acelerador de íons, analisador de massas e detector de íons. Dentro dos principais métodos existentes, destaca-se: El (ionização por impacto de elétrons). Este método é o mais utilizado para na análise orgânica. A FIG.22 ilustra a fonte de íons/quadrupolo e a FIG.23 ilustra o quadrupolo do GC/MS da Perkin Elmer. 


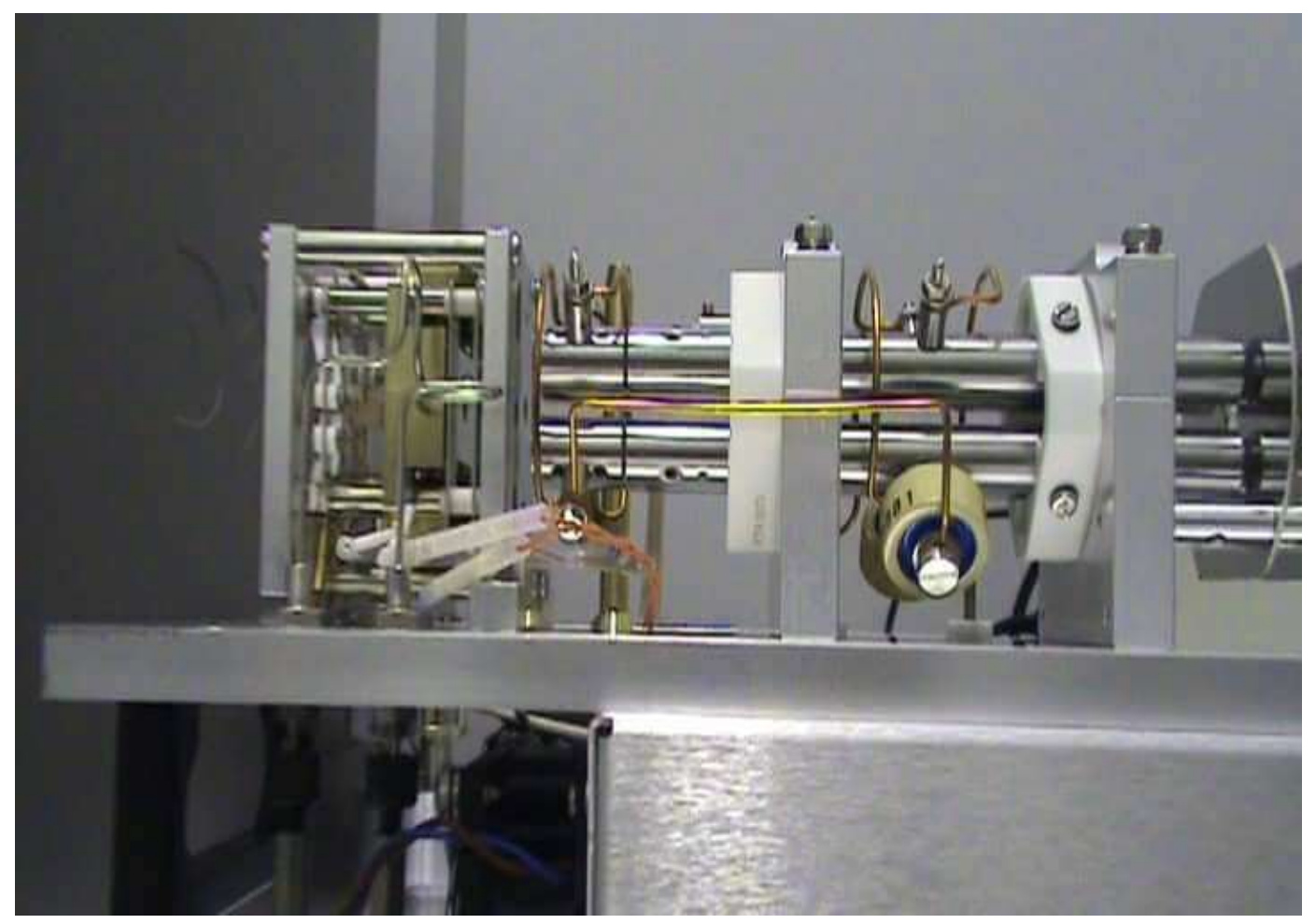

FIGURA 22 Fonte de íons e quadrupolo do GC/MS da Perkin Elmer. (o autor, 2017)

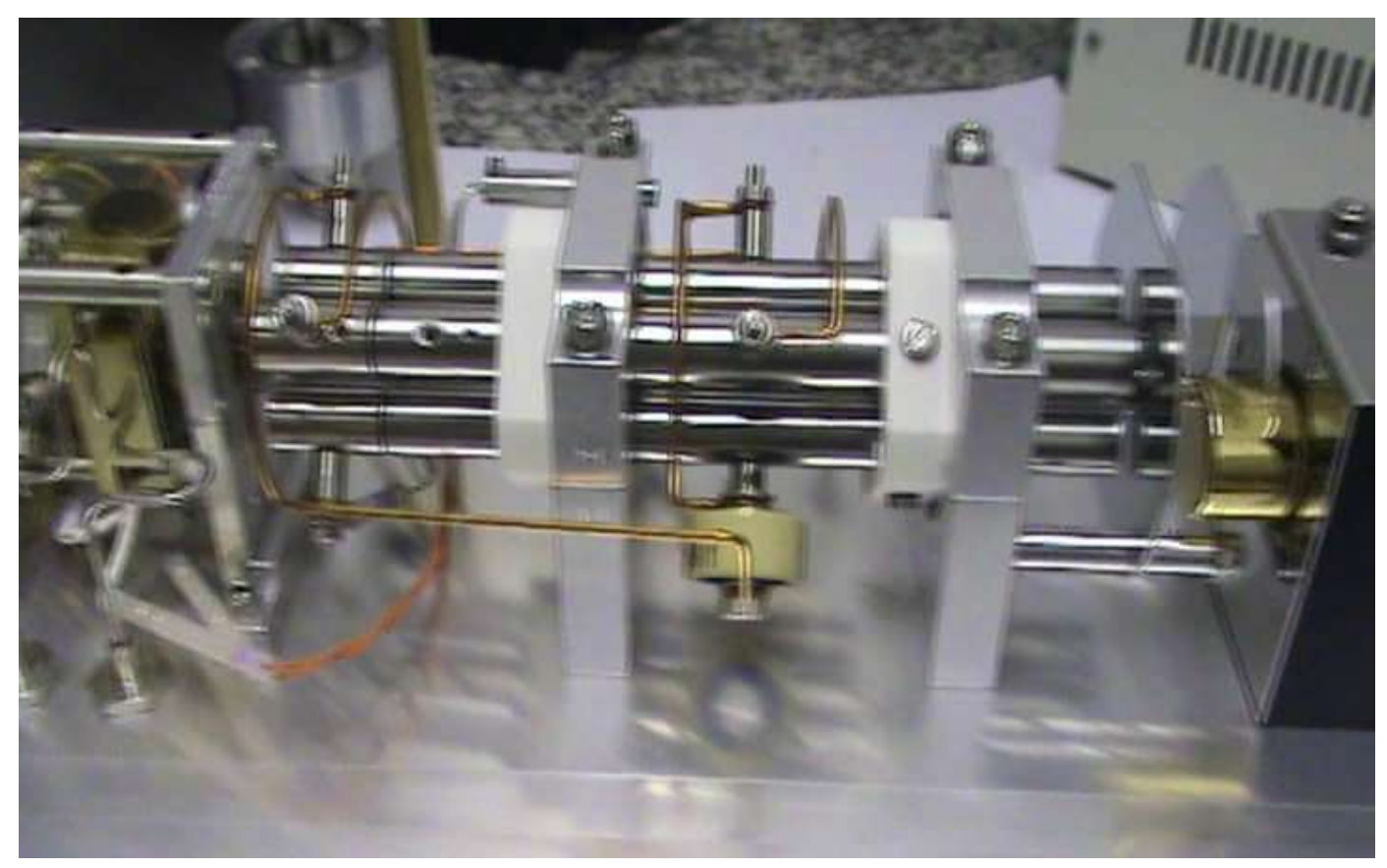

FIGURA 23 Quadrupolo do GC/MS da Perkin Elmer. (o autor, 2017) 
A fonte por impacto de elétrons possui em sua composição o filamento, que geralmente é composto por tungstênio, quando aquecido sob vácuo de $10^{-5}$ a $10^{-6}$ mbar, emite elétrons que são acelerados para a câmara de ionização por uma diferença de potencial de $70 \mathrm{eV}$ (elétron-volt) $\mathrm{O}$ feixe de elétrons produzido passa por uma fenda da câmara de ionização e colide com analitos vaporizados da amostra. Quando as moléculas neutras do gás interagem com esse feixe de elétrons, um elétron é removido da molécula, criando o íon. (Bustillos et. al, 2003)

No processo de ionização por impacto de elétrons, formam-se tanto íons negativos, quanto íons positivos e ambos possuem elétrons desemparelhados, no entanto a formação de íons positivos é 100 vezes maior que para íons negativos. (Oliveira, 2011)

Acoplado ao cromatógrafo à gás, líquido ou plasma, o espectrômetro de massas funciona como detector de alta seletividade e sensibilidade. (Bustillos et. al, 2003)

O Espectrômetro de Massas, acoplado ao Cromatógrafo a gás, funciona como detector de alta seletividade e sensibilidade. Neles, uma amostra com pressão de vapor moderada é introduzida num sistema de injeção operado sob vácuo e temperatura superior a $300{ }^{\circ} \mathrm{C}$. Após vaporização, a amostra com moléculas (M), do analito é levada à fonte de ionização onde sofre impacto por feixe de elétrons de alta energia, produzindo o íon positivo $\mathrm{M}^{+}$, chamado íon molecular. (Collins et. al, 2006)

O íon molecular é produzido em diferentes estados de energia. A energia interna é dissipada por reações de fragmentação e os fragmentos de menores massas são ionizados e convertidos a íons. $\mathrm{O}$ íon $\mathrm{M}^{+}$permite determinar diretamente o peso molecular do composto ou número inteiro mais próximo deste e os demais íons com razões massa-carga $(\mathrm{m} / \mathrm{z})$, fornecem informações importantes para a elucidação da estrutura. (Collins et. al, 2006) 


\subsubsection{Formação do Espectro de Massas}

Um espectro de massas fornece várias informações quanto à natureza de um composto químico. Um gráfico de espectro de massas possui na abcissa a razão massa/carga e na ordenada à abundância relativa dos íons. Possui também informações isotópicas de elementos, informações estruturais do estudo de fragmentos das moléculas e a massa molecular nos casos em que o íon molecular está presente. As linhas espectrais num espectro de massas correspondem a reações de fragmentação das moléculas submetidas ao bombardeamento eletrônico. (Bustillos et. al, 2003)

\subsubsection{Varredura e suas funções}

A função de varredura é uma representação visual da sequência de segmentos de programa no "software" que controla a operação do espectrômetro de massas quadrupolar. (Bustillos et. al, 2003)

O tipo de varredura a ser aplicado pode ser selecionado pelo analista/técnico, de acordo com o que se quer analisar. Os modos de varredura são: Varredura

(SCAN) e SIM (Select lon Monitoring). É possível também obter o MIC (Monitoring Ion Current) por meio do "software" de operação do equipamento. (Bustillos et. al, 2003)

\subsubsection{SCAN}

A função SCAN nada mais é do que uma faixa de massas a ser analisada. Esta faixa é pré determinada pelo analista/técnico, onde o detector aplicará potencias de corrente direta DC (Direct Current) e radio freqüência RF (Radio Frequency) adequados. (Bustillos et. al, 2003)

Em uma primeira análise, é recomendada realizar uma varredura SCAN, pois ela faz a leitura de todas as massas no intervalo pré determinado, de todas as substâncias presentes na amostra. É o chamado "Screaning". Esta etapa é 
fundamental para a elaboração de cada novo método cromatográfico. Por meio de um padrão de concentração conhecida, injeta-se (usa-se este termo, pois é utilizada uma microseringa para inserir a amostra dentro do equipamento) e posteriormente, faz-se a identificação por meio dos tempos de retenção e do espectro de massas, para posteriormente, realizar quantificação dos analitos. (Bustillos et. al, 2003)

\subsubsection{Método de Varredura SIM}

O método de varredura SIM (Selected lon Monitoring) é realizado por meio da escolha dos íons a serem monitorados pelo analista/técnico. Ao monitorar apenas alguns íons de interesse, aumenta-se a sensibilidade significativamente. Os íons escolhidos são os de maior intensidade do analito. A NIST (National Institute of Standards and Technology) é uma biblioteca espectral onde é possível consultar o espectro de interesse. (Bustillos et. al, 2003)

Este método de varredura é o ideal para a quantificação e análise de traços, pois devido à sua seletividade ser muito maior que o SCAN, proporciona às análises com menores limites de detecção e quantificação. O SIM é realizado pelo "hardware" e não pelo "software". (Bustillos et. al, 2003)

\subsubsection{Método de Varredura MIC}

Este método de varredura MIC, é uma "lente de aumento" para os íons monitorados pelo modo SCAN. O analista/técnico seleciona os íons de interesse a serem analisados em um cromatograma obtido no modo SCAN. O método MIC é realizado pelo "software" e não pelo "hardware". (Bustillos et. al, 2003)

Dentre as varreduras SCAN. SIM e MIC, a varredura SCAN foi a técnica utilizada neste trabalho. 


\subsubsection{Análise no GC/MS e GC-ECD}

Para iniciar uma análise no cromatógrafo, ele necessitou de um método de análise. Neste método de análise, foram incluídas as condições de operação dos cromatógrafos, dentre elas a rampa de temperatura e as condições cromatográficas. Estas condições foram testadas variando seus componentes até chegar em um método onde os resultados obtiveram melhores respostas.

A TAB.2 apresenta as condições de análise, da rampa de aquecimento do forno dos cromatógrafos ECD e GC/MS.

TABELA 2 Rampa de Temperatura para o forno do cromatógrafo. (o autor, 2017)

\begin{tabular}{c|c|c}
$\begin{array}{c}\text { Razão de } \\
\text { aquecimento } \\
\left({ }^{\circ} \mathrm{C} / \mathrm{min}\right)\end{array}$ & Temperatura $\left({ }^{\circ} \mathrm{C}\right)$ & Tempo de retenção (min) \\
\hline- & 40 & 1 \\
\hline 20 & 160 & 3 \\
\hline 3 & 275 & 1 \\
\hline 20 & 310 & 0 \\
\hline
\end{tabular}

As condições cromatográficas foram:

Coluna: HP-5, 30m x 0,32 $\mathrm{mm} \times 0,25 \mu \mathrm{m}$

Detector: ECD 
Gás de arraste: Hélio.

Temperatura do injetor: $200^{\circ} \mathrm{C}$

Temperatura do Detector: $300^{\circ} \mathrm{C}$

Temperatura da base do injetor: $250^{\circ} \mathrm{C}$

Modo: Splitless

Volume de injeção: $3 \mu \mathrm{L}$.

Fluxo de gás de arraste: $10,0 \mathrm{~mL} / \mathrm{min}$.

Pressão constante :136 kPa

Corrente de Referência :1.0 nA

Amplitude de pulso: $50 \mathrm{~V}$

Largura do pulso:1.0 msegundos

Fluxo: $60 \mathrm{~mL} / \mathrm{min}$

Após a preparação do método de análise para o cromatógrafo, foi preparada uma curva de calibração para quantificação dos resultados. Para o preparo da curva de calibração, foi utilizado o mix do padrão de organoclorados, conforme figura do apêndice A. Este certificado deve possuir a norma ABNT NBR ISO/IEC 17025:2005 e a ISO GUIDE 34:2009 (Requisitos gerais para a competência dos produtores de materiais de referência).

A curva de calibração foi injetada nos dois cromatógrafos GC/MS e GC-ECD juntamente com um branco ( $1 \mathrm{~mL}$ do solvente $\mathrm{n}$-hexano) para avaliar se houvessem contaminações e um padrão controle a fim de verificar a resposta (concentração) dos analitos. Através desta foram realizadas a quantificação dos resultados, sendo expresso em $\mu \mathrm{g} / \mathrm{kg}$.

\section{6 - Validação}

Neste trabalho, foram utilizados para a validaçãoos seguites parâmetros: Limite de Detecção (LD), Limite de Quantificação (LQ), Recuperação, Repetitividade e Incerteza de Medição. 
Em laboratórios ambientais segue-se a normatização do INMETRO, sendo assim, este trabalho foi validado segundo os parâmetros deste órgão.

\subsubsection{Limite de Detecção}

O Limite de Detecção utilizado foi o primeiro ponto da curva de calibração.

\subsubsection{Limite de Quantificação}

O Limite de Quantificação utilizado foi o segundo ponto da curva de calibração

\subsubsection{Repetitividade}

Foram injetados 7 brancos com adição de duas concentrações diferentes do analito.

\subsubsection{Recuperação}

Foram injetados no cromatógrafo gasoso ECD, 7 leituras de branco com adição de e uma única concentração dos POPs.

\subsection{Análises Cromatográficas}

As análises cromatográficas foram realizadas após a validação do método. Obedecendo a ordem de um branco, um padrão controle, quatro amostras com "Spike" e oito amostras coletadas. As análises foram realizadas no GC/MS para análise qualitativa e no GC-ECD para análise quantitativa. 


\section{5 - RESULTADOS E DISCUSSÃO}

Após coletar as amostras de sedimento da Represa Billings, foi iniciado o processo de validação do método, utilizando padrões de alta pureza, conforme apêndice A.

\section{1 - Resultados da validação}

Para realização da curva de calibração, foram testadas concentrações de 0,1 e $0,2 \mu \mathrm{g} / \mathrm{kg}$, mas não foram obtidas respostas significativas para que se iniciasse uma curva de calibração com estas concentrações. A concentração que obteve resposta significativa foi de $0,3 \mu \mathrm{g} / \mathrm{kg}$.

Foi realizada uma curva de calibração para cada composto, onde foram adicionadas em vial de $2 \mathrm{~mL}$, nas concentrações de 0,3 a $20 \mu \mathrm{g} / \mathrm{kg}$ com solvente $\mathrm{n}$ hexano. As FIG.24 a 30 ilustram as curvas de calibração dos compostos estudados neste trabalho.

O INMETRO exige linearidade mínima do coeficiente de correlação $R=0,9$. Nas figuras observa-se a equação da reta para cálculo da linearidade, assim como o gráfico da curva, sendo a resposta em área no eixo $\mathrm{Y}$ e os pontos da curva no eixo X. A TAB 3, apresenta a linearidade das curvas dos POPs. 


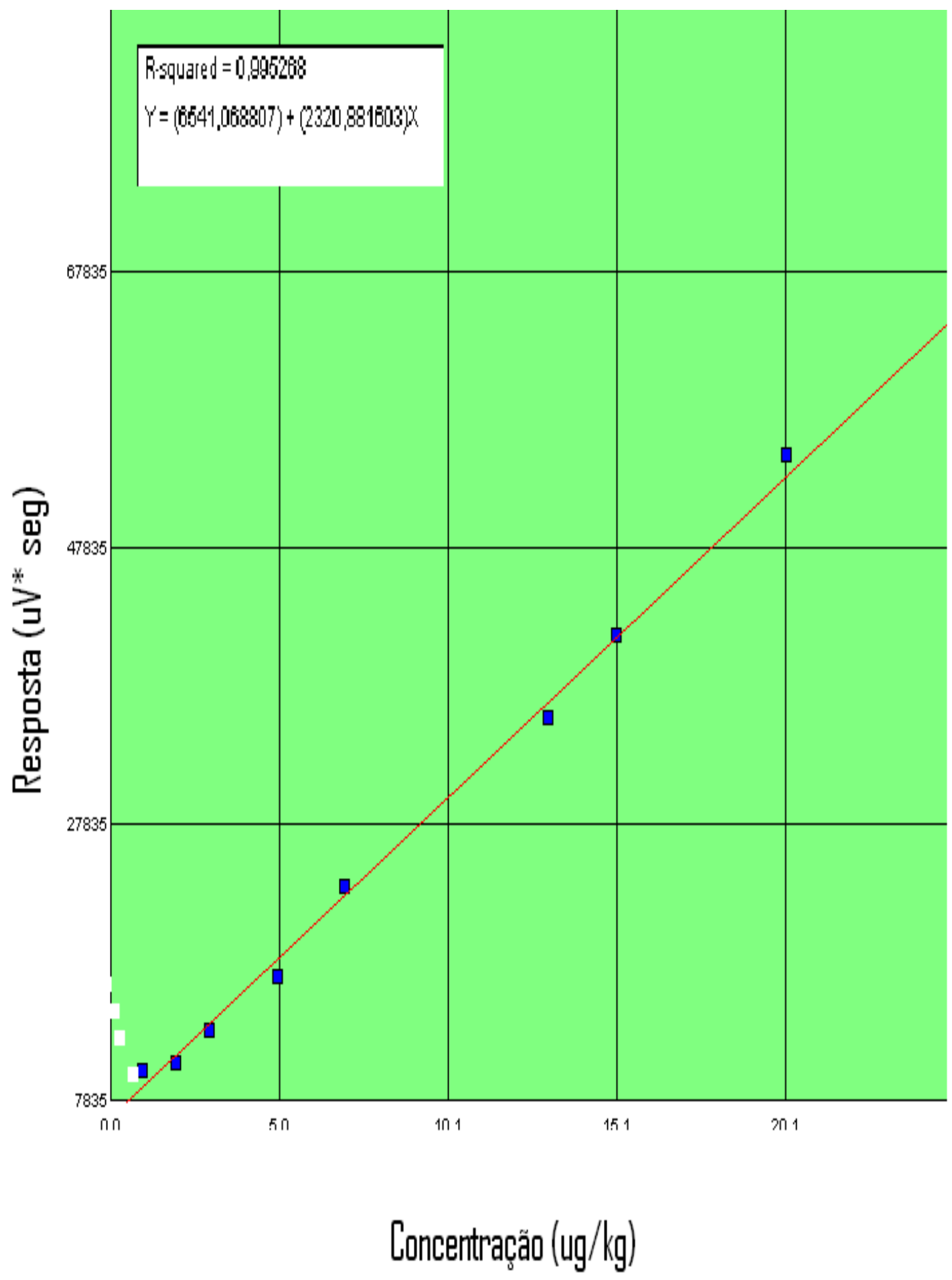

FIGURA 24 Curva de calibração do Aldrin. (o autor, 2017) 


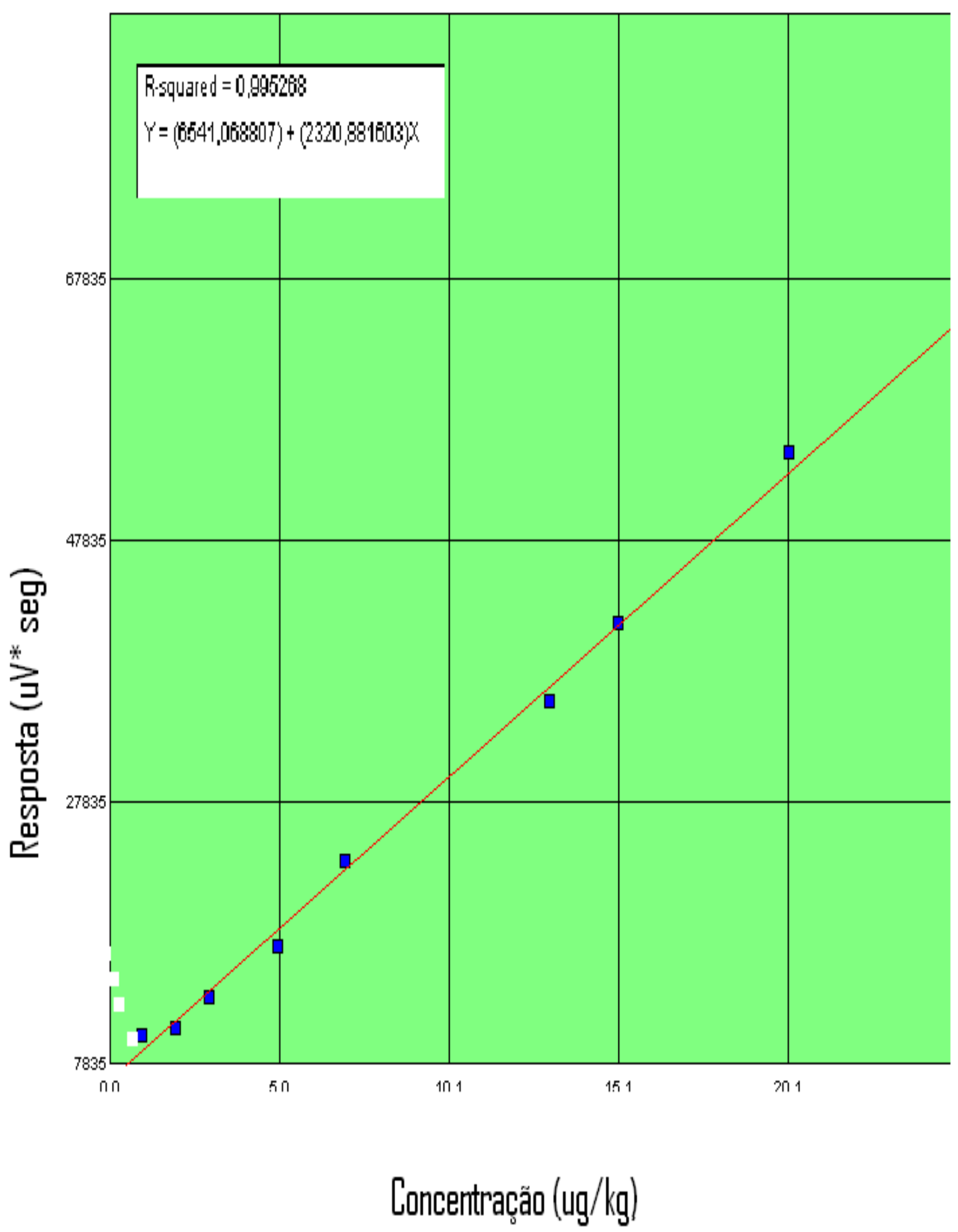

FIGURA 25 Curva de calibração do DDD. (o autor, 2017) 


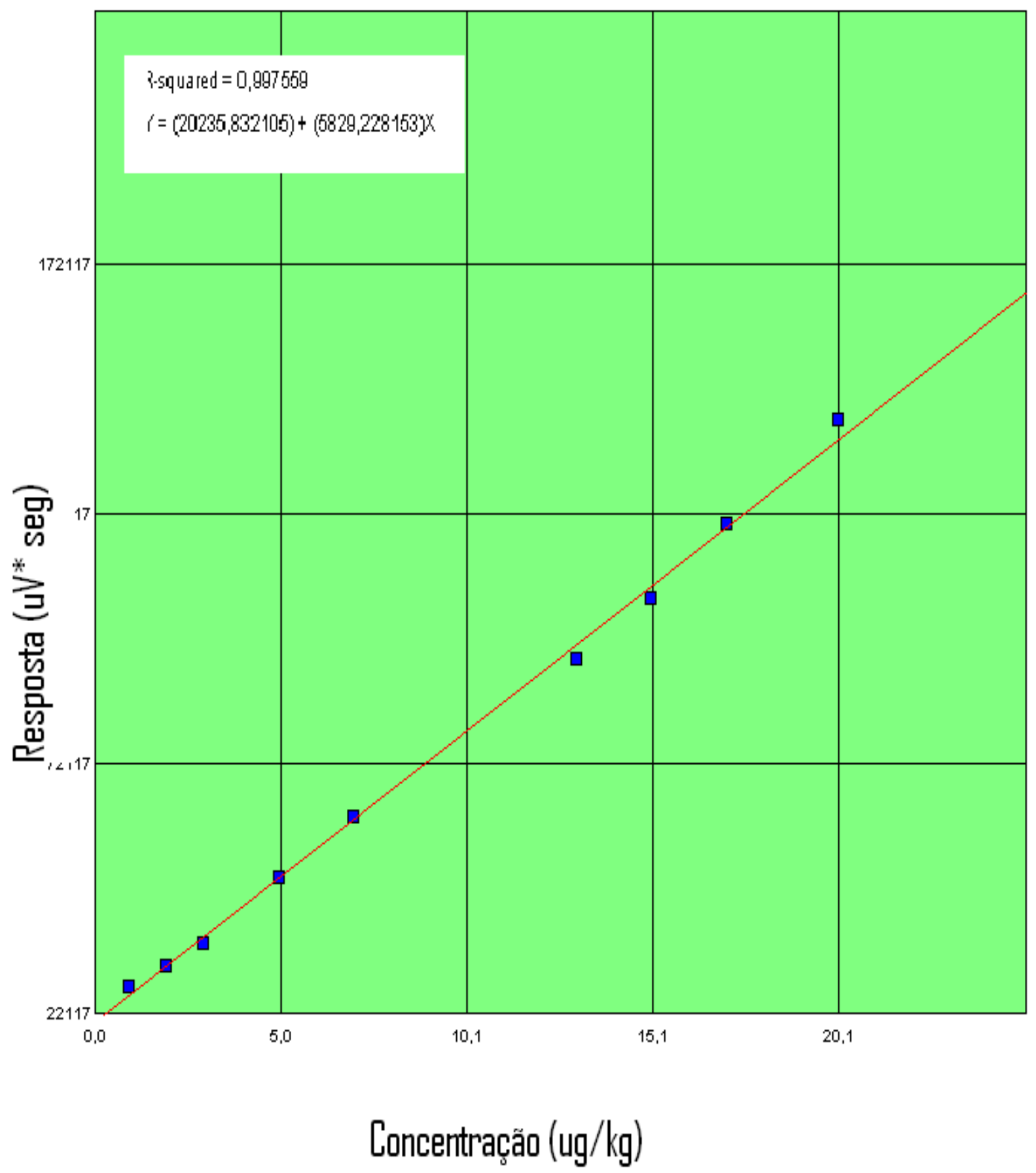

FIGURA 26 Curva de calibração do DDE. (o autor, 2017) 


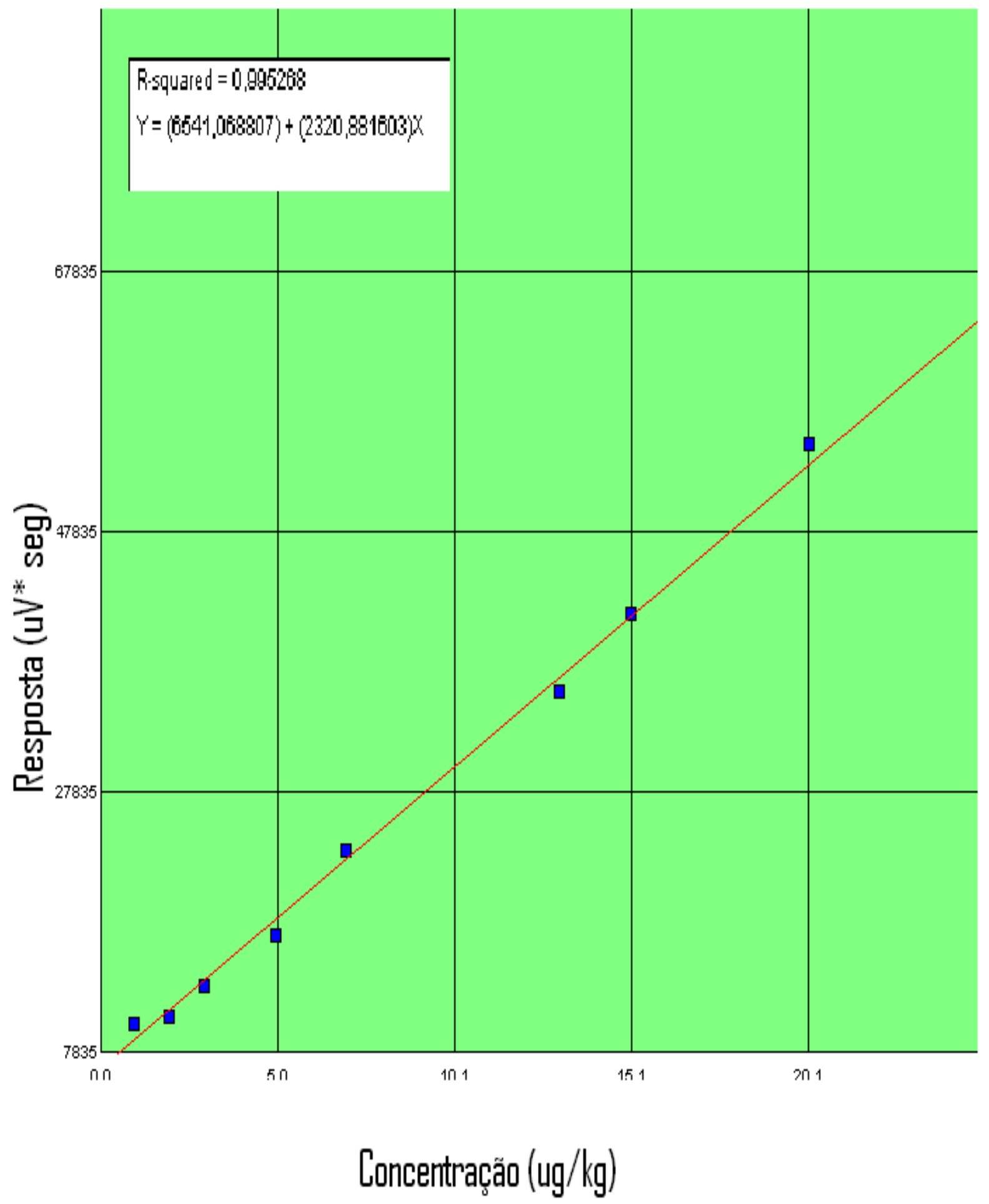

Figura 27 Curva de calibração do DDT. (o autor, 2017) 


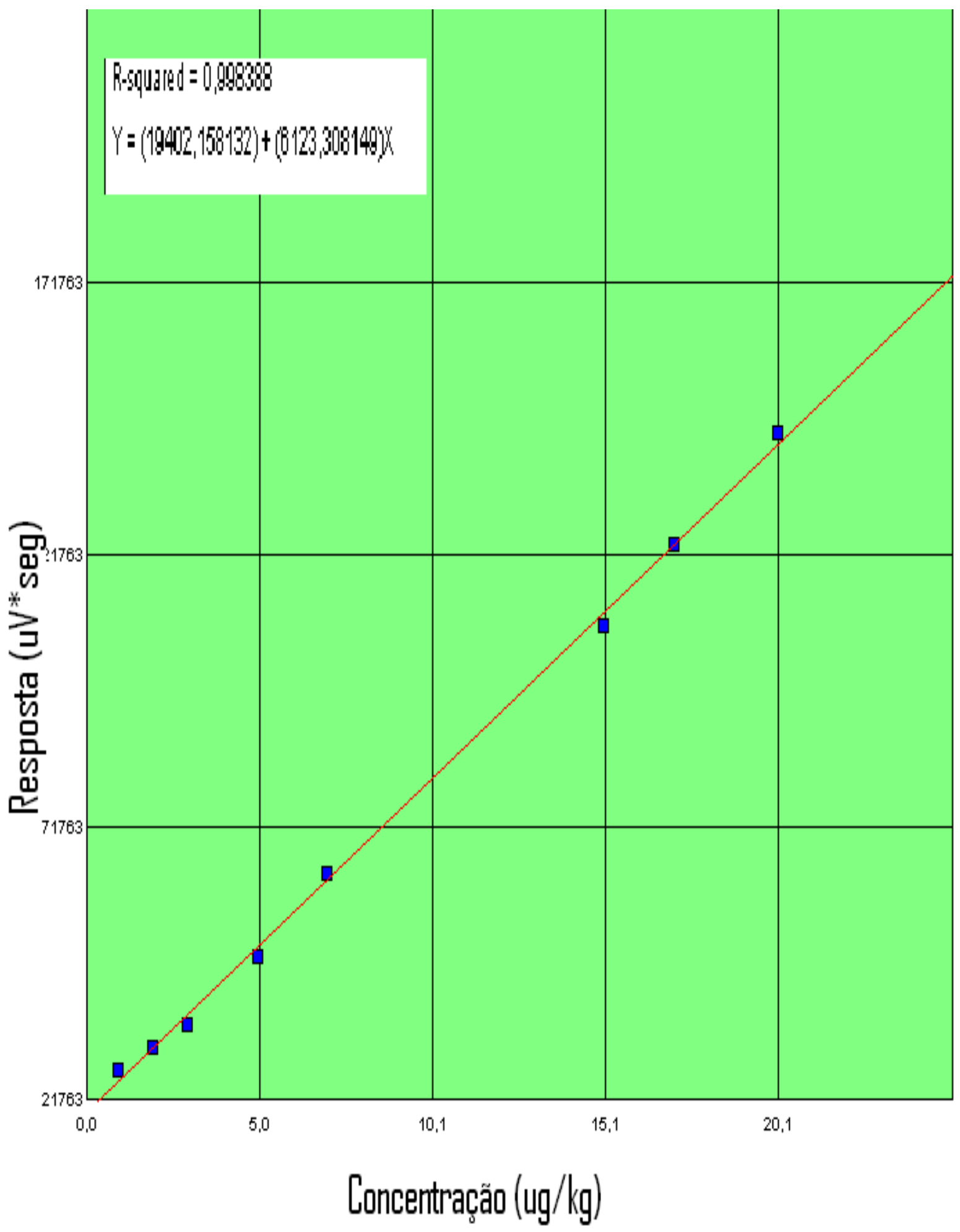

Figura 28 Curva de calibração do Dieldrin. (o autor, 2017) 


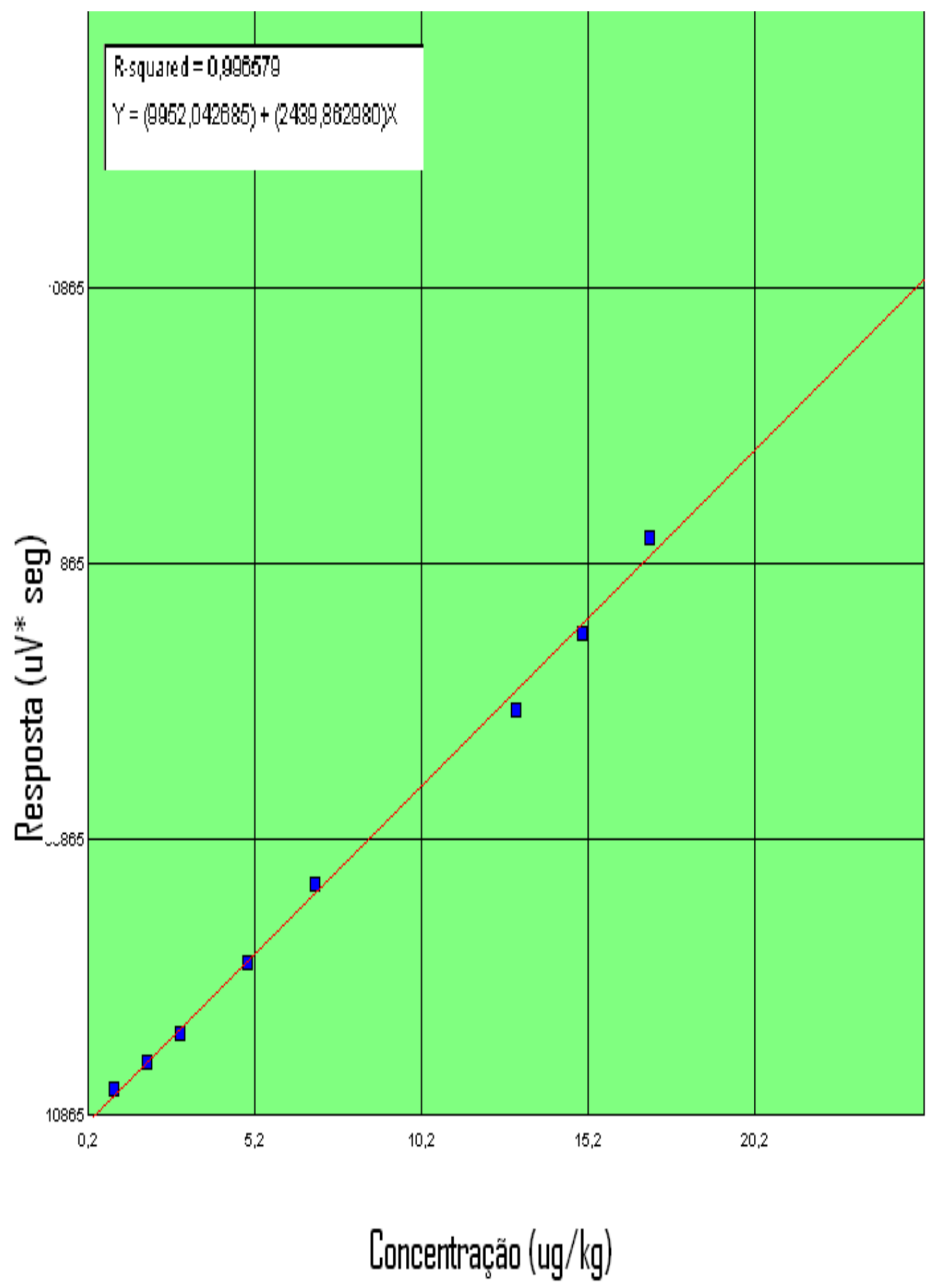

FIGURA 29 Curva de calibração do Endrin. (o autor, 2017) 


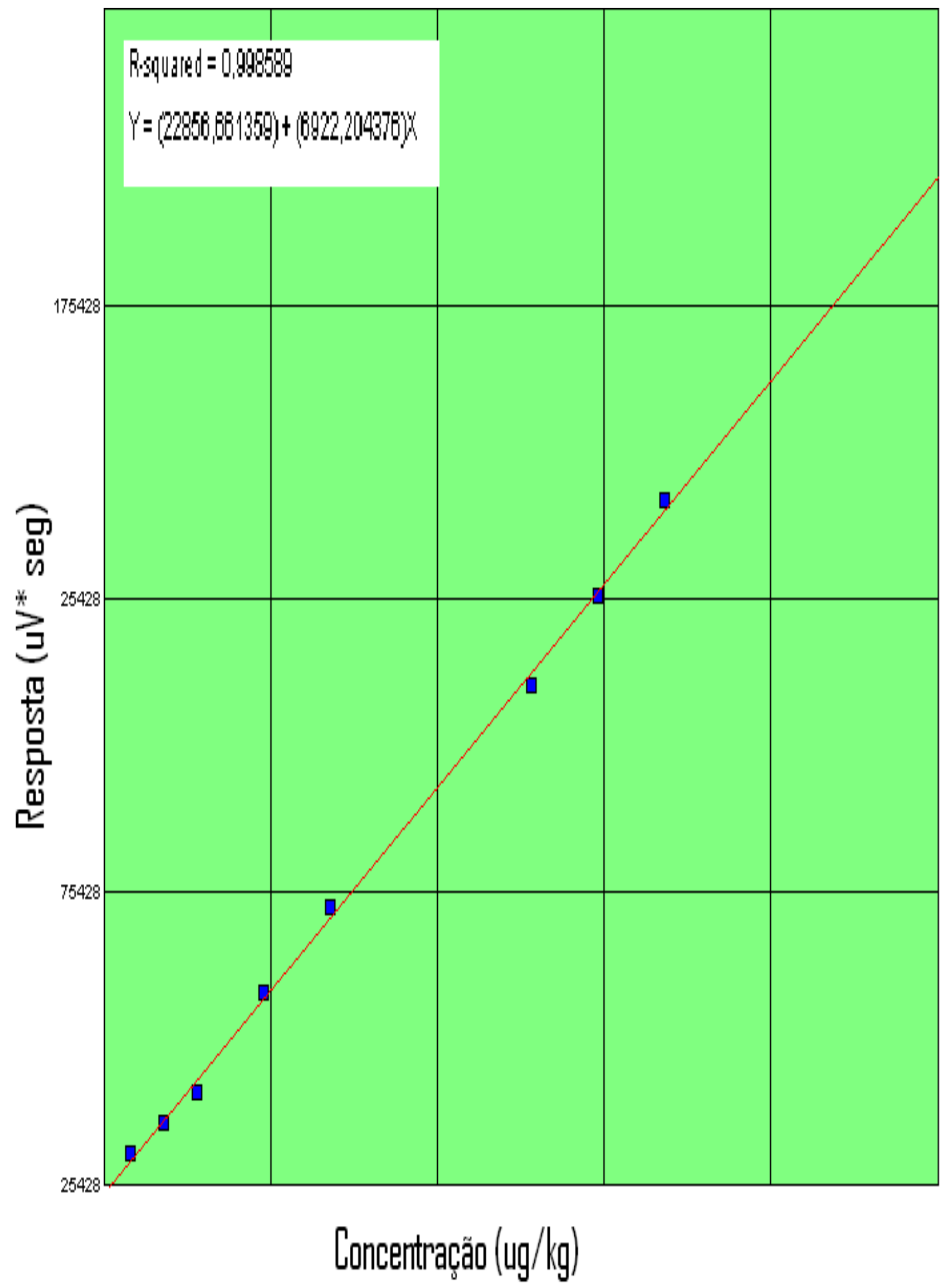

FIGURA 30 Curva de calibração do Heptacloro. (o autor, 2017) 
TABELA 3 Linearidade das curvas dos POPs. (o autor, 2017)

\begin{tabular}{cc}
\hline POPs & Linearidade da curva \\
\hline Aldrin & 0,995 \\
Dieldin & 0,998 \\
Endrin & 0,996 \\
DDT & 0,995 \\
DDE & 0,997 \\
DDD & 0,995 \\
Heptacloro & 0,998 \\
\hline
\end{tabular}

\section{2 - Resultados de Limite de Detecção}

A curva de calibração possui como primeiro ponto $0,3 \mu \mathrm{g} / \mathrm{kg}$ sendo este o LD deste método para todos os POPs estudados.

\section{3 - Resultados de Limite de Quantificação}

A curva de calibração possui como segundo ponto $0,5 \mu \mathrm{g} / \mathrm{kg}$ sendo este o LQ deste método. 


\section{4 - Resultados de Recuperação}

A TAB 4 apresenta os resultados obtidos para Recuperação.

TABELA 4 Recuperação dos POPS. (o autor, 2017)

\begin{tabular}{cc}
\hline POPs & \% Recuperação \\
\hline Aldrin & 60 \\
Dieldrin & 61 \\
Endrin & 61 \\
DDE & 59 \\
DDD & 65 \\
DDT & 57 \\
Heptacloro & 57 \\
\hline
\end{tabular}

Para cálculo de Recuperação, foi utilizado o anexo 2 como exemplo, onde consta o nome do composto que foi validado - Aldrin, a matriz - sedimento, o nome do responsável pela análise - Katia Mesquita, a data das análises - 02/08/2016, o método utilizado foi - 8081 da Environmental Agency Protection (EPA), o nome do equipamento GC-001, a concentração dos analitos - 0,100, a unidade de concentração - $\mu \mathrm{g} / \mathrm{kg}$, o valor do branco de análise - 0, a unidade de sinal analítico 0 , e uma planilha com o número das leituras com seus respectivos sinais analíticos e a porcentagem de cada recuperação. Todas as análises de Recuperação foram realizadas na mesma planilha de dados. 


\subsection{Resultados de Repetitividade}

A TAB 5 apresenta os resultados de Repetitividade.

TABELA 5: Repetitividade dos POPs em $\mu \mathrm{g} / \mathrm{kg}$. (o autor, 2017)

\begin{tabular}{ccccc}
\hline POP & Concentração & Média & SD & RSD \\
\hline & 1 & 1,097 & 0,05407 & 492,846 \\
Aldrin & 2 & 1,87 & 0,08793 & 470,264 \\
\hline \multirow{2}{*}{ Dieldrin } & 1 & 1,061 & 0,04598 & 433,202 \\
Endrin & 2 & 2,137 & 0,03817 & 178,614 \\
\hline & 1 & 1,081 & 0,04561 & 421,825 \\
DDE & 2 & 2,084 & 0,03207 & 153,872 \\
\hline & 1 & 1,069 & 0,04879 & 456,637 \\
DDD & 2 & 2,076 & 0,06241 & 300,676 \\
\hline & 1 & 1,089 & 0,05398 & 495,917 \\
DDT & 2 & 2,081 & 0,07010 & 336,797 \\
\hline & 1 & 1,091 & 0,05209 & 477,345 \\
Heptacloro & 2 & 2,094 & 0,05472 & 261,324 \\
\hline
\end{tabular}

\subsection{Resultados de Incerteza de Medição}

As FIG.31 a 37 ilustram as contribuições de incerteza. Nelas são calculadas, a concentração (são utilizadas para cálculo as incertezas da vidraria e equipamento), a variabilidade (são feitas nove leituras de uma concentração de um ponto da curva de calibração) e a curva de calibração (cálculo da incerteza da curva de calibração). 


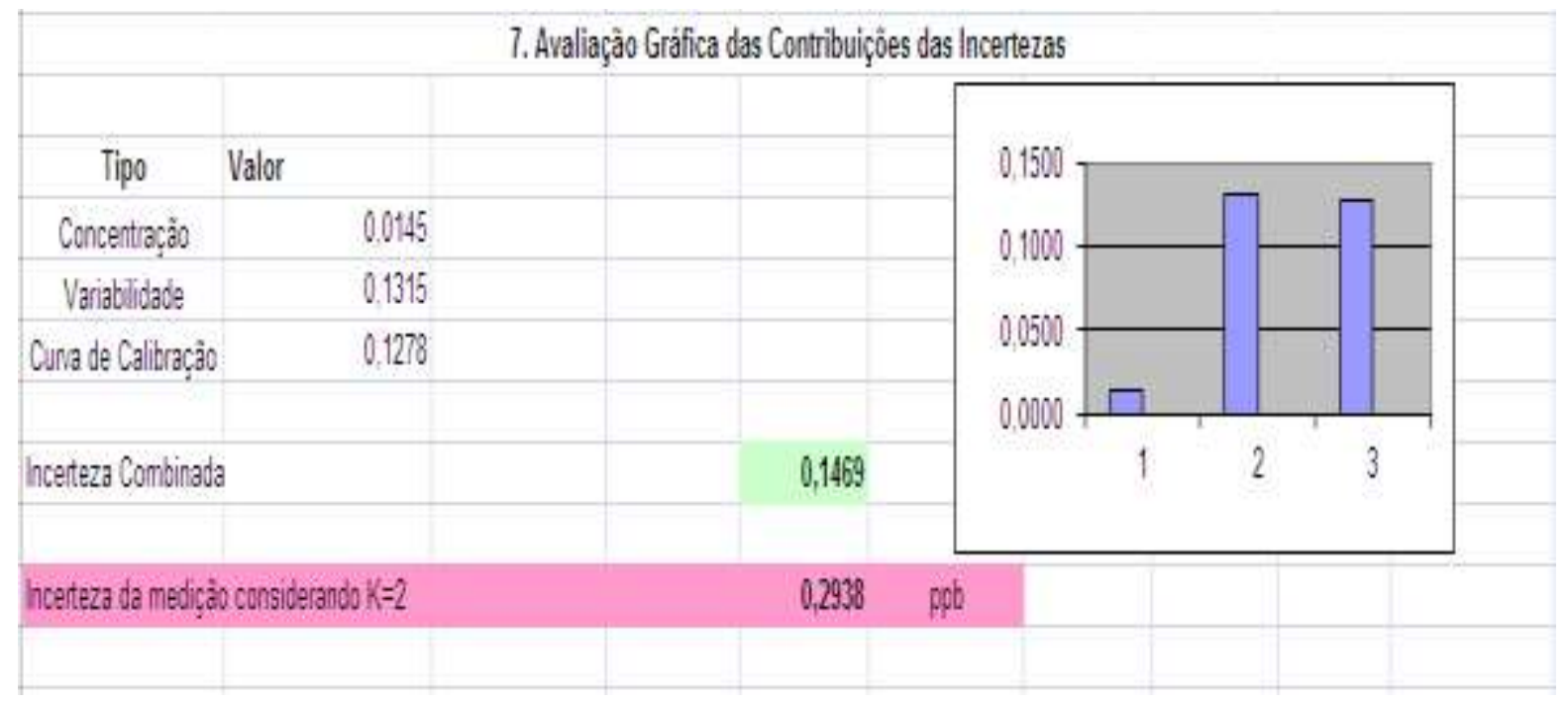

FIGURA 31 Avaliação gráfica com a contribuição das incertezas do Aldrin. (o autor, 2017)

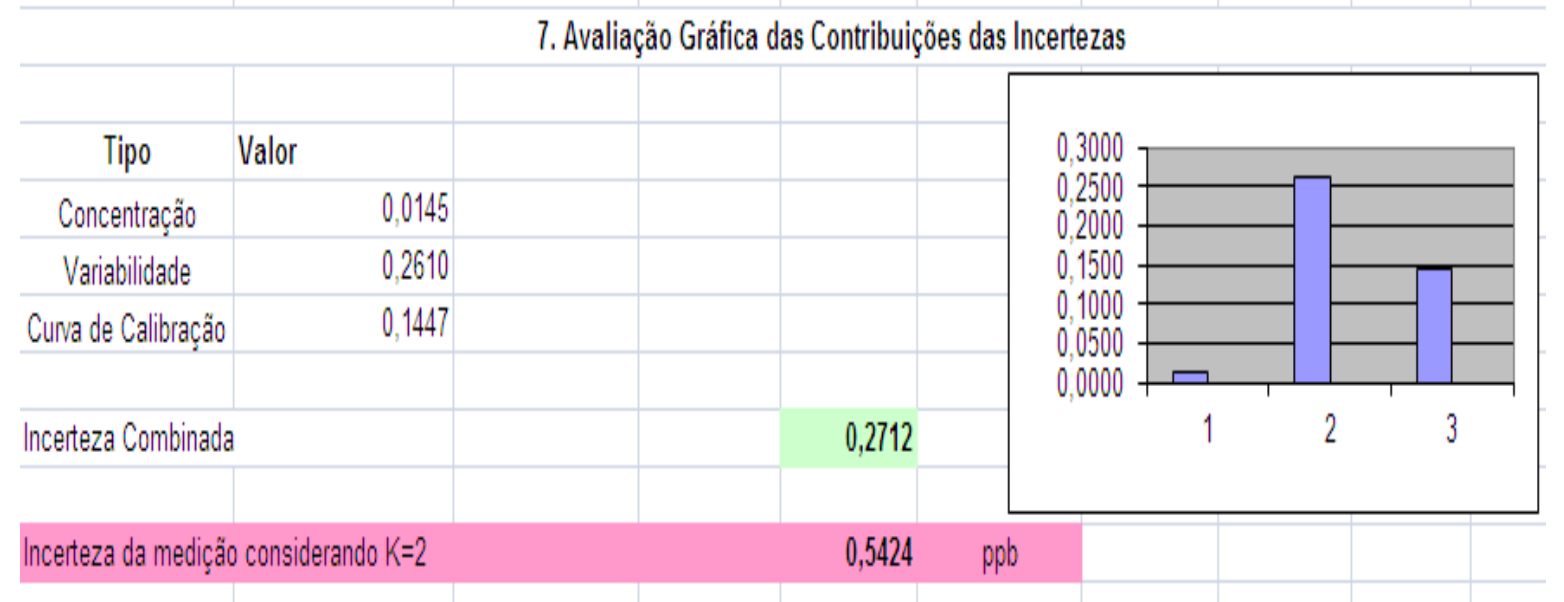

FIGURA 32 Avaliação gráfica com a contribuição das incertezas do Dieldrin. (o autor, 2017) 


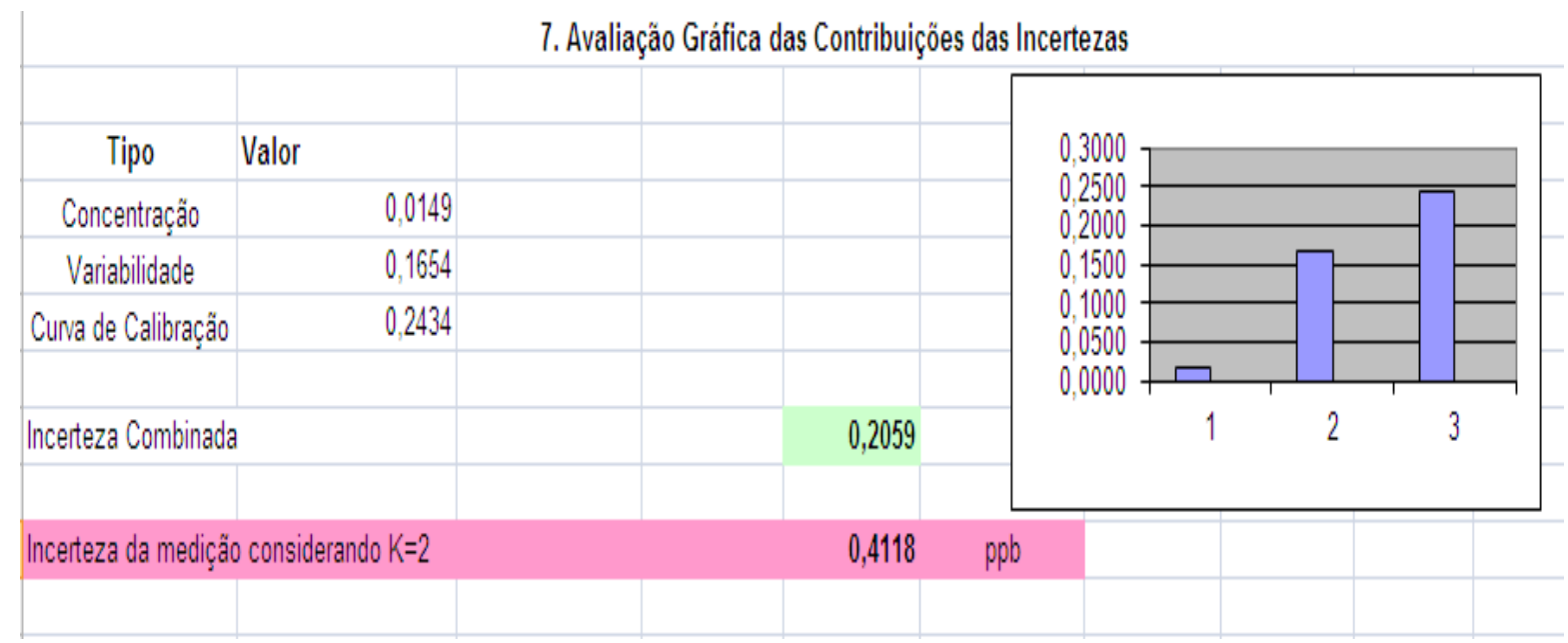

FIGURA 33 Avaliação gráfica com a contribuição das incertezas do Endrin. (o autor, 2017)

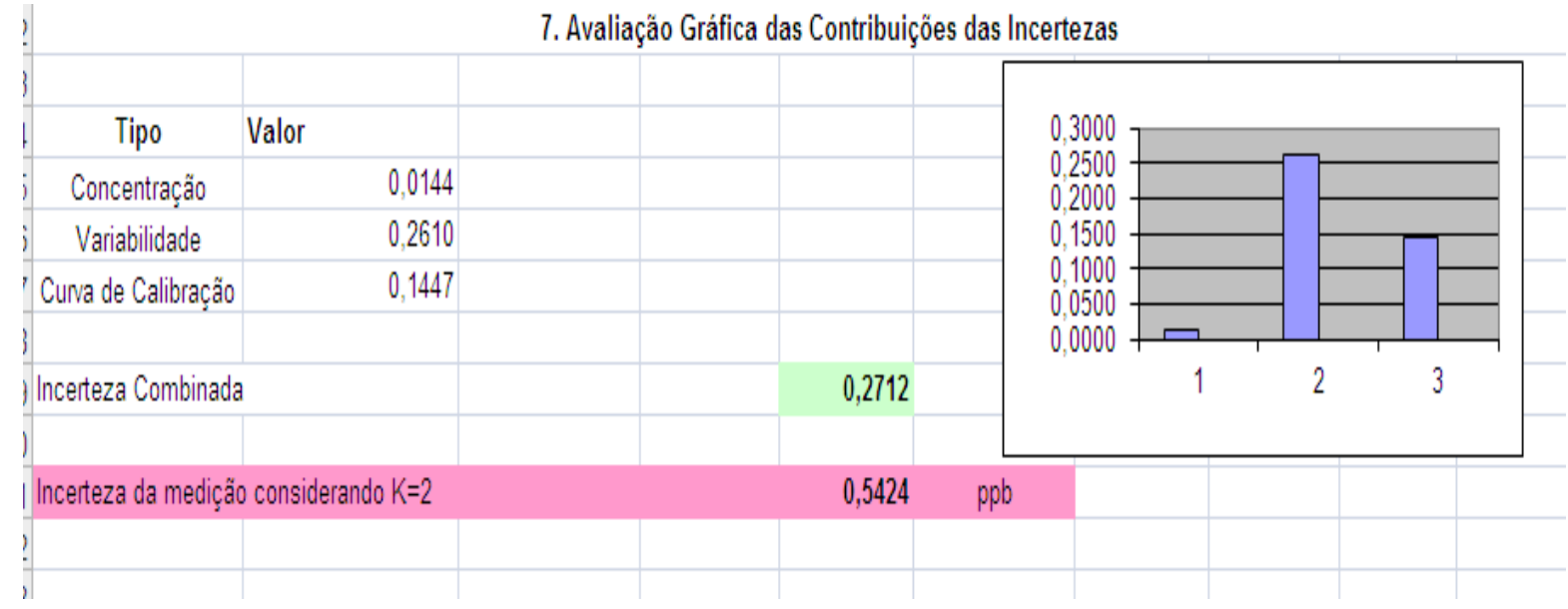

FIGURA 34 Avaliação gráfica com a contribuição das incertezas do DDE. (o autor, 2017) 


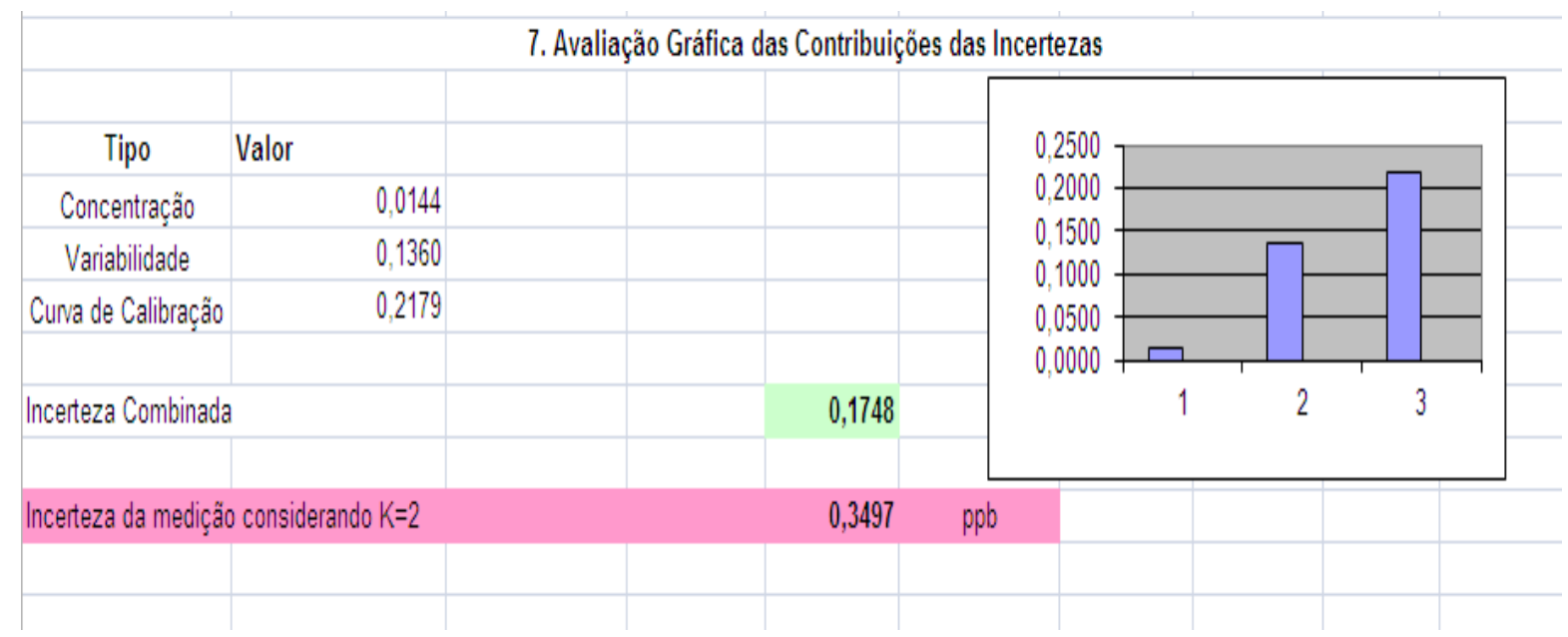

FIGURA 35 Avaliação gráfica com a contribuição das incertezas do DDT. (o autor, 2017)

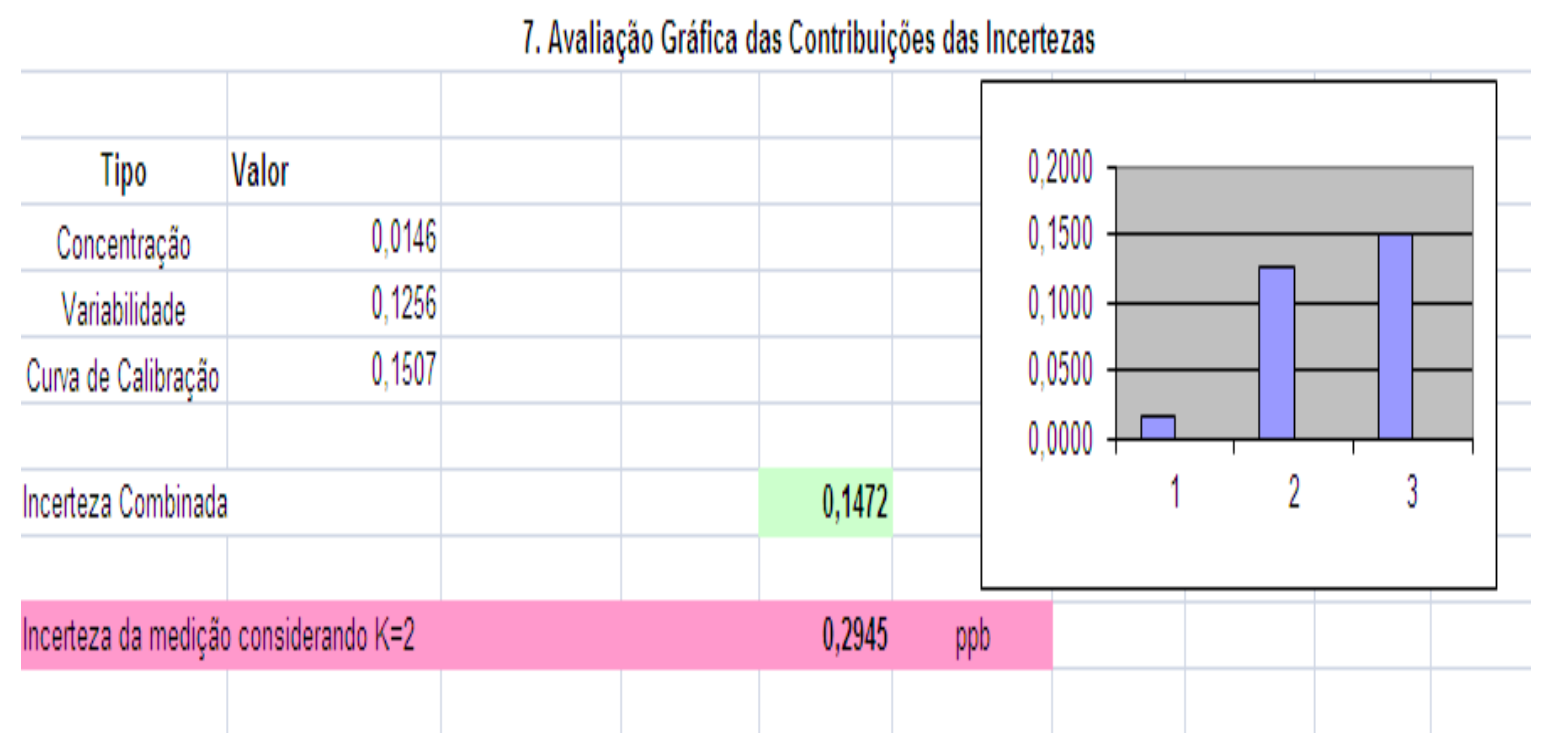

FIGURA 36 Avaliação gráfica com a contribuição das incertezas do DDD. (o autor, 2017) 
7. Avaliaçăo Grafica das Contribuiçoes das Incertezas

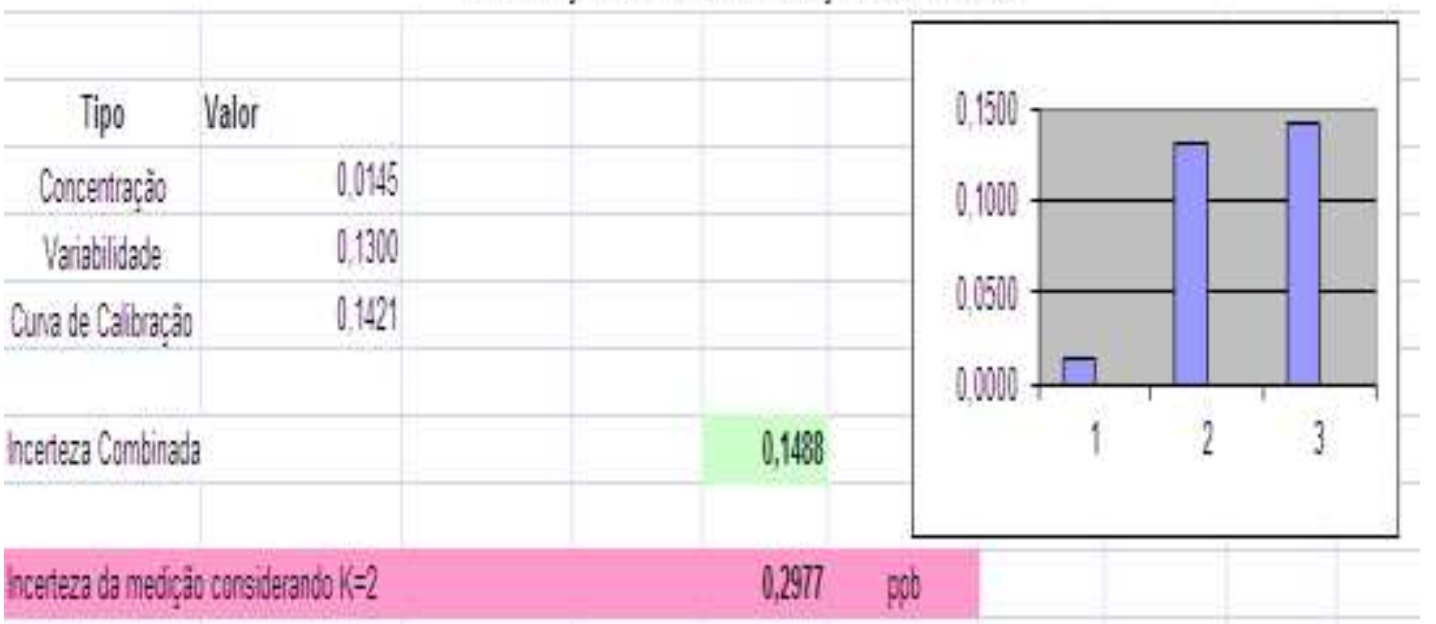

FIGURA 37 Avaliação gráfica com a contribuição das incertezas do Heptacloro. (o autor, 2017)

\subsection{Resultados do padrão controle}

A FIG.38 ilustra o cromatograma do padrão controle e a TAB. 6 os valores encontrados para os POPs neste padrão. A concentração foi de $0,3 \mu \mathrm{g} / \mathrm{kg}$.

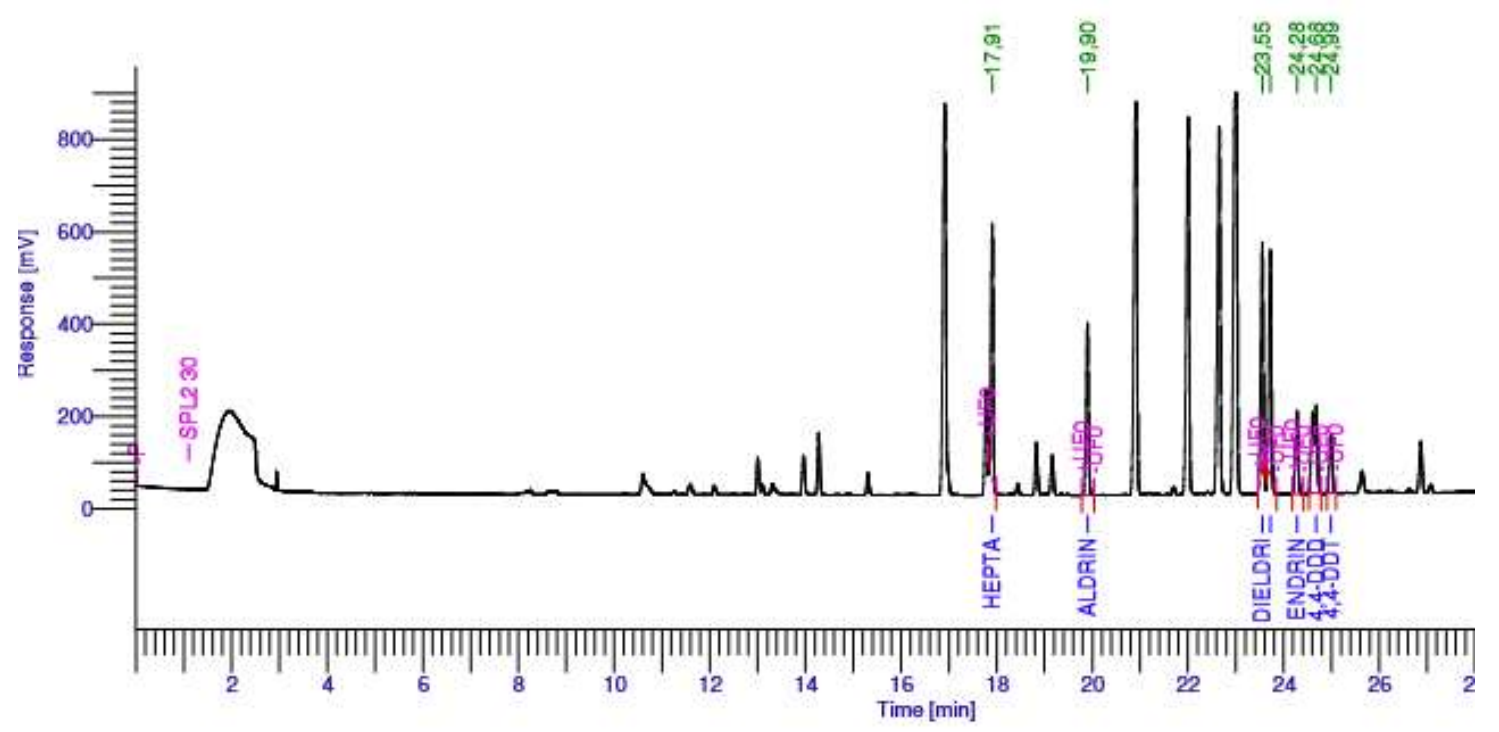

FIGURA 38 Cromatograma do padrão controle. (o autor, 2017) 
TABELA 6 Resultado do padrão controle dos POPs (o autor, 2017)

\begin{tabular}{cccc}
\hline $\begin{array}{c}\text { Tempo em } \\
\text { minutos }\end{array}$ & $\begin{array}{c}\text { Nome do } \\
\text { Composto }\end{array}$ & $\begin{array}{c}\text { Área } \\
(\mathbf{u V} \text { seg) }\end{array}$ & $\begin{array}{c}\text { Concentração } \\
\mathbf{e m ~} \boldsymbol{\mu g} / \mathbf{k g}\end{array}$ \\
\hline 17,9 & Heptacloro & 1775279,4 & 0,25 \\
19,8 & Aldrin & 1356700,4 & 0,17 \\
23,5 & Dieldrin & 1713277,2 & 0,27 \\
23,7 & DDE & 1723101,4 & 0,29 \\
24,2 & Endrin & 742388,3 & 0,30 \\
24,6 & DDD & 13744680,8 & 0,24 \\
24,9 & DDT & 529139,7 & 0,22 \\
\hline
\end{tabular}

\subsection{Resultados do amostras "spike"}

As amostras com "spike" estão ilustradas na FIG. 39. Os resultados das quatros amostras com Spike, estão nas TAB. 7 a 10.

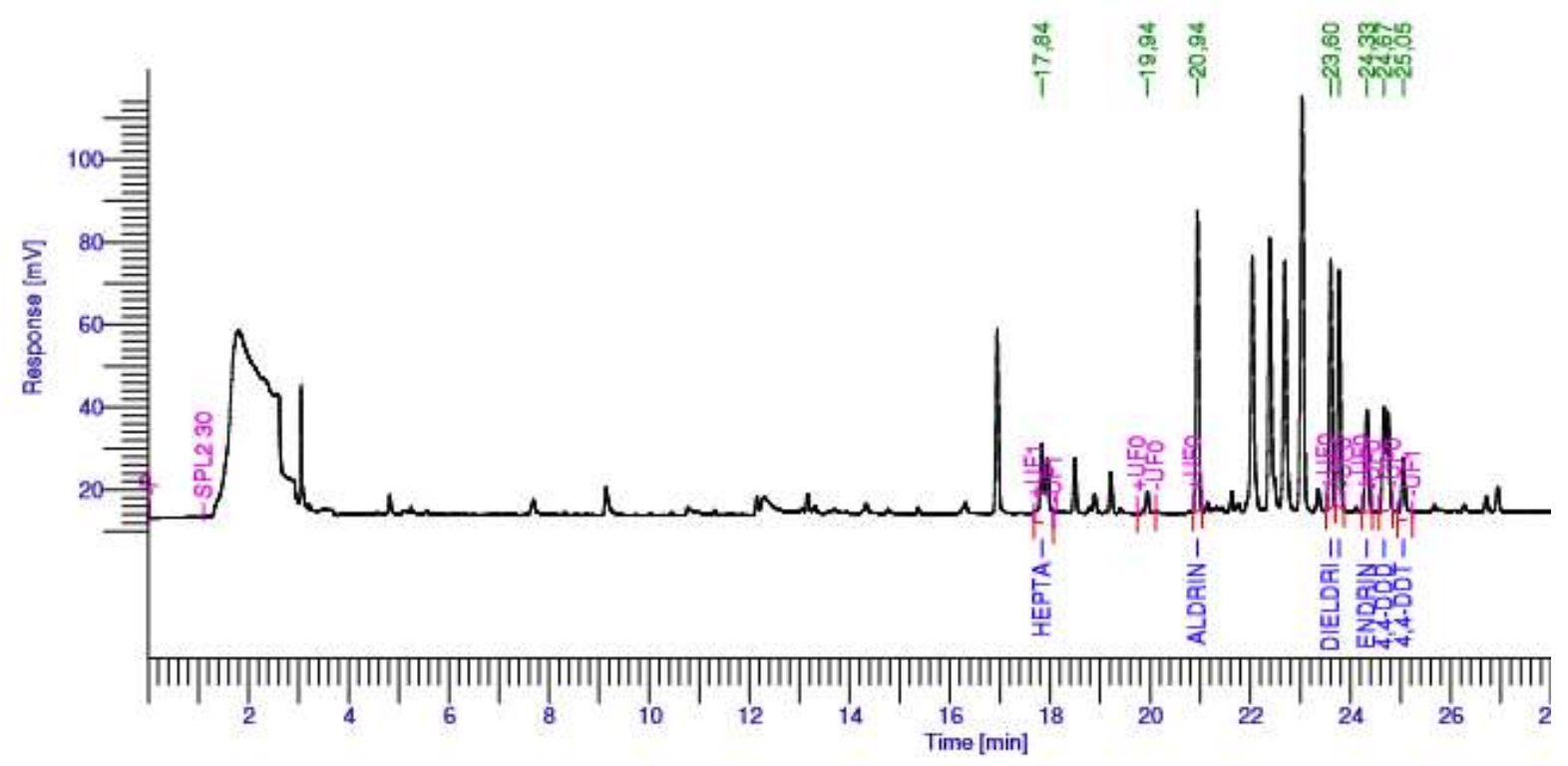

FIGURA 39 Cromatograma do spike $2 \stackrel{\circ}{\circ}$ Linha. (o autor, 2017)

As TAB.7 a 10, ilustram os resultados dos spikes realizados em 4 pontos dentre as amostras estudadas. 
TABELA 7 Resultados do spike de $0,03 \mathrm{mg} / \mathrm{kg}$ da amostra $2^{\circ}$ Linha. (o autor, 2017)

\begin{tabular}{cccc}
\hline $\begin{array}{c}\text { Tempo em } \\
\text { minutos }\end{array}$ & $\begin{array}{c}\text { Nome do } \\
\text { Composto }\end{array}$ & $\begin{array}{c}\text { Área } \\
\left(\mathbf{u V}^{*} \mathbf{s e g}\right)\end{array}$ & $\begin{array}{c}\text { Concentração } \\
\mathbf{e m ~} \mathbf{~ g} / \mathbf{k g}\end{array}$ \\
\hline 17,9 & Heptacloro & 183786,2 & 0,02 \\
19,8 & Aldrin & 285206,6 & 0,03 \\
23,5 & Dieldrin & 232115,9 & 0,03 \\
23,7 & DDE & 224829,5 & 0,03 \\
24,2 & Endrin & 123360,8 & 0,04 \\
24,6 & DDD & 194864,3 & 0,03 \\
24,9 & DDT & 90465,9 & 0,03 \\
\hline
\end{tabular}

TABELA 8 Resultados do spike de 0,010 mg/kg da amostra Bororé. (o autor, 2017)

\begin{tabular}{cccc}
\hline $\begin{array}{c}\text { Tempo em } \\
\text { minutos }\end{array}$ & $\begin{array}{c}\text { Nome do } \\
\text { Composto }\end{array}$ & $\begin{array}{c}\text { Área } \\
\left(\mathbf{u V}^{*} \mathbf{s e g}\right)\end{array}$ & $\begin{array}{c}\text { Concentração } \\
\mathbf{e m ~} \mathbf{~ m g} / \mathbf{k g}\end{array}$ \\
\hline 17,9 & Heptacloro & 581909,0 & 0,08 \\
19,8 & Aldrin & 713696,0 & 0,09 \\
23,5 & Dieldrin & 553704,3 & 0,08 \\
23,7 & DDE & 519973,4 & 0,08 \\
24,2 & Endrin & 281054,2 & 0,09 \\
24,6 & DDD & 464767,0 & 0,08 \\
24,9 & DDT & 177089,7 & 0,07 \\
\hline
\end{tabular}


TABELA 9 Resultados do spike de 0,10 mg/kg da amostra Corpo Central. (o autor, 2017)

\begin{tabular}{cccc}
\hline $\begin{array}{c}\text { Tempo em } \\
\text { minutos }\end{array}$ & $\begin{array}{c}\text { Nome do } \\
\text { Composto }\end{array}$ & $\begin{array}{c}\text { Área } \\
\left(\mathbf{u V}^{*} \mathbf{s e g}\right)\end{array}$ & $\begin{array}{c}\text { Concentração } \\
\mathbf{e m ~} \mathbf{~ m g} / \mathbf{k g}\end{array}$ \\
\hline 17,9 & Heptacloro & 641827,5 & 0,08 \\
19,8 & Aldrin & 750095,4 & 0,09 \\
23,5 & Dieldrin & 549670,8 & 0,08 \\
23,7 & DDE & 508166,2 & 0,08 \\
24,2 & Endrin & 279811,8 & 0,09 \\
24,6 & DDD & 440953,9 & 0,07 \\
24,9 & DDT & 169276,9 & 0,07 \\
\hline
\end{tabular}

TABELA 10 Resultados do spike de 0,050 mg/kg da amostra Estoril. (o autor, 2017)

\begin{tabular}{cccc}
\hline $\begin{array}{c}\text { Tempo em } \\
\text { minutos }\end{array}$ & $\begin{array}{c}\text { Nome do } \\
\text { Composto }\end{array}$ & $\begin{array}{c}\text { Área } \\
\left(\mathbf{u V}^{*} \mathbf{s e g}\right)\end{array}$ & $\begin{array}{c}\text { Concentração } \\
\mathbf{e m ~} \mathbf{~ m g} / \mathbf{k g}\end{array}$ \\
\hline 17,9 & Heptacloro & 293670,1 & 0,03 \\
19,8 & Aldrin & 416657,1 & 0,05 \\
23,5 & Dieldrin & 312586,5 & 0,04 \\
23,7 & DDE & 282518,0 & 0,04 \\
24,2 & Endrin & 154722,8 & 0,05 \\
24,6 & DDD & 235424,7 & 0,03 \\
24,9 & DDT & 115256,69 & 0,04 \\
\hline
\end{tabular}




\subsection{Resultados das amostras da Represa Billings}

Foram extraídas 8 amostras via Quechers, dos seguintes pontos: $1^{\circ}$ Linha, $2^{\circ}$ Linha, Estoril, Corpo Central, Braço Capivari, Bororé, Elta e Tahiti.

Em todas as amostras analisadas não foram encontrados nenhum dos POPs estudados neste trabalho acima do limite de detecção. Em algumas amostras, foram encontrados traços de Gama-BHC, conforme FIG.40 e TAB.11 a 13. Nas demais amostras não encontrados resultados.

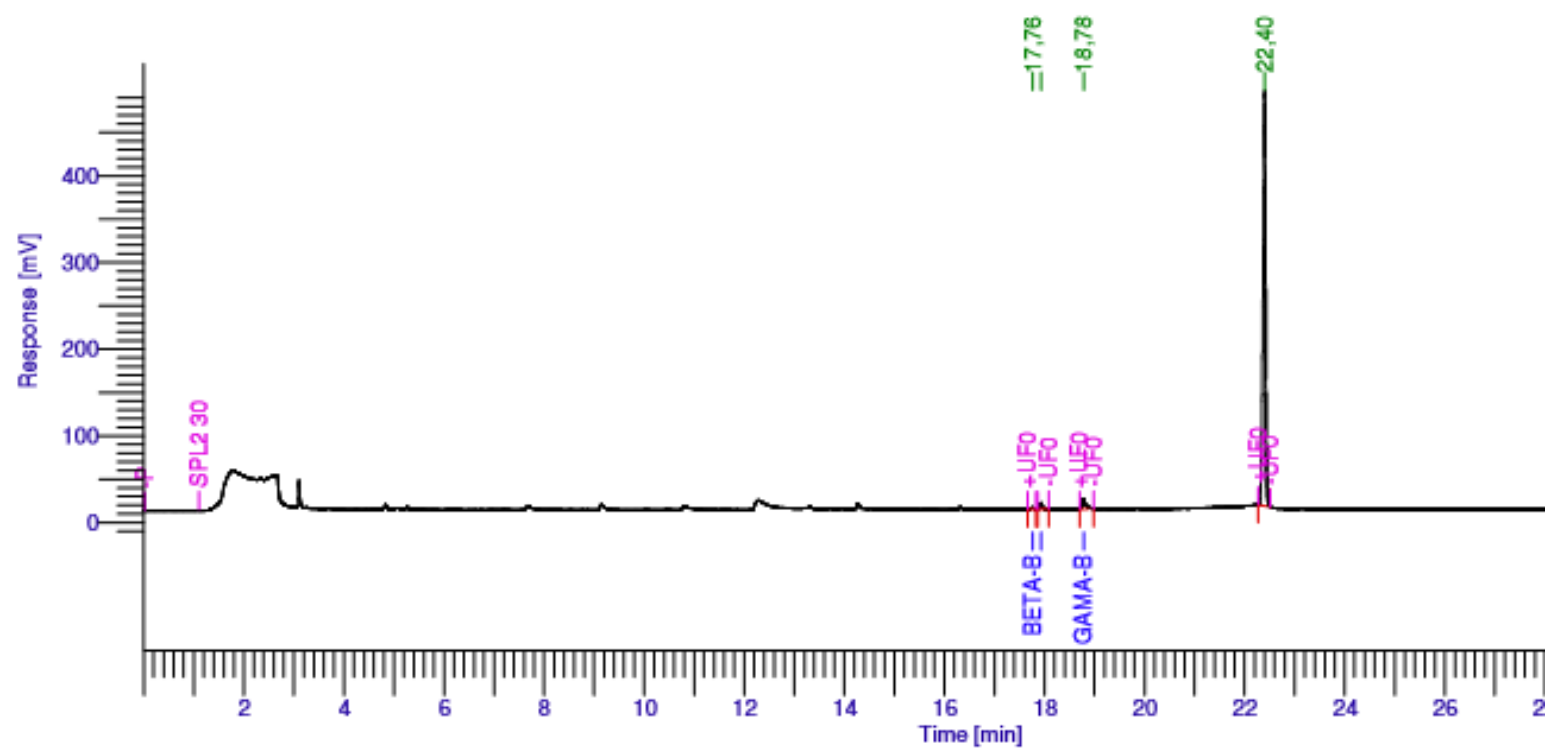

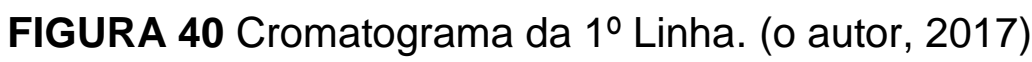

TABELA 11 Resultados em $\mu \mathrm{g} / \mathrm{kg}$ das amostras. (o autor, 2017)

\begin{tabular}{|c|c|c|c|c|}
\hline $\begin{array}{c}\text { Tempo em } \\
\text { minutos }\end{array}$ & $\begin{array}{l}\text { Nome do } \\
\text { Composto } \\
\end{array}$ & $\begin{array}{c}\text { Concentração } \\
1^{\circ}=\mathrm{Linha} \text { em } \\
\mu \mathrm{g} / \mathrm{kg}\end{array}$ & $\begin{array}{c}\text { Concentração } \\
20 \text { Linha em } \\
\mu \mathrm{g} / \mathrm{kg}\end{array}$ & $\begin{array}{c}\text { Concentração } \\
\text { Bororé em } \\
\mu \mathrm{g} / \mathrm{kg}\end{array}$ \\
\hline 18,7 & $\begin{array}{c}\text { Gama } \\
\text { BHC }\end{array}$ & 0.0098 & 0.0011 & 0.0067 \\
\hline
\end{tabular}




\subsection{Comparação dos resultados}

A CETESB possui histórico de suas amostras. Neste trabalho, foram coletadas duas amostras onde há histórico de contaminação dos anos de 2007 e 2008 de pesticidas organoclorados, dentre eles, alguns POPs.

As amostras com histórico são Braço do Capivari sobre a Linha de alta tensão e amostra Braço do Bororé. As FIG.41 a 51 apresentam os resultados dos pontos BILL 02100 (amostra Braço do Bororé) e BILL 02900 (amostra Braço do Capivari sob a linha de alta tensão) comparados com o CONAMA 454/CONAMA 344 e com a média dos resultados obtidos pela CETESB nos anos de 2007 e 2008.

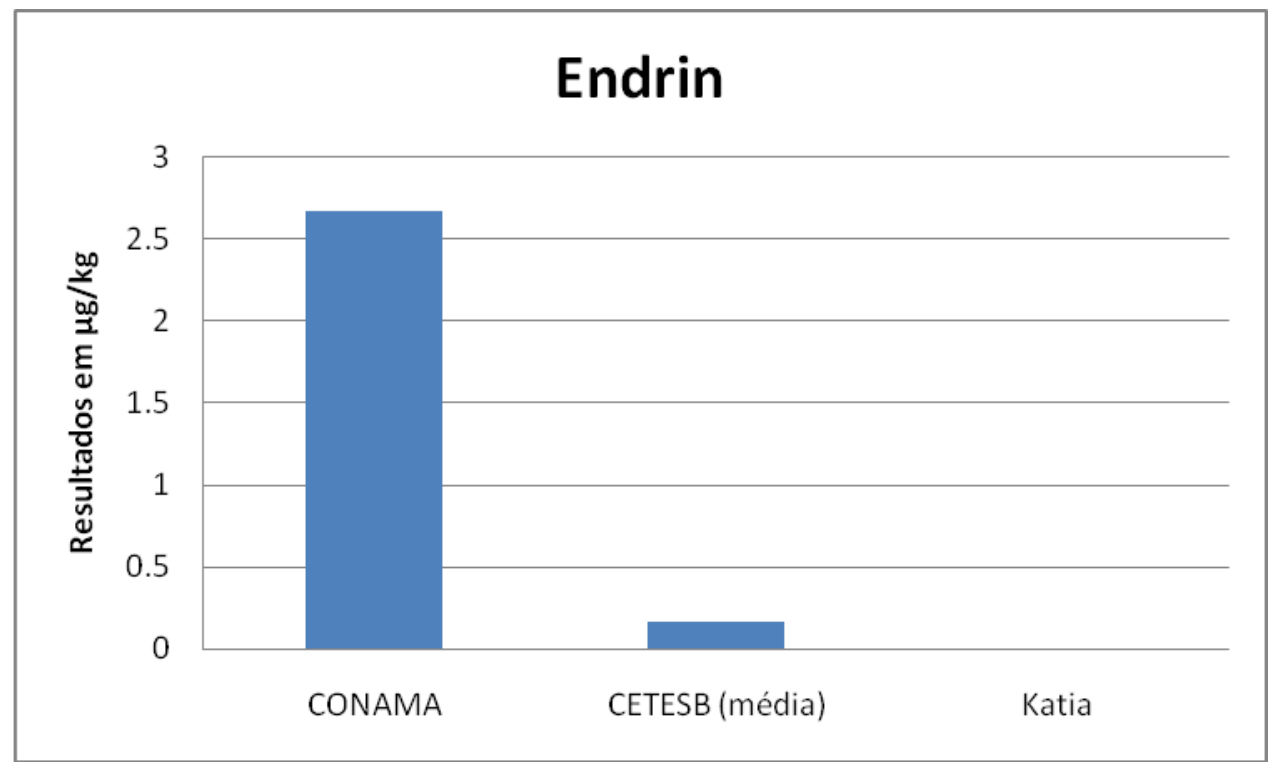

Figura 41 Gráfico compativo entre os valores de Endrin da amostra BILL 2100 na Legislação CONAMA, os resultados obtidos pela CETESB e os encontrados neste trabalho. 


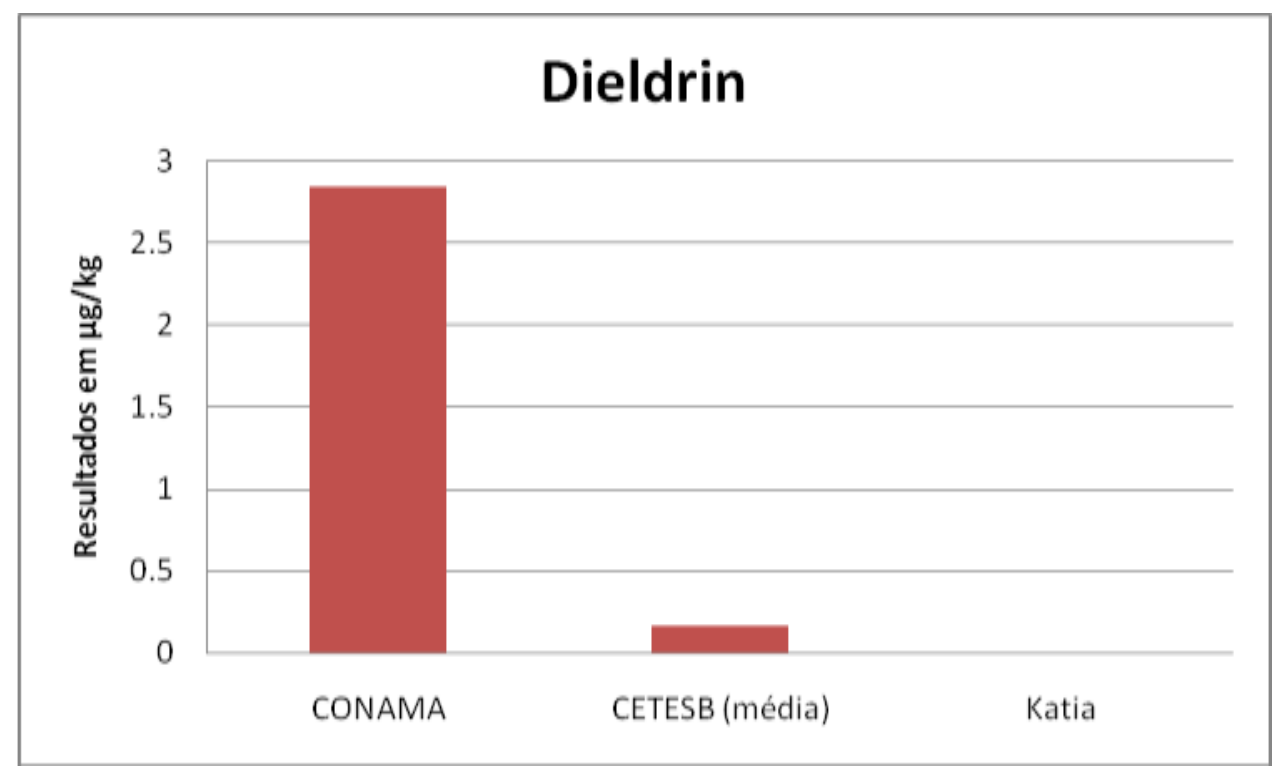

Figura 42 Gráfico compativo entre os valores de Dieldrin da amostra BILL 2100 na Legislação CONAMA, os resultados obtidos pela CETESB e os encontrados neste trabalho.

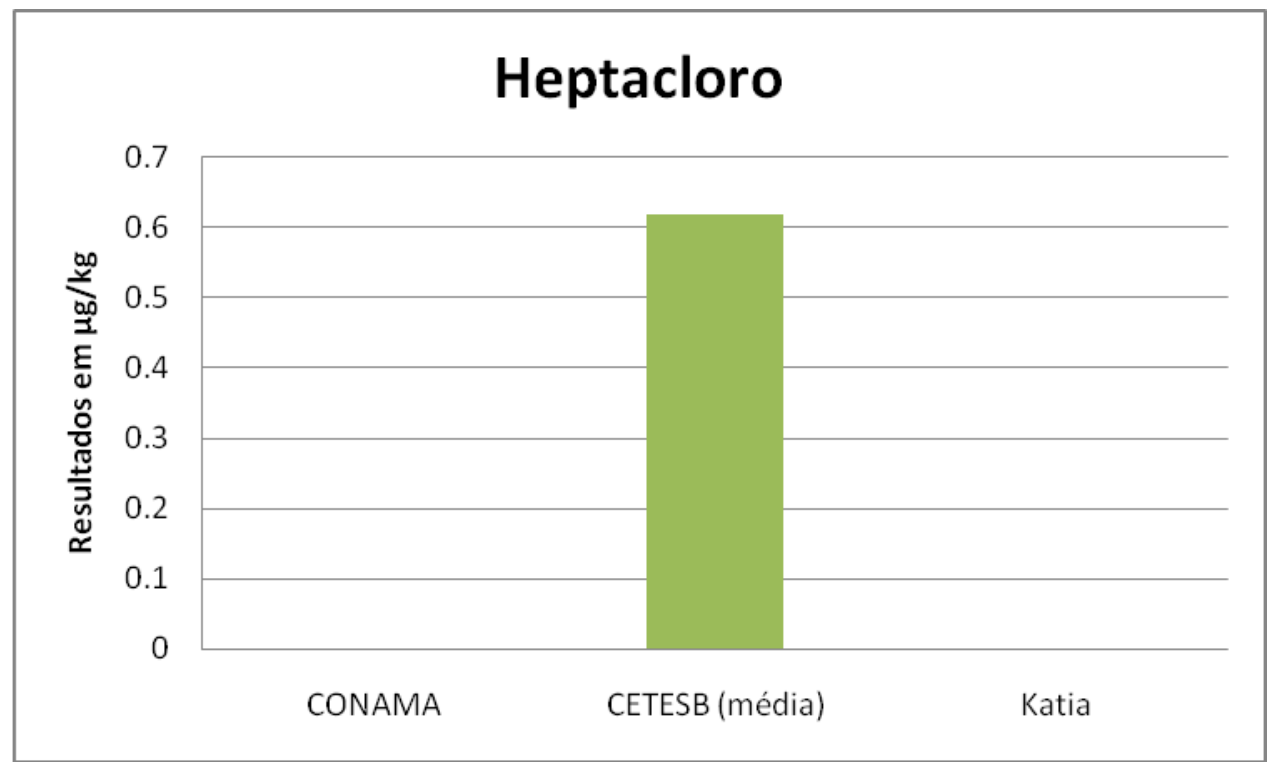

Figura 43 Gráfico compativo entre os valores de Heptacloro da amostra BILL 2100 na Legislação CONAMA, os resultados obtidos pela CETESB e os encontrados neste trabalho 


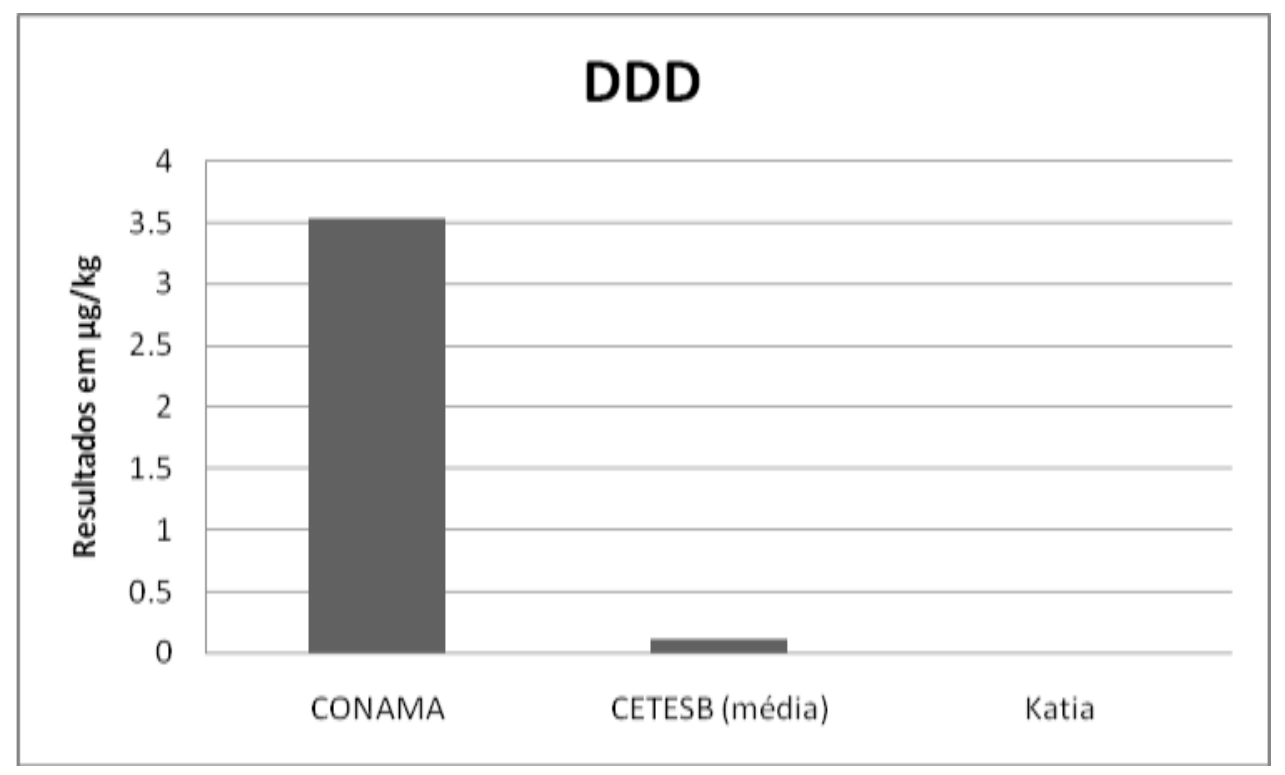

Figura 44 Gráfico compativo entre os valores de DDD da amostra BILL 2100 na Legislação CONAMA, os resultados obtidos pela CETESB e os encontrados neste trabalho

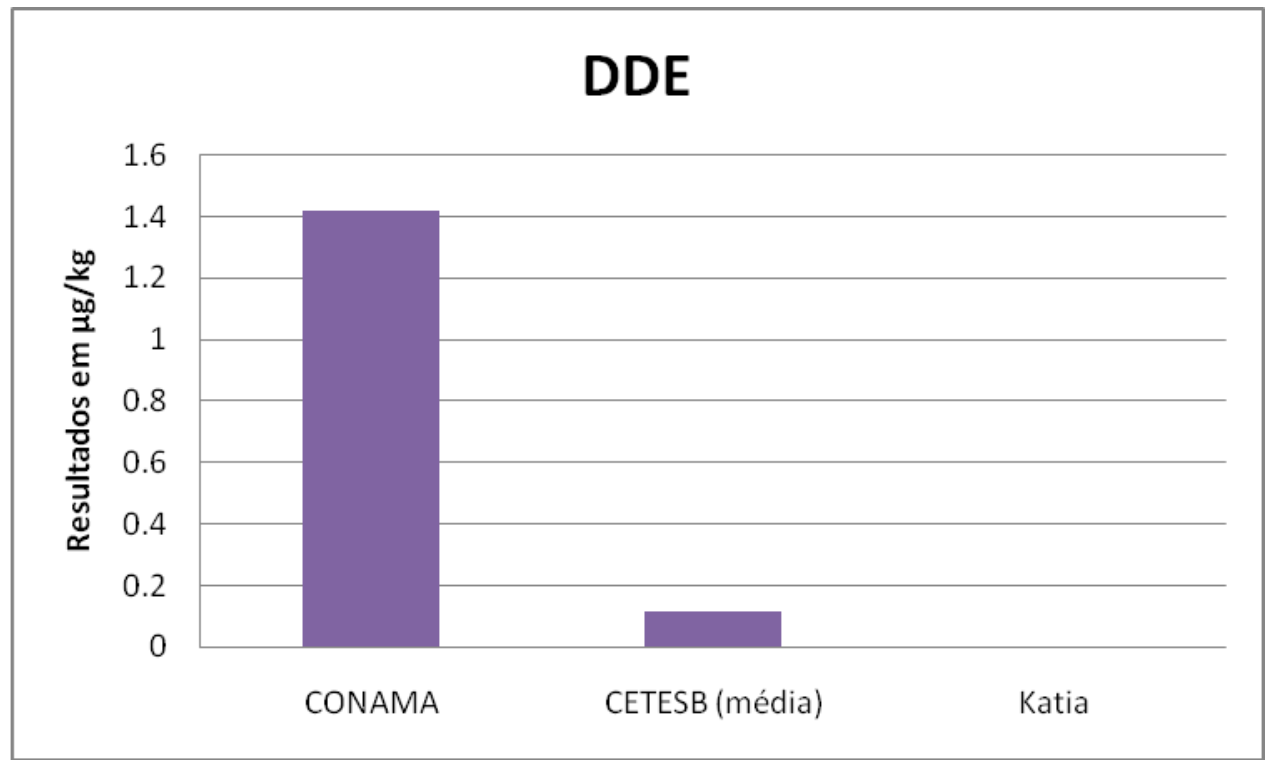

Figura 45 Gráfico compativo entre os valores de DDE da amostra BILL 2100 na Legislação CONAMA, os resultados obtidos pela CETESB e os encontrados neste trabalho. 


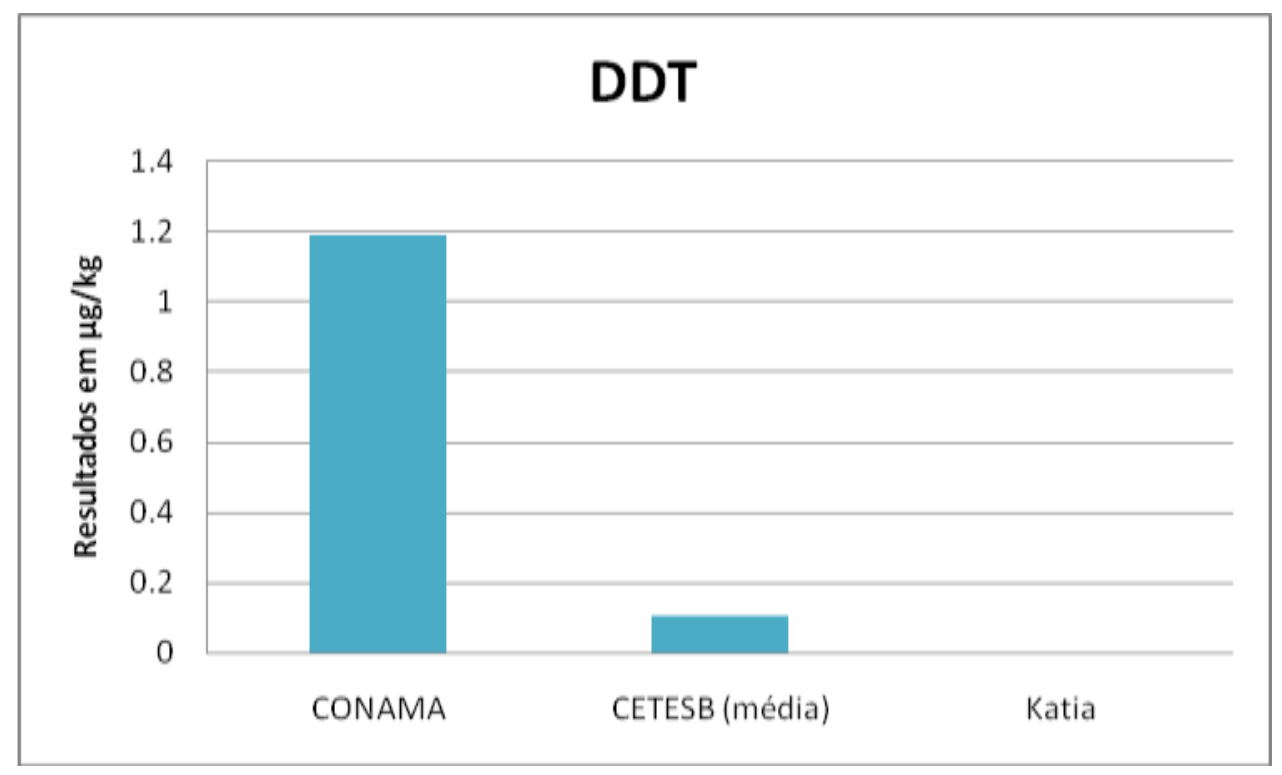

Figura 46 Gráfico compativo entre os valores de DDT da amostra BILL 2100 na Legislação CONAMA, os resultados obtidos pela CETESB e os encontrados neste trabalho.

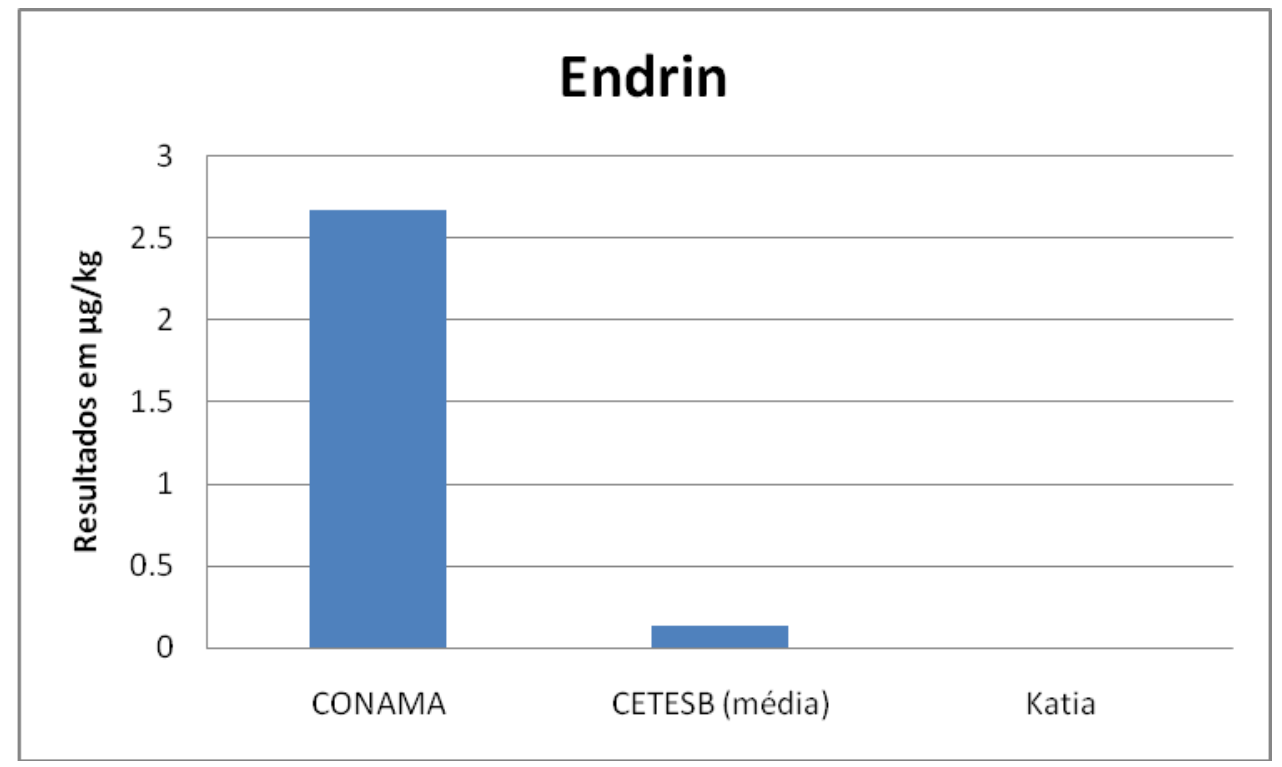

Figura 47 Gráfico compativo entre os valores de Endrin da amostra BILL 2900 na Legislação CONAMA, os resultados obtidos pela CETESB e os encontrados neste trabalho. 


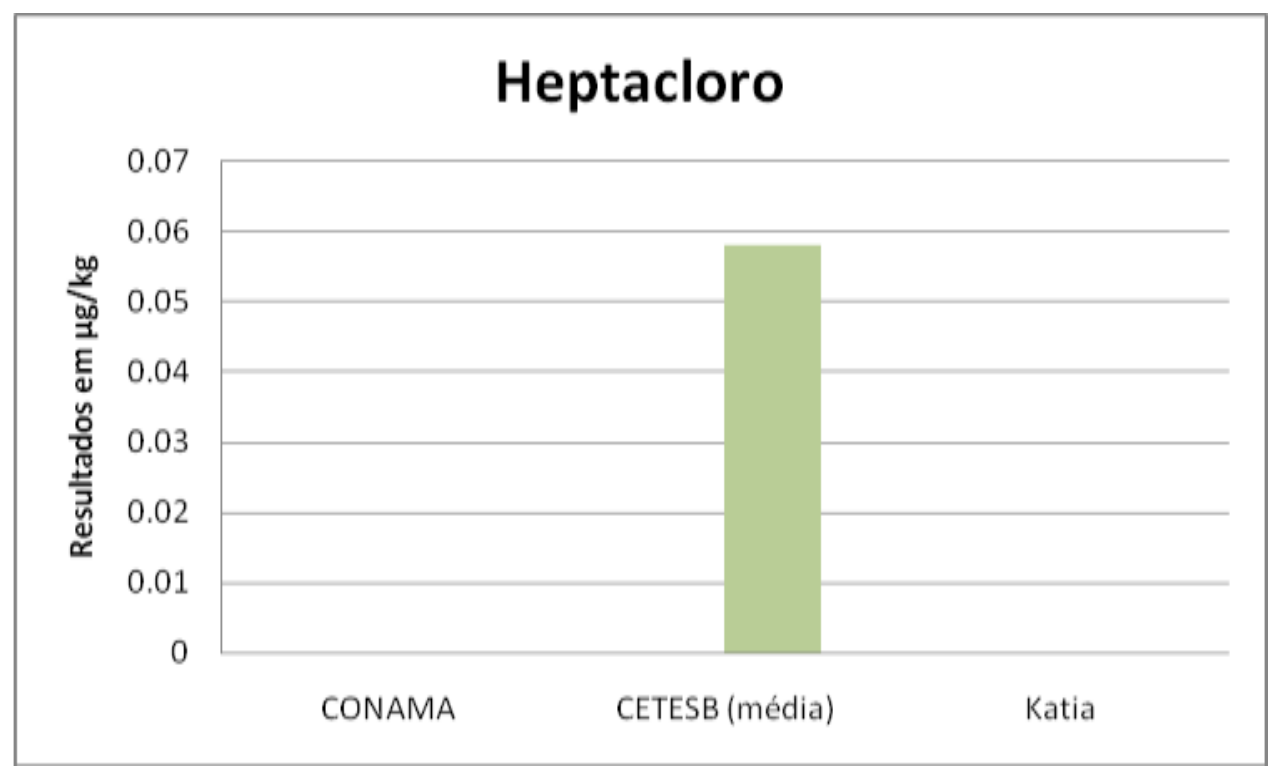

Figura 48 Gráfico compativo entre os valores de Heptacloro da amostra BILL 2900 na Legislação CONAMA, os resultados obtidos pela CETESB e os encontrados neste trabalho.

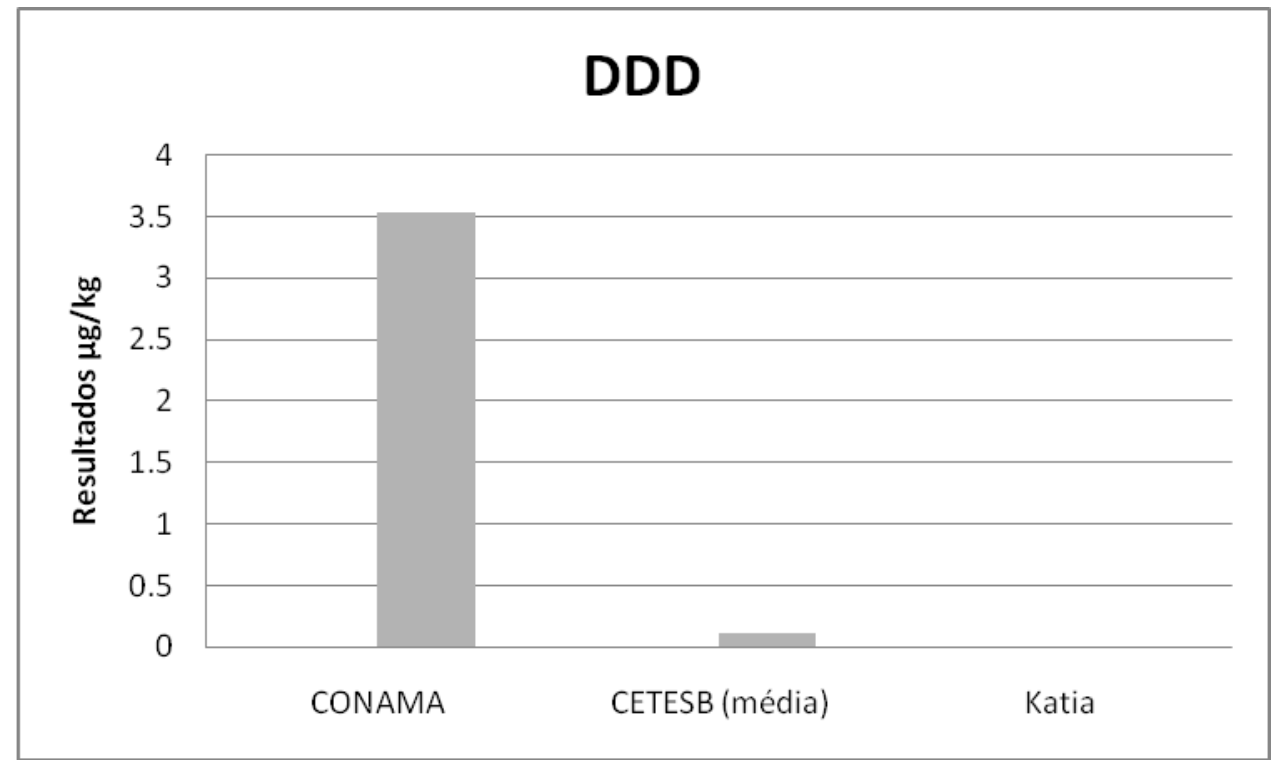

Figura 49 Gráfico compativo entre os valores de DDD da amostra BILL 2900 na Legislação CONAMA, os resultados obtidos pela CETESB e os encontrados neste trabalho. 


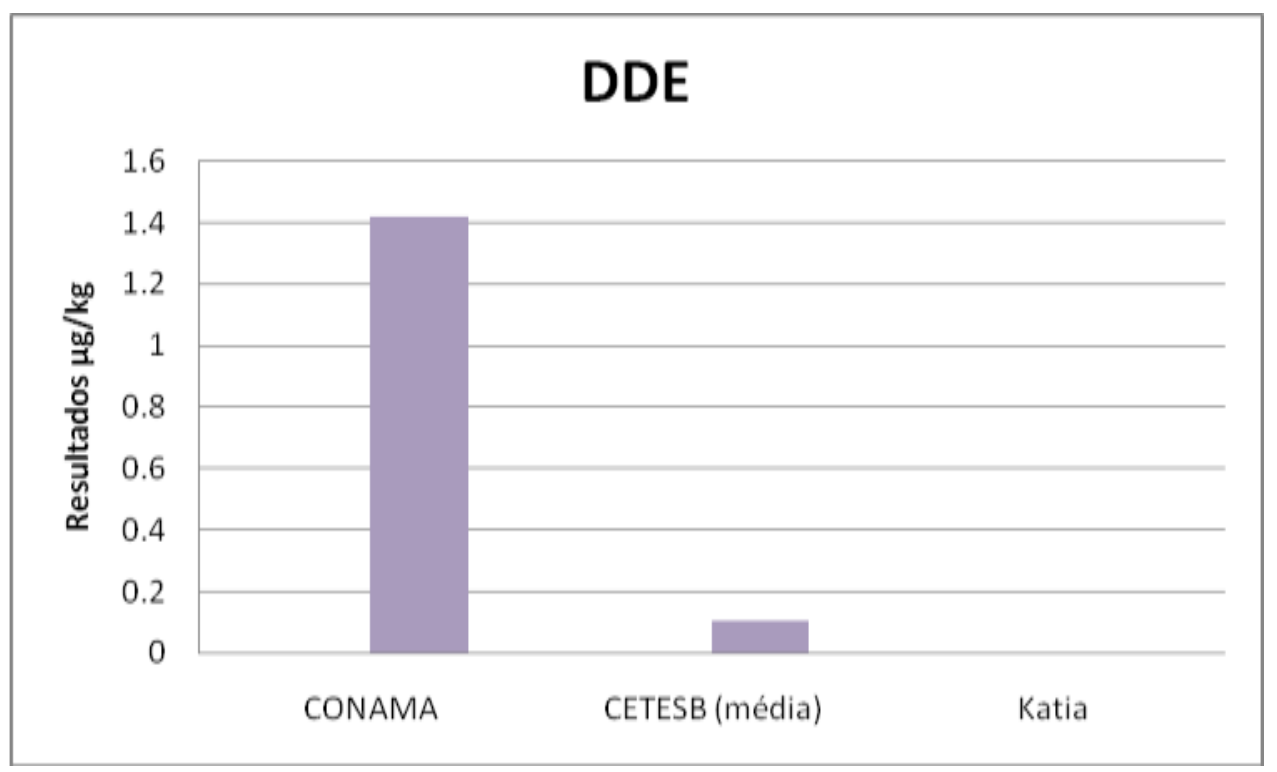

Figura 50 Gráfico compativo entre os valores de DDE da amostra BILL 2900 na Legislação CONAMA, os resultados obtidos pela CETESB e os encontrados neste trabalho.

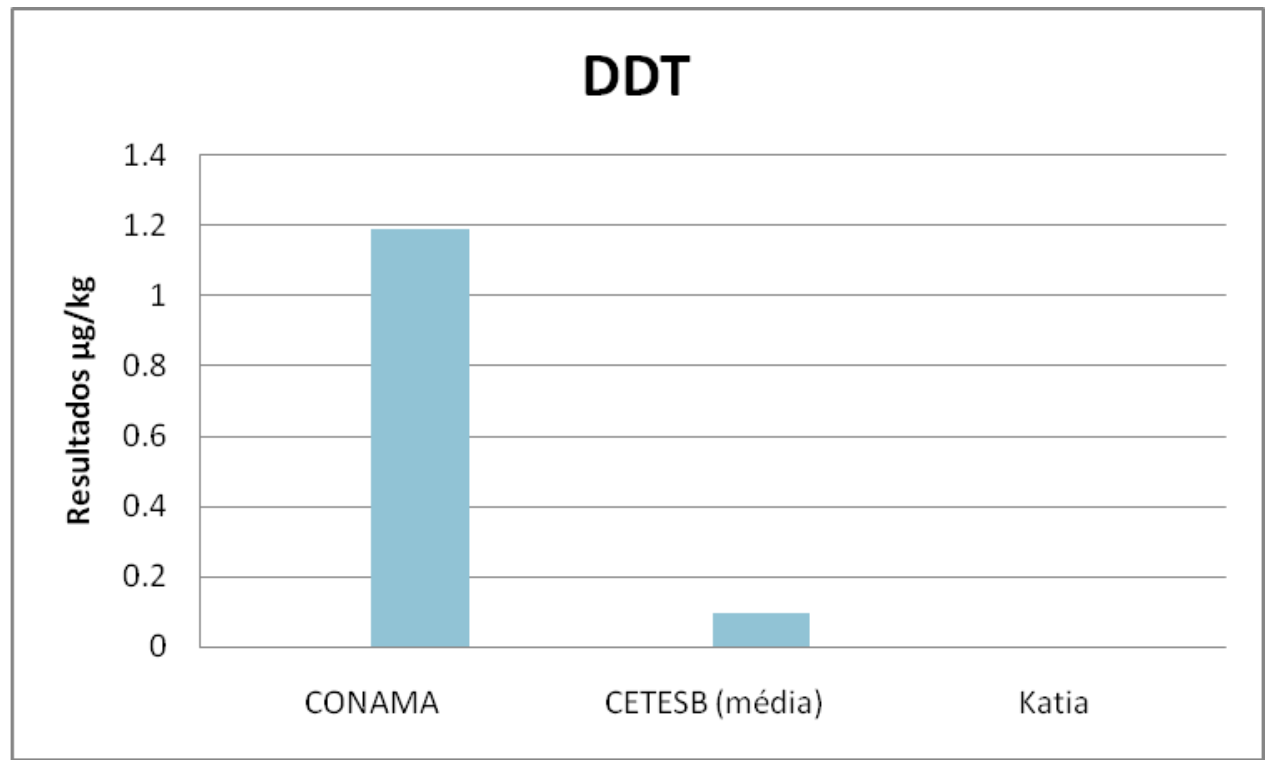

Figura 51 Gráfico compativo entre os valores de DDT da amostra BILL 2900 na Legislação CONAMA, os resultados obtidos pela CETESB e os encontrados neste trabalho. 
Os resultados obtidos da comparação entre legislação, CETESB e valores obtidos neste trabalho, mostram que todos os valores estão abaixo da legislação CONAMA, com exceção do POP heptacloro que não há critério no CONAMA. 


\subsection{CONCLUSÕES}

As principais conclusões deste trabalho foram as seguintes:

1- A extração via Quechers é inédita para matriz sedimento, desta forma, foi desenvolvido um novo método de extração e análise dos POPs em sedimento utilizando a técnica de extração via Quechers sendo analisada via GC-ECD e GC/MS.

2 - As análises qualitativas e quantitativas foram otimizadas, utilizando padrão da com certificação ABNT ISO/IEC 17025:2005 e ISO GUIDE 34. Comparada a outras técnicas de extração, como soxhlet e ultrassom, Quechers é uma análise rápida, pois é realizada em cerca de 20 minutos, é mais barata, pois usa pouco solvente (o que favorece a Química Verde) e poucos sais, é de fácil preparo, é barata, pois utiliza produtos químicos em pequenas quantidades.

3- O método de extração via Quechers foi validado, atingindo valores de limite de detecção de 0,3 $\mu \mathrm{g} / \mathrm{kg}$, limite de quantificação de $0,5 \mu \mathrm{g} / \mathrm{kg}$, A eficácia desta validação foi constatada obtendo valores de recuperação entre 40 e $120 \%$ para matriz sedimento.

4- As amostras foram coletadas na Represa Billings, por meio de draga de Van Veen, acondicionadas em frasco âmbar e armazenadas em refrigeração de $4^{\circ} \mathrm{C}+/$ $0,5^{\circ} \mathrm{C}$.

5- Os sedimentos da Represa Billings foram analisados por GC/MS e GC-ECD. Foram encontrados resultados traços de Gama-BHC, um composto organoclorado, mas os valores encontrados nos pontos $1^{\circ}$ Linha, $2^{\circ}$ Linha e Bororé, estão abaixo muito abaixo dos LD e LQ do método, sendo considerados irrelavantes.

Há cerca de 9 anos não realizavam análises para monitoramento de compostos organoclorados na Represa Billings. Devido à tamanha importância da toxicidade destes compostos, faz-se necessário um monitoramente mais rígido e com frequência anual em toda a Represa, não apenas nos pontos estudados neste trabalho. Ate o momento não foi possível afirmar o grau de contaminação de POPs na Represa Billings já que são necessárias análises para estudo de toda a Represa. 
6- Foram coletadas oito amostras na Represa Billings, destas, duas em pontos que possuem histórico de contaminação da CETESB, no ano de 2007 e 2008. Estes dados foram utilizados para comparação, juntamente com os resultados obtidos neste trabalho e a Legislação CONAMA 454/344. A comparação entre os resultados indica que não há contaminação na Represa Billings por POPs nos pontos estudados. 


\subsection{CONSIDERAÇÕES E PERSPECTIVAS}

Como sugestão para trabalhos posteriores, outros parâmetros importantes, como análise de metais, pois pode haver metais pesados na Represa Billings, e análise microbiológica, a fim de avaliar o grau toxicológico, além de realizar um novo estudo de POPs na Represa inteira. 


\section{APÊNDICE A - Certificado de análise do padrão.}

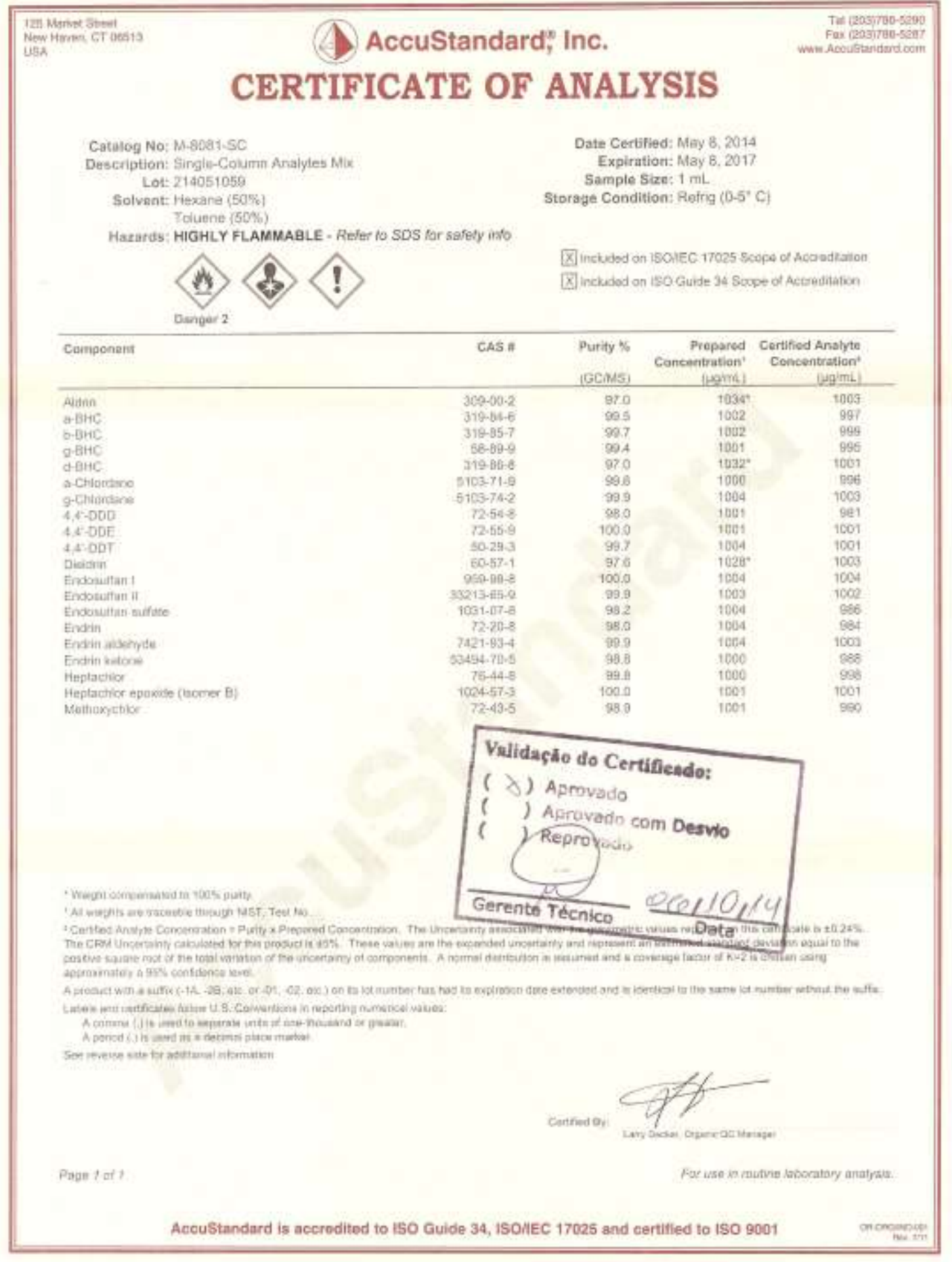


APÊNDICE B - Planilha para cálculo de Recuperação

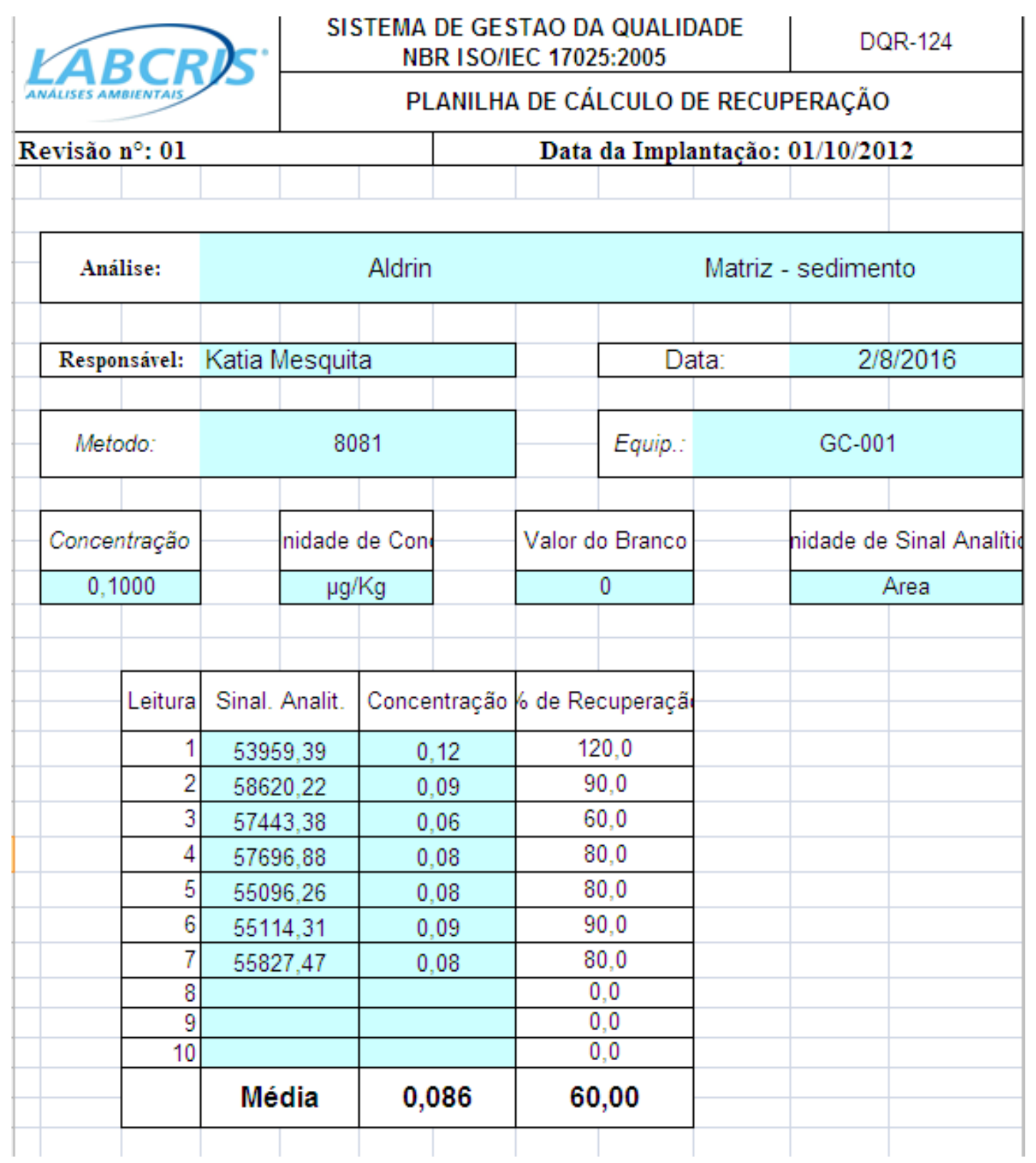


APÊNDICE C - Planilha de dados de Repetitividade

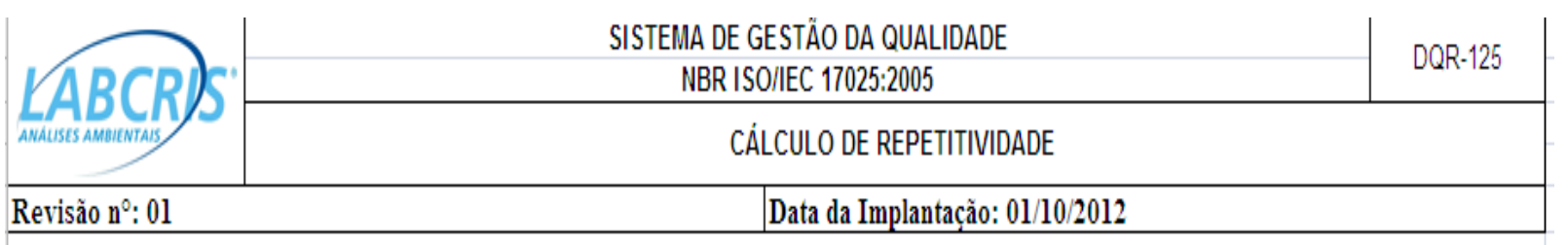

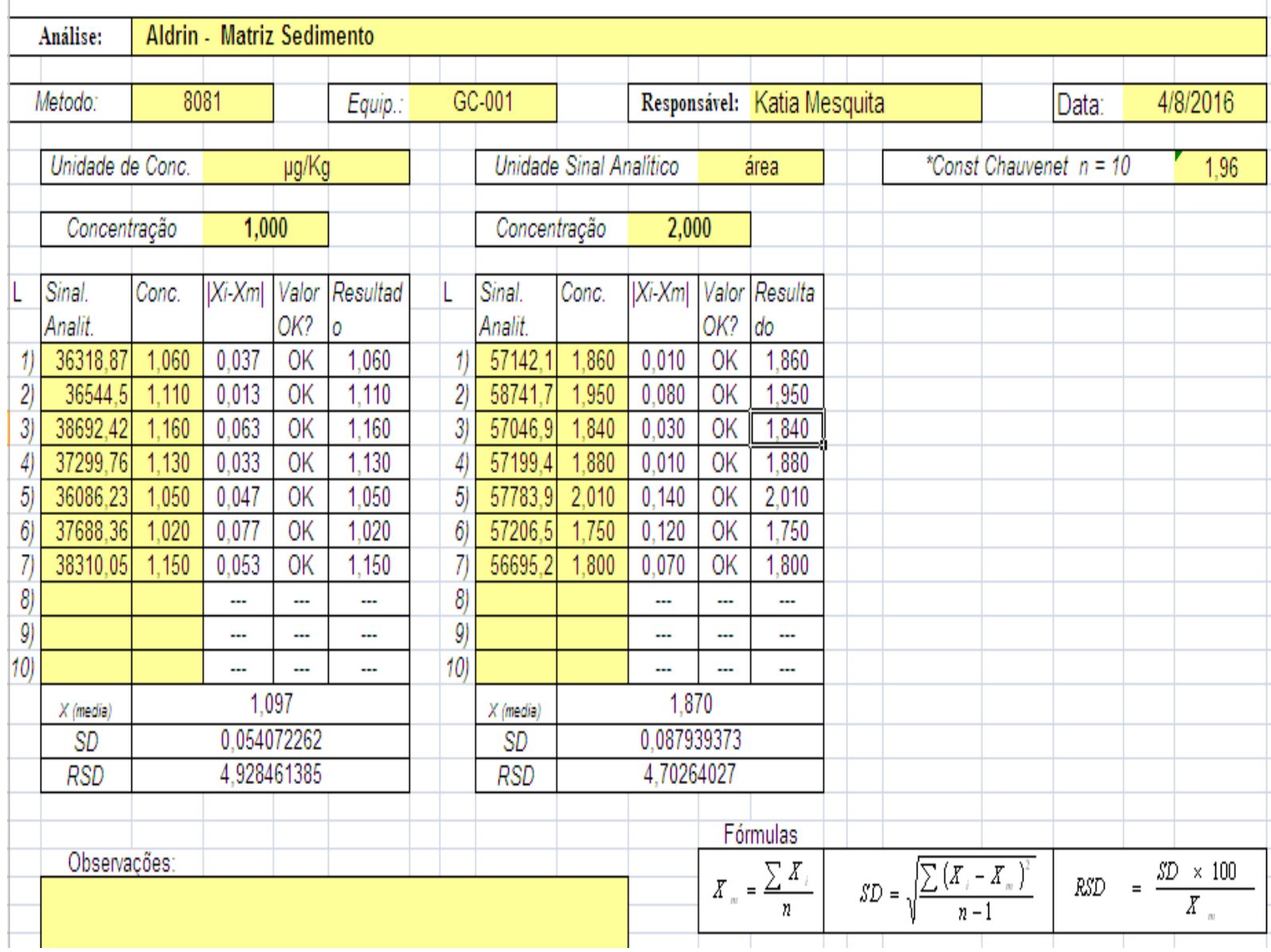




\title{
APÊNDICE D - Artigo aceito pelo INAC (- ANALYSIS OF PERSISTENT ORGANIC POLLUTANTS (POPS) IN SEDIMENTS BY GC/ECD GENERATED BY NUCLIDE ${ }^{63} \mathrm{Ni}$
}

\author{
Katia A. Mesquita ${ }^{1}$, Priscila O. Amaral ${ }^{1}$ and José O. V. Bustillos ${ }^{1}$ \\ ${ }^{1}$ IPEN-CNEN/SP, Av. Lineu Prestes, 2.242 , 05508-900, São Paulo, SP.
}

\begin{abstract}
Persistent Organic Pollutants (POPs) are toxic organic compounds resistant to environmental degradation. Besides, POPs bioaccumulate with potential significant impacts on human health and the environment. The Global Monitoring Plan (GMP) under the Stockholm Convention on POPs is a program that enables collection of comparable monitoring data from all regions of the world to assess the effectiveness in minimizing human and environmental exposure to POPs. In compliance with the Stockholm Convention, which Brazil is one of the 179 countries that ratified the Convention this work aims to contribute positively to this environmental issue. The scope of this work is to develop and validate a method for the extraction and determination of POPs in sediments collected at Billings dam locate in São Paulo Metropolitan City. The compounds studied in this work are: Dieldrin $\left(\mathrm{C}_{12} \mathrm{H}_{8} \mathrm{Cl} \mathrm{C}_{6} \mathrm{O}\right)$, Endrin $\left(\mathrm{C}_{12} \mathrm{H}_{8} \mathrm{Cl} 6 \mathrm{O}\right)$, Aldrin $\left(\mathrm{C}_{12} \mathrm{H}_{8} \mathrm{Cl}_{6}\right)$, DDE $\left(\mathrm{C}_{14} \mathrm{H}_{8} \mathrm{Cl}_{14}\right)$, DDT $\left(\mathrm{C}_{14} \mathrm{H}_{9} \mathrm{Cl}_{5}\right)$, DDD $\left(\mathrm{C}_{14} \mathrm{H}_{10} \mathrm{C}_{14}\right)$ and Heptachlor $\left(\mathrm{C}_{10} \mathrm{H}_{5} \mathrm{Cl}_{7}\right)$. This work use the extraction method QuEChERS (Quick, Easy, Cheap, Effective, Rugged, and Safe) for sediment samples and the analysis of the compounds were carried out by gas chromatography with the electron capture detector (GC/ECD). The ECD detector ionizes the analytes by the beta particles from the nuclide sources ${ }^{63} \mathrm{Ni}$ within carrier gas $\mathrm{N}_{2}$. The electrons produced in this process are collected and create a current that is amplified and generates a chromatographic peak. The recovery of this method obtained values between 57\% and 65\% and the Relative Standard Deviation (RSD) values are between 1 and $4 \%$. Details of the analytical method beside quantitative analyses data are presented in this work.
\end{abstract}

Key words: POPs, GC/ECD, Billings dam. 


\section{REFERÊNCIA BIBLIOGRÁFICA}

Agência Nacional de Vigilância Sanitária (ANVISA). Resolução RE no899: 2003.

AGÊNCIA NACIONAL DE ÁGUAS. ANA. Guia Nacional de coleta e preservação. Brasília, 2011

AMATO, C. et al. DDT (Dicloro Difenil Tricloroetano): toxicidade e contaminação ambiental - uma revisão. Química Nova. 1002 f. Instituto de Biofísica Carlos

Chagas Filho, Universidade Federal do Rio de Janeiro, Centro de Ciências da Saúde. Rio de Janeiro, Rio de Janeiro, 2011

ANASTESSIADES, M. et al. Crop protetion health, envornmental safety. WileiVCH, 2007.

ASSOCIAÇÃO GRUPO DE ANALISTAS DE RESÍDUOS DE PESTICIDAS (GARP). Manual de Resíduos de Pesticidas em Alimentos. 1999.

Box, G. E. P. et al. Statistics for Experimenters, Wiley: New York, 1987.

BRAULT, E, K. et al. Inter-annual variation of Persistent Organic Pullutants (POPs) in a Antartic Top Predator Arctocephalus gazell. Environmental Science \& Technology. 2013.

BUSTILLOS, O.V. et al. A espectrometria de massas quadrupolar. Scortecci, 2003.

CAMPOS, M. J. A.; NAKANO, V. Poluentes Orgânicos Persistentes, POPs e Metais Tóxicos. São Paulo, 2010.

CHALLONER, J. 1001 Invenções que mudaram o mundo. Sextante, 2010

COCKERMAN, G. L. Basic environmental toxicology. Boca Raton, Flórida: CRC Press, 1994 
COLABUONO, F. I. Poluentes Orgânicos Persistentes e ingestão de plásticos em albratrozes e pétreis. São Paulo, 2011.

COLLINS, C. H. et al. Fundamentos de Cromatografia. 1a.ed. Campinas: Editora UNICAMP, 2006.

COMPANHIA AMBIENTAL DO ESTADO DE SÃO PAULO, CETESB. Stockholm Convention. Disponível em: <http://www.cetesb.sp.gov.br/institucional/> Acessado em: $24 / 08 / 2014$

COMPANHIA AMBIENTAL DO ESTADO DE SÃO PAULO, CETESB. Guia de coleta e preservação de amostras de água. CETESB, 2011.

COMPANHIA AMBIENTAL DO ESTADO DE SÃO PAULO. Disponível em: <http://laboratorios.cetesb.sp.gov.br> Acessado em: 24/04/2014

CONSELHO NACIONAL DO MEIO AMBIENTE. CONAMA 344 e 454

DIAS, P. S. Poluentes Orgânicos Persistentes na Biota Marinha do Arquipélago de São Paulo e São Pedro. São Paulo, 2010

DORES, E. F. G. C, FREIRE, E. M. D. L. Contaminação do ambiente aquático por pesticidades. Estudo de caso: águas usadas para consumo humano em primavera do Leste, Mato Grosso - Análise Preliminar. Quimica Nova, Vol. 24, № 1, 27-26, 2001

EPA. Sediment classification methods compendium. cap. 1. Quality assurance, quality control, sampling and analytical considerations, cap. 2. EPA, Office of Water sept. 1992.

Fernanda V. Almeida. et al. Substâncias tóxicas persistentes (stp) no brasil. Jardim Quim. Nova, Vol. 30, No. 8, 1976-1985, 2007

GOVERNO DO ESTADO DE SÃO PAULO. Programa de despoluição da represa Billings beneficiará 250 mil habitantes. Disponível em : <http://www.saopaulo.sp.gov.br/spnoticias/ultimas-noticias/represa-billings-teraobras-para-despoluicao/> Acessado em: 30/04/2017 
GUIMARÃES, G, A, R. et al. Pesticidas - métodos de análise \& informações técnicas, vol 1, Paraná, 1988.

INSTITUTO NACIONAL DE METROLOGIA. Normalização e Qualidade Industrial (INMETRO); Orientações sobre Validação de Métodos de Ensaios Químicos. DOQ-CGCRE-008, 2011.38. THOMPSON, M.; ELLISON, S. L. R.; WOOD, R. Pure Appl. Chem. 2002, 74, 835.

INTERNATIONAL CONFERENCE ON HARMONISATION (ICH). Validation of Analytical. Procedures: Methodology. Q2B (CPMP/ICH/281/95), 1995.

INTERNATIONAL STANDARD ORGANIZATION. General Requirements for the Competence of Testing and Calibration Laboratories. ISO/IEC 17025, 1999.

KOELMANS, A, A. et al. Plastic as a Carrier of POPto aquatic organisms: A model analysis. Environmental Science \& Technology. 2013.

LEITE, F. Validação em Análise Química. 4ª ed. Campinas: Editora Átomo, 2002.

MACIEL, C. SP: com dez vezes mais água que Cantareira, Billings pode ser alternativa. Agência Brasil, São Paulo, Jan. 2015. Disponível em:<http://agenciabrasil.ebc.com.br/geral/noticia/2015-01/com-dez-vezes-mais-aguaque-o-cantareira-billings-pode-ser-alternativa>. Acessado em: 07/04/2017

MALLIAROS, C.; GUITONAS, A. Pre-treatment and elimination systems of toxic industrial waste and sludges. The case study of the department of Attika. Wat. Sci. Tech, v.36, p. 91-100, 1997

MARONI, M. et al. Introduction. Toxicology. v. 143, p. 5-8, 2000.

MILLER, J. C.; MILLER, J. N. Statistics for Analytical Chemistry. 2ª ed. Chichester: Ellis Horwood, 1988.

MINISTÉRIO DO MEIO AMBIENTE. Disponível em: $<$ http://www.mma.gov.br/seguranca-quimica/convencao-de-estocolmo> Acessado em: 06/04/2017 
MOZETO, A.; PATELLA, E. Como avaliar a quantidade de água de mananciais. Ciência Hoje v.22, p. 127, 1997

O Reservatório Billings, São Paulo. Disponível em:

$<w w w 2$. santoandre.sp.gov.br/site/?link=miolo\&topico $=3 \&$ conteudo $=12>$ Acessado em: $22 / 04 / 2017$

OLIVEIRA, J, P, R. Estudo dos Poluentes Orgânicos Persistentes (POPs) em regiões industriais da Grande São Paulo - via Cromatografia a Gás acoplada a espectrometria de massas (GC-MS) e Captura de Elétrons (GC-ECD). São Paulo, 2011

PINTO, C.G. et al. Simplified QuEChERS approach for the extraction of chlorinated compounds from soil samples. Talanta, v. 81, 385391,2010 .

PRESTES, D, O. et al. Quechers - um método moderno de preparo de amostra para determinação multirresíduo de pesticidas em alimentos por métodos cromatográficos acoplados a espectrometria de massas. Quim. Nova, Vol. 32, No. 6, 1620-1634, 2009

SANCHES, S. et al. Pesticidas e seus respectivos riscos associados à contaminação da água. Curitiba, 2003.

SILVA, M. A. Otimização de amostradores passivos para a determinação de pesticidas em água utilizando SPE e GC-MS. Salvador, 2012.

SNYDER, L. R.; KIRKLAND, J. J.; GLAJCH, J. L. Practical HPLC Method Development. 2 a ed. Wiley: New York, 1997, cap. 15.

Standard methods for the examination of water and wastwater. 2005. 21st edition. métodos 1060A, B e C, 9060A e B e 9060 A

Stockholm, Sweden, 2001. Declaration on the elimination of Persistent Organic Polluants (POPs). Stockholm Declaration. 
STUMM, W., MORGAN, J. J. Aquatic chemistry, chemical equilibria andm rates in natural Waters. 3 ed. John Willwy \& sons, 1996, 1022p

TOLEDO, H. H. B.; INOMATA, O. N. K.; LEMES, V. R. R. Curso Análise de Resíduos de Pesticidas. Instituto Adolfo Lutz, São Paulo, 1997

UNITED STATES FOOD AND DRUG ADMINISTRATION, CENTER FOR DRUG EVALUATION 